The Practice of Informal Tourism Entrepreneurs: A Bourdieusian Perspective

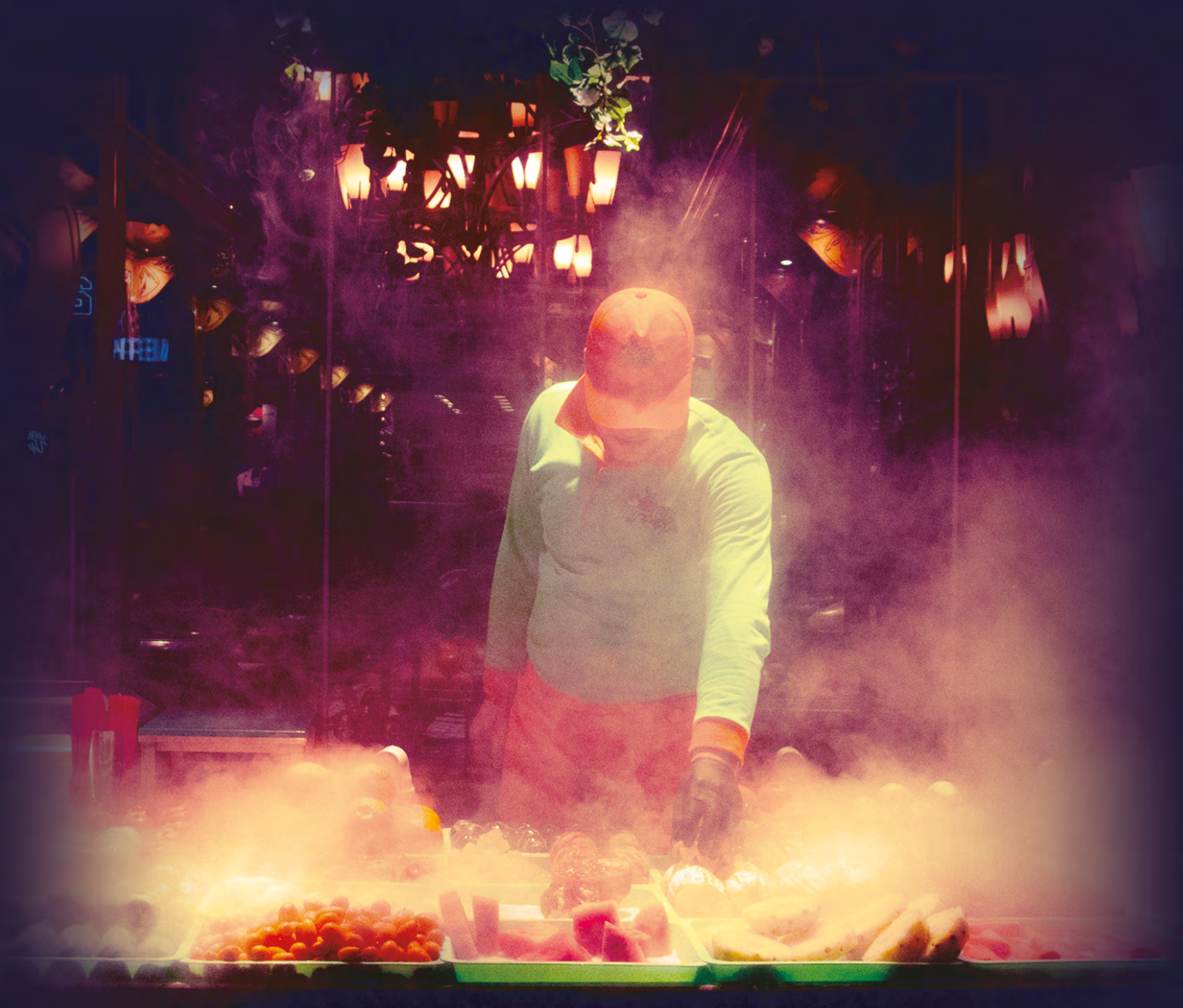

Erdinç Çakmak 


\section{The Practice of Informal Tourism Entrepreneurs: A Bourdieusian Perspective}

Erdinç Çakmak 


\section{Propositions}

1. The informal tourism sector is a complex social system that cannot be reduced to isolated elements.

(this thesis)

2. Informal tourism entrepreneurs decrease capital inequality in a society by creating jobs for vulnerable people.

(this thesis)

3. Using binary oppositions might be useful in the classroom to explain the differences between concepts to students but they are less useful in the research process.

4. Research in the domain of social sciences requires Bourdieusian relational thinking and reflexivity in the construction of the research object and the researcher's position.

5. A hybrid person is not an average person.

6. An illegal action does not necessarily mean that it is unethical.

Propositions belonging to the thesis, entitled

'The Practice of Informal Tourism Entrepreneurs: A Bourdieusian Perspective'

Erdinç Çakmak

Wageningen, 11 March 2020. 


\section{Thesis committee}

\section{Promotor}

Prof. Dr C. Leeuwis

Professor of Knowledge, Technology and Innovation

Wageningen University \& Research

\section{Co-promotors}

Dr R. Lie

Assistant Professor, Knowledge, Technology and Innovation Group

Wageningen University \& Research

Prof. T. Selwyn

Professorial Research Associate, Department of Anthropology and Sociology SOAS University of London, United Kingdom

\section{Other members}

Em. Prof. D. Airey, Surrey University, United Kingdom

Prof. Dr. V.R. van der Duim, Wageningen University \& Research

Dr M. L. Mangion, University of Malta, Malta

Em. Prof. V. Platenkamp, Breda University of Applied Sciences

This research was conducted under the auspices of the Wageningen Graduate School of Social Sciences (WASS). 


\title{
The Practice of Informal Tourism Entrepreneurs: A Bourdieusian Perspective
}

\author{
Erdinç Çakmak
}

\section{Thesis}

submitted in fulfilment of the requirements for the degree of doctor at Wageningen University \& Research by the authority of the Rector Magnificus

Prof. Dr. A.P.J. Mol, in the presence of the

Thesis Committee appointed by the Academic Board to be defended in public on Wednesday 11 March 2020 at 4 p.m. in the Aula. 
Erdinç Çakmak

The Practice of Informal Tourism Entrepreneurs: A Bourdieusian Perspective 204 pages

$\mathrm{PhD}$ thesis, Wageningen University \& Research, Wageningen, the Netherlands (2020)

With references, with summary in English.

DOI: https://doi.org/10.18174/507882

ISBN: 978-94-6395-230-9 
To my dear girls,

Lavinia, Aydan Su,

Selin. 


\section{Acknowledgements}

An African proverb says that "it takes a village to raise a person". In this research I have had the privilege of being supported by many people whose number is more than a village. All provided me with enormous and invaluable support and finally made this book possible. It is not possible to mention all of their names but I am grateful to all of them.

First, I thank to my promotor Cees Leeuwis for sharing his vast experience and knowledge with me. In addition, my second supervisor Rico Lie deserves enormous credit for being a dedicated mentor, for always supporting me, for providing very focused feedback and for also being a kind human being. Tom Selwyn, as my other supervisor, also deserves credit. I greatly appreciate his guidance, immense knowledge, inspirational talks, and I am grateful that he acted as an older brother to me during the whole process. Alongside my supervisors, I would like to thank to the members of my reading committee for finding time in their busy schedules to read this dissertation and being at the public defense. I offer my sincere thanks to my other co-authors Alper Çenesiz and Scott McCabe, who increased the quality of two chapters in this book by editing them and who continuously asked me critical questions on several issues while I was writing these chapters. Furthermore, Ray Boland was brilliant in his fine work in copy-editing the whole book. I need to extend my gratitude to Jos van der Sterren who introduced the topic of the informal tourism economy to me, and who conducted co-research on this topic before I started my own $\mathrm{PhD}$ research. My heartful appreciation goes to my paranymphs Carin Rustema and Ariane Portegies, who stand next to me as my angels on the stage.

During my PhD I have had the privilege of collaborating with many colleagues and students. I am very grateful them for providing me with their constructive feedback on the chapters, helping me with gathering primary data, challenging me with their critical questions, and sharing their ideas and experiences whenever I needed them. I acknowledge all the participants in this research, all the silenced voices, who allowed me to access their work lives, welcomed me warmly each time during my fieldwork, and contributed to my research by providing multiple sources of data. This research would have not been possible without you. I acknowledge colleagues and fellow PhD students in the chair group Knowledge, Technology, and Innovation at Wageningen University and Research, for providing me with the 
best institutional environment and making the entire period in Wageningen a very pleasant and memorable one. I acknowledge my employer Breda University of Applied Sciences for giving me the opportunity and time to conduct this $\mathrm{PhD}$ research. I acknowledge my friends, who are spread all over the globe. Life is beautiful with friends and particularly when you are with them on vacation. Long dinners, chats, lots of wine, and laughter. I hope this will never end.

Besides friends, there is family. My parents Meryem and Şevki have always stimulated me to study as much as possible. My brother Tamer, my sister Döndü, I am grateful for your unconditional love and being there. My final thank words is reserved to my immediate family, my love, Ömür; my children Lavinia, Aydan Su and Selin. I cannot complete this research without your constant patience, unending understanding of all my time constraints, and your support and affection. I dedicate this dissertation to my daughters.

\section{Erdinç Çakmak}

7 January 2020

Eindhoven 


\section{Contents}

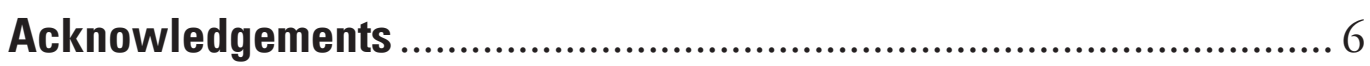

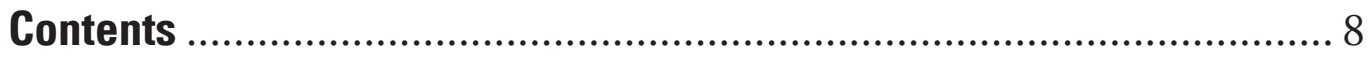

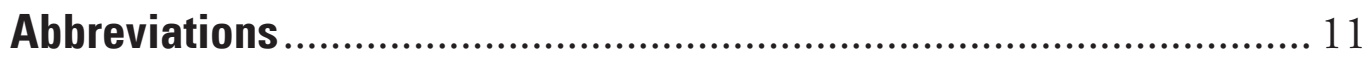

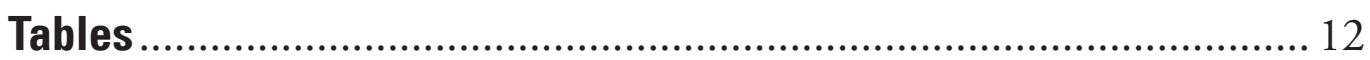

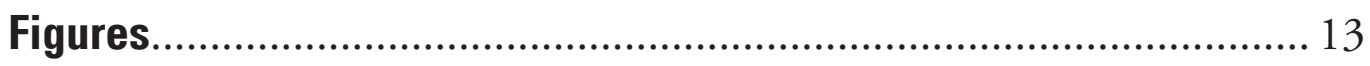

\section{Chapter 1:}

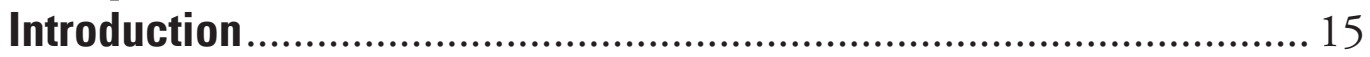

1.1 Informal Economies and The Practice of Informal Tourism

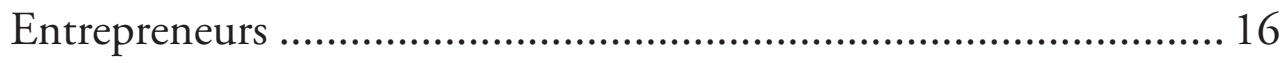

1.2 Bourdieusian Praxeology ............................................................ 19

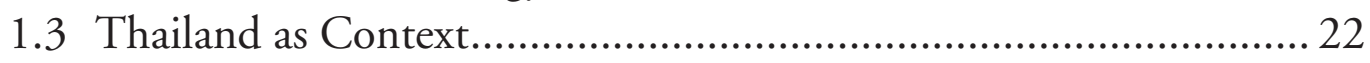

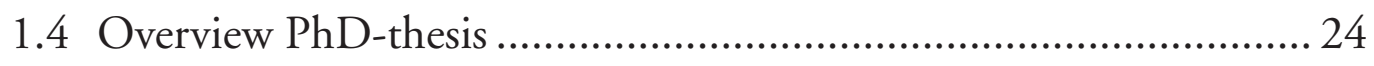

\section{Chapter 2:}

Reframing Informal Tourism Entrepreneurial Practices: Capital and Field Relations Structuring the Informal Tourism Economy of

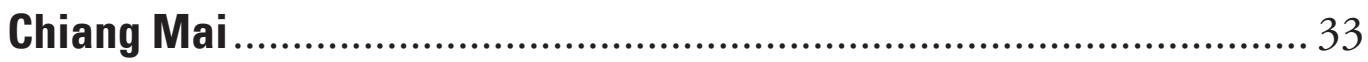

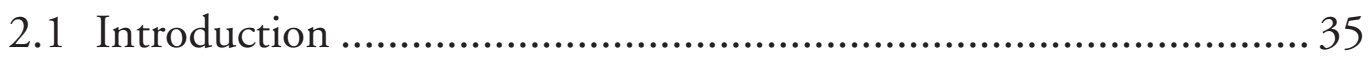

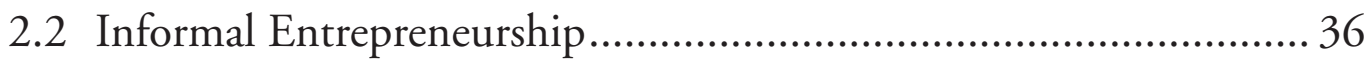

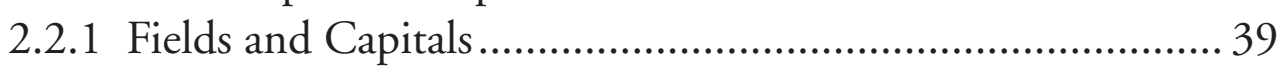

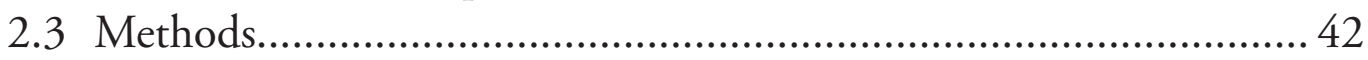

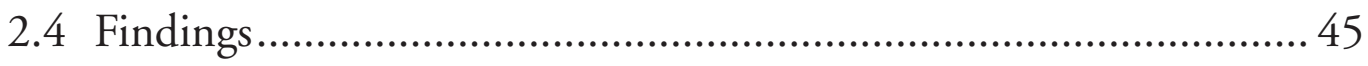

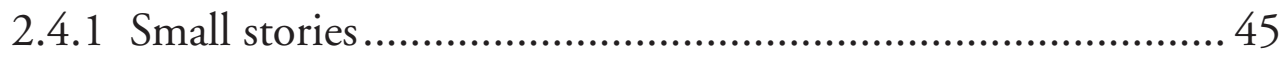

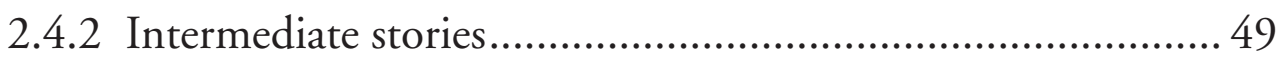

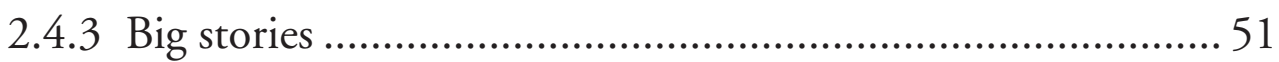

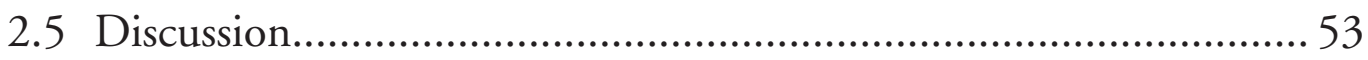

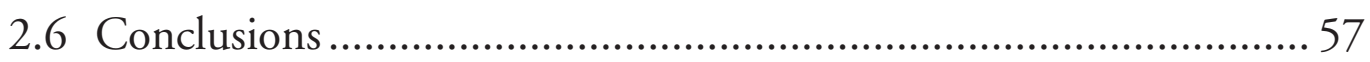

\section{Chapter 3:}

Informal Tourism Entrepreneurs' Capital Usage and Conversion ........61

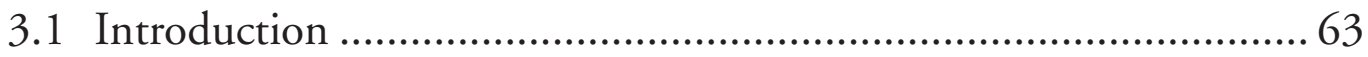

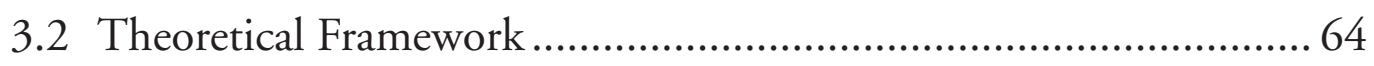

3.2.1 The Entrepreneurship Context in Tourism Economies......... 64

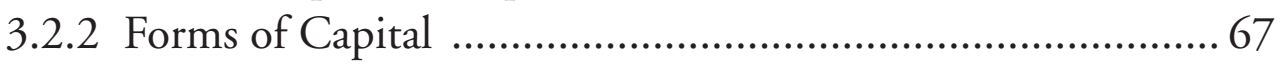

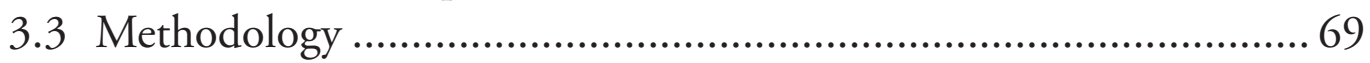




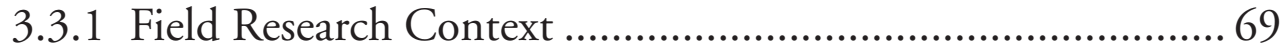

3.3.3 Data Analysis ................................................................... 72

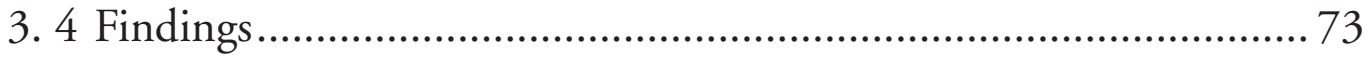

3.4.1 Informal Entrepreneurs' Profiles........................................... 73

3.4.2 Capital Usage and Conversion by Informal Tourism Entrepreneurs ................................................................... 73

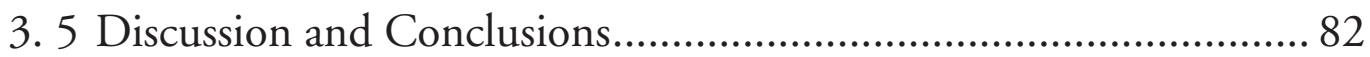

\section{Chapter 4:}

Habitus Adaptation of Informal Tourism Entrepreneurs........................ 87

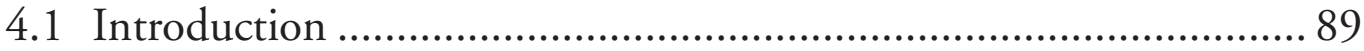

4.2 Theoretical Framework ................................................................. 90

4.2.1 Habitus Formation in Bourdieu's Theory of Practice............ 90

4.2.2 Habitus and Individual and Social Structural Change .......... 93

4.2.3 Informal Entrepreneurs in the Tourism Sector ...................... 94

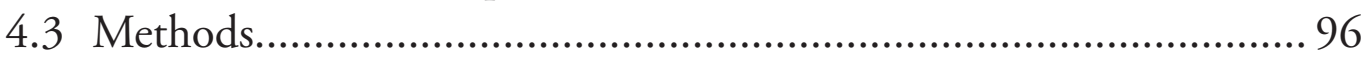

4.3.1 The Field Research Context ............................................... 96

4.3.2 Data Collection and Analysis ................................................ 97

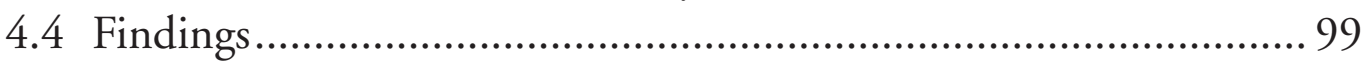

4.4.1 Understanding and Appreciating the Field and its Conditions....................................................................... 99

4.4.2 Challenging Core Belief Systems........................................ 102

4.4.3 Applying a Practical Sense to 'Objective Possibilities' .......... 104

4.4.4 Challenging Non-Reflective Dispositions............................ 106

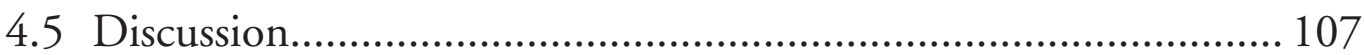

4.5.1 The Mode of Understanding and Appreciating the Field and its Conditions .............................................................. 109

4.5.2 The Mode of Challenging Core Beliefs Systems .................. 110

4.5.3 The Mode of Applying a Practical Sense to 'Objective Possibilities'........................................................ 110

4.5.4 The Mode of Challenging Non-Reflective Dispositions ..... 111

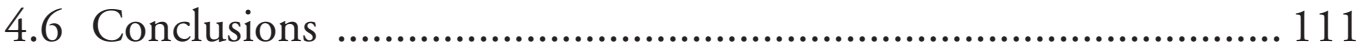

\section{Chapter 5:}

Measuring the Size of the Informal Tourism Economy in Thailand ... 115

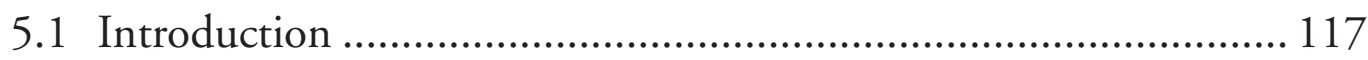

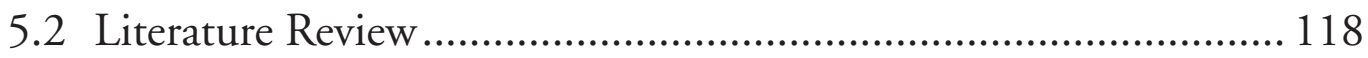

5.2.1 Informal Economy in the Developing World ...................... 118

5.2.2 Informal Tourism Economy and Labour ........................... 120 
5.2.3 The Thai Tourism Sector and Dynamics of the Informality . 122

5.2.4 The Informal Economy Theory and Measuring its Size ..... 123

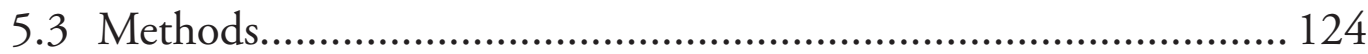

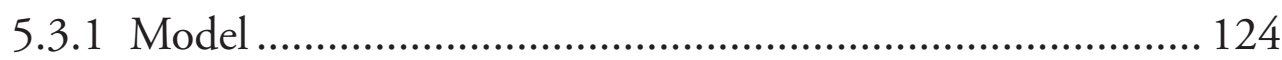

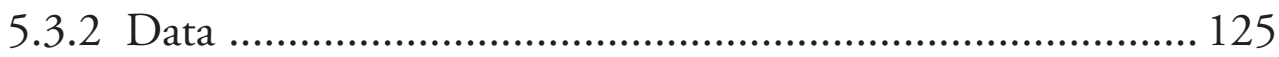

5.3.3 Size of the Formal and Informal Tourism Output ............... 128

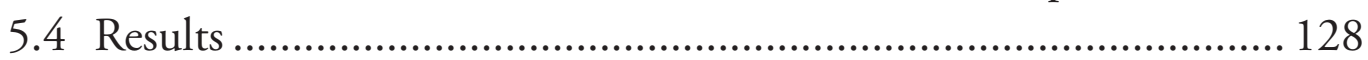

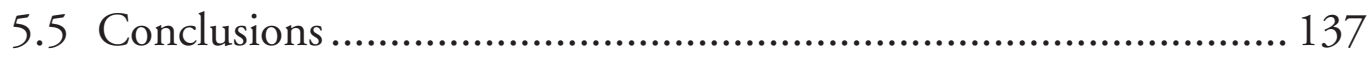

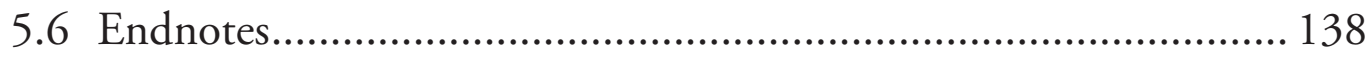

\section{Chapter 6:}

Concluding Synthesis and Directions for Future Research ............... 141

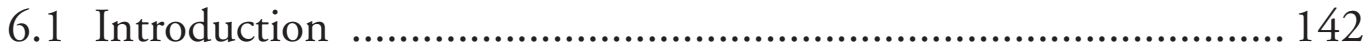

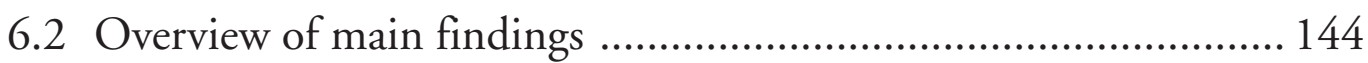

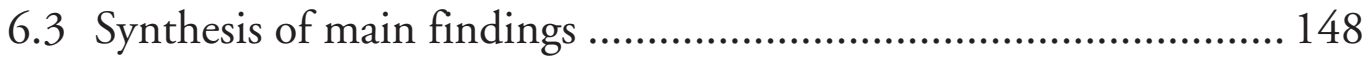

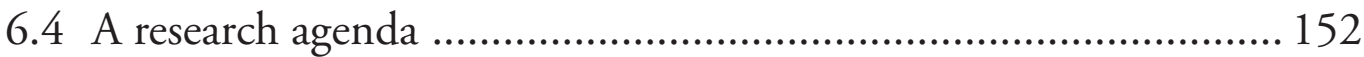

6.4.1 Destination capital mix and (mis)fit with entrepreneurs' capital portfolio ……......................................................... 152

6.4.2 Dream capital as a new input in the entrepreneurship competence framework ...................................................... 153

6.4.3 Symbolic violence and social exclusion practices ................ 153

6.4.4 Contested terrains: doxa and discourses in informality ....... 154

6.4.5 Paradox of fixed/singular entrepreneurship vis-à-vis hybrid entrepreneurship and liquid identities ................................. 154

6.4.6 Sustainable Development Goals (SDGs) and informal

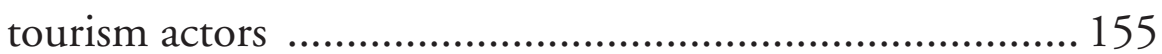

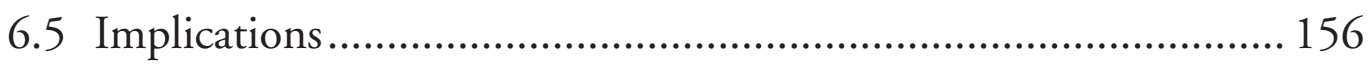

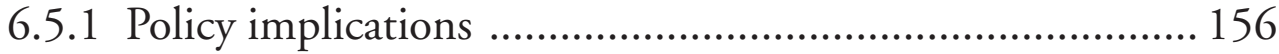

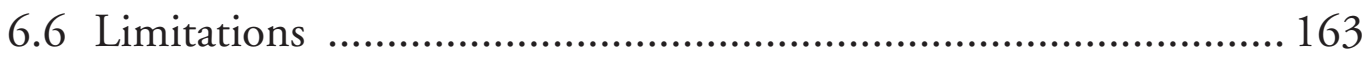

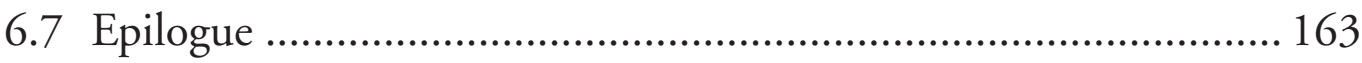

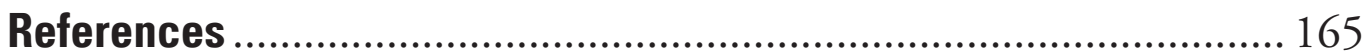

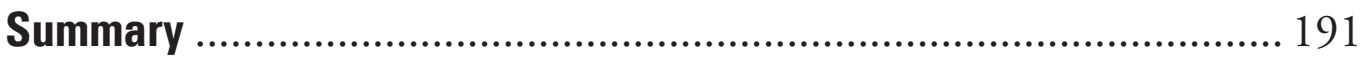

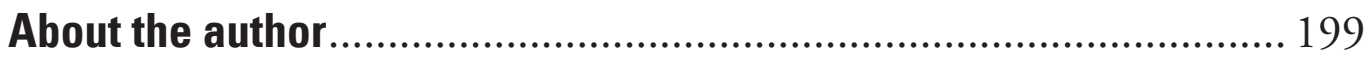




\section{Abbreviations}

$\begin{array}{ll}\text { FTO } & \text { Formal Tourism Output } \\ \text { GDP } & \text { Gross Domestic Product } \\ \text { HP Filtering } & \text { Hodrick-Prescott Filtering } \\ \text { ILO } & \text { International Labour Organization } \\ \text { ITO } & \text { Informal Tourism Output } \\ \text { LFO } & \text { Labour Force Participation } \\ \text { MENA } & \text { Middle East and North Africa } \\ \text { MIMIC } & \text { Multiple Indicators Multiple Causes Model } \\ \text { NGO } & \text { Non-government Organisation } \\ \text { OECD } & \text { The Organization for Economic Cooperation and } \\ & \text { Development } \\ \text { PWT } & \text { Penn World Table } \\ \text { TAT } & \text { Tourism Authority Thailand } \\ \text { TOT } & \text { Tourism Organisation of Thailand } \\ \text { WDI } & \text { World Development Indicators } \\ \text { WTTC } & \text { World Travel \& Tourism Council } \\ \end{array}$




\section{Tables}

Table 1 Overview of Chapters ...................................................... 31

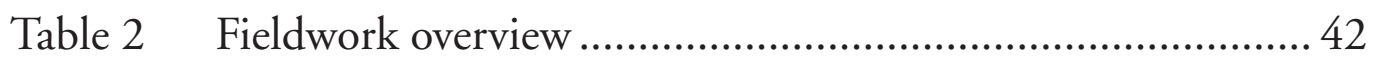

Table 3 Participant profiles of narrative interviews............................. 44

Table 4 Number of filmed interviews across three fieldwork destinations by type of entrepreneur....................................... 72

Table 5 Capital distribution among informal entrepreneurs by stage of development.......................................................... 83

Table 6 PWT Data: variables, acronyms, range............................... 125

Table 7 WDI Data: variables, acronyms, range …………............... 126

Table 8 Correlations of tourism output .......................................... 136

Table 9 Summary of the main findings........................................... 145 


\section{Figures}

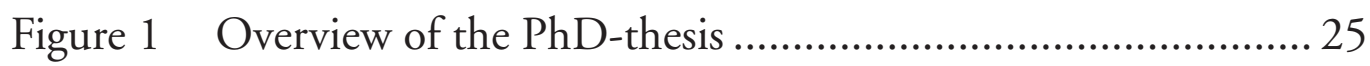

Figure 2 Fields, capitals and stakeholders .......................................... 55

Figure 3 Modes of habitus adaptation as they relate to major and minor changes in individual and social structure ......... 109

Figure 4 Informal versus formal GDP ............................................ 129

Figure 5 Informal versus formal tourism output.............................. 131

Figure 6 Informal tourism output versus (un)employment............... 132

Figure 7 Informal tourism output versus labour force participation.... 134

Figure 8 Informal tourism output versus self-employed in the service sector …………..................................................... 135

Figure 9 Fields, capitals and stakeholders ..................................... 149

Figure 10 Modes of habitus adaptation as they relate to major and minor changes in individual and social structure ......... 151 


\section{Chapter 1}

Introduction 


\subsection{Informal Economies and The Practice of Informal Tourism Entrepreneurs}

Informal economies are large and not diminishing. More than 2 billion people worldwide (i.e. $61.2 \%$ of the world's employed population) make their living in the informal economies (ILO, 2018). Informal economies or informal sectors are often defined from an economic perspective, primarily focussing on their role in generating employment and income. The perspective taken in this $\mathrm{PhD}$-thesis goes beyond such a core economic perspective and sees the informal sector as a social system in which people continuously shape and reshape their livelihoods, individually and collectively. Such a social systems perspective on the informal economy allows us to consider the whole and focus on the construction of the system through the social, political, cultural and economic interactions of its members.

Researchers were already impressed six decades ago by the size of the informal economy, but they anticipated that the modern formal economy would absorb its counter part rapidly with the advent of globalisation (Light, 2013). In fact, the informal economy has been growing, especially in the developing world where globalisation has been fortified by outsourcing as organisations move work to so-called economically developing countries. The informal economy provides essential products and services, enhances supply chains, and generates employment (Chen, 2006). Despite its connotations of the traditional, the underdeveloped, marginality and even illegality, the informal economy and its actors contribute substantially to the economic and social life of communities worldwide.

While the vast bulk of literature on formal economies and entrepreneurs highlights the liberating side of formal economic systems and the novel combination of resources, sociological and anthropological studies focus more on informal economies as socially constructed systems. This PhD-thesis primarily seeks to understand the informal economy from such a sociological and anthropological perspective. Such a perspective centralizes informal entrepreneurs as social actors and as active contributors to, and constructers of, the informal system. From an interactional and socio-political perspective, the focus is on the transformation of capitals and on how informal entrepreneurs co-construct their own informal system. The primary focus is thus on how informal entrepreneurs co-construct their practice. 
Such a focus on co-construction, which is grounded in a constructivist ontology, calls for a qualitative research approach, which also suits the explorative character that the research seeks to pursue. Therefore, the methodologies adopted in three of the four chapters of the $\mathrm{PhD}$-thesis are narrative inquiry, discursive thematic analysis and ethnographic field research (for details see the specific descriptions of the different chapters further on in this introductory chapter). The overall focus on the sociologically fuelled construction of practices is not to say that this $\mathrm{PhD}$ research ignores an economic perspective. In fact it aims to incorporate an economic perspective within a social constructivist approach.

In the field of tourism, researchers have studied the informal economy and the people working in the informal tourism sector by taking an interdisciplinary approach; sometimes seeing it as a world of opportunities and sometimes as a barrier to sustainable development. It is obvious that the epistemology of tourism inquires "different forms of knowing about tourism [related issues]" (Tribe, 1997: p. 639). Recognizing the knowledge that flows in the field of tourism is "rooted elsewhere in more than one discipline" (Hirst 1965: p. 130), this study follows the suggestion that knowledge production within tourism can be called interdisciplinary (Tribe, 1997). Epistemologically speaking, researchers have often had a disciplinary education and justify their knowledge claims on the practices in tourism using their specific disciplinary methodologies and approaches. For instance, economists focus on tourism related capitals and how to utilize these capitals mainly in the formal economy, and address topics such as efficiency of usage of capitals, allocation of capitals, and the stakeholders' access to these capitals within tourism. They often suggest formalising the informal economy and controlling its actors' activities, which have no place in the official structures. However, sociologists and anthropologists mainly focus on the relations between the stakeholders in tourism. They investigate the practices of stakeholders within tourism from a particular context of applications using sociologically and anthropologically distinct theoretical structures, concepts, and research methods. In terms of the informal tourism economy and its actors, they mainly focus on the power related issues (e.g., how vulnerable groups have been dominated by powerful actors in the field) and how the structure is structured, destructured, and restructured in the light of practices within tourism.

Although this $\mathrm{PhD}$-thesis primarily adopts an anthropological/sociological perspective to understanding the practices of informal tourism entre- 
preneurs, this is not to suggest that an approach taken from sociology and anthropology is better than an approach rooted in economics. In fact, this $\mathrm{PhD}$-thesis consists of three chapters that depart from an anthropological/ sociological perspective, but also includes one chapter that departs from a fundamentally economic perspective. The main research question that clusters the first three chapters is "How do informal tourism entrepreneurs construct their informal tourism economy through their practices?"

Despite theories of practice being mostly neglected within tourism research (Lee \& Scott, 2017), this PhD research uses Bourdieu's theory of practice $(1977,1986,1990,1998)$ to answer the research question. Using Bourdieu's work is relevant because his theory - constituting a unique operational focus on practice - and its close attention to the day-to-day practices of people who do their work within the conditioned and socially embodied knowledge, makes his work well suited for examining the practices of informal tourism actors. Also his methodological ideas, which are a synthesis of the quantitative and qualitative approaches that necessitate reflexivity and relational thinking, can provide a foundation for analysing the relations in the field and the capital exchange among actors, and ultimately the dynamic practices of actors in the informal tourism economy. Bourdieu's theory and methodology will be explained in more detail in the next section.

While recently there has been an increasing emphasis on the informal tourism economy and its actors (e.g., Damayanti, Scott \& Ruhanen, 2017; Pécot, Gavilanes \& De Viteri, 2018; Truong, 2018; Trupp \& Sunanta, 2017), there are no studies that depart from Bourdieu's theoretical work on practice and apply his central concepts (i.e. field, capital, habitus). This $\mathrm{PhD}$ research will, by using Bourdieu's central concepts, create understanding by

a) Contrasting the networks of social relations in the field, where informal tourism entrepreneurs take positions or struggle over capital, stakes, and access,

b) Comparing the different forms of capital owned by informal tourism entrepreneurs, and by

c) Compiling insights from analyses of informal tourism entrepreneurs' habitus.

In addition, the PhD-thesis consists of a fourth economic chapter. This chapter shifts attention to macroeconomic indicators and focusses on the size 
of the informal tourism economy. The objective of this paper is to estimate the size of the informal tourism economy and to advance understanding by evaluating the dynamic interplay between the informal tourism economy and the labour market. To this end, this paper seeks answers to four interrelated questions. First, what is the contribution of the informal tourism economy to a country's the national gross domestic product? Second, how do formal and informal tourism economies influence each other? Third, how does the informal tourism economy react to the economic and political up- and down-turns? Finally, how does the informal tourism economy link to the labour market?

These questions have endured for decades because their resolution requires a methodological polytheism combining the social science disciplines and extensive datasets with advanced modelling techniques. Despite the vast quantity of research in the economics literature examining the size of the informal economy in aggregate over the last decade, there is no research at the sectoral level, in particular examining the size of the informal tourism economy. It is not possible to calculate the total contribution of the tourism sector to the national economy - only examining concepts through formal economy - without knowing the size of the informal tourism economy. Although the dearth of datasets tracking informal tourism economic activities across countries makes our understanding of country level dynamics deficient, this thesis attempts to measure the size of the informal tourism economy using available statistics with an emphasis on the tourism development, political events, and other macroeconomic indicators.

The four chapters together thus seek to offer a comprehensive and rigorous analysis of the practice and size of the informal tourism economy.

\subsection{Bourdieusian Praxeology}

Bourdieu's theory of practice, in his own words, "social praxeology" (praxis refers to action and logia refers to study) consists of theoretical as well as methodological ideas as they co-exist and interrelate. The core of his social praxeology consists of the three central concepts "field", "capital" and "habitus", with which he captures the concept of "practice". Practices are then seen as the result of the dynamic relations between field, capital and habitus. 
Based on these concepts Bourdieu suggests a three-step approach to researchers in their investigation of a social phenomenon. These steps will also guide this $\mathrm{PhD}$ research. The first step includes a determination of actors and the nexus of their interconnected relations and the characters of a field. Bourdieu suggests that it is not enough to focus only on the outcomes (what happened) of actions but also one needs to observe, measure and map the determinant relations, transactions and events happening in a field. Such a reading necessitates examining a field in relation to other fields and particularly the field of power. Here the researcher attempts to determine which actors dominate the space on the field and seek to establish a monopoly (Wacquant, 1993). Based on this the researcher maps out the structural relations in the field.

Secondly, the researcher uncovers the species and the volumes of capital the actors hold in relation to their positions on the field. Bourdieu (1986) extends the term "capital" into four different forms: economic, social, cultural, and symbolic. It is necessary to examine here whether the actors based on their capital - occupy a determined position on the field.

Finally, as a third step, Bourdieu suggests looking at the perspective of "objectivity of the second order" by means of conducting a habitus analysis of social agents. This perspective necessitates a focus on less easily measurable items such as symbolic templates of practical activities, mundane knowledge, subjective meaning and practical competency (Bourdieu, Wacquant, 1992). For this last step the researcher is asked to analyse the categories of perception, appreciation and the lived experiences of social agents - also known as a disposition analysis (Wacquant, 1989).

His social praxeology - consisting of the perspectives on practices explained above - allows for a polytheistic approach and synthesizes both qualitative and quantitative techniques in constructing the research object, its boundaries, content and character (Bourdieu \& Wacquant, 1992). It necessitates relational thinking and reflexivity in the construction of the research object and the researcher's position. Accordingly, a relational analysis as applied in this $\mathrm{PhD}$-thesis requires that:

"... the first precept of method, that which requires us to resist by all means available our primary inclination to think the social world in a substantialist manner... one must think relationally... it is easier to think in terms of realities that can be touched with the finger" (Bourdieu \& Wacquant, 1992: p. 228). 
To conduct a relational analysis, the construction of a research object requires first a radical doubt, which is also a critical break with common sense - the "representations shared by all... present both in the objectivity of social organizations and in the minds of their participants" (ibid. p. 235). Consequently, the observation program and analysis are accomplished:

"Little by little, though a whole series of small rectifications and amendments inspired by what is called le métier, the "know-how", that is, by the set of practical principles that orients choices at once minute and decisive" (ibid. p. 227).

Thus, the whole observation program and analysis cannot be fixed and drawn like a blue print in advance.

The second important necessity in Bourdieu's social praxeology that informs this $\mathrm{PhD}$ research is the researcher's relation to the object, reflexivity. This enables a social scientist to achieve a "first order knowledge" of the phenomenon that is under research and sharpens the researcher's gaze into the research instruments and methods. Bourdieu recommends that researchers acknowledge that their orientations to the world influence their research claims. Further he suggests that researchers address three key possible biases (i.e. social, field, intellectual), which may blur the researcher's sociological gaze at each stage of research process. First, the social bias arises from the researcher's social origins and coordinates (e.g. class, gender, ethnicity). This bias is the most obvious one and needs to be monitored with self-criticism. Secondly, the researcher's academic field bias which is linked to the researcher's position in the microcosm of the academic field. Hence, a researcher's gaze is determined by his or her occupation of position (e.g. power) in the field. The third is the intellectualist bias- Bourdieu also calls it "the scholastic point of view" - that persuades the researcher to interpret "the world as a spectacle, as a set of significations" rather than to recognize the concrete problems, which can be solved practically. To overcome this bias the researcher needs to focus on the action and its practical logic rather than think of the world holistically.

The analysis contained in Chapter 2 (structural relations among the actors on the field), Chapter 3 (species and volumes of capital hold by informal entrepreneurs) and Chapter 4 (habitus adaptation of informal tourism entrepreneurs) belong to the classification of praxeological steps of the Bourdieusian methodology as described earlier. In Chapter 5 his analysis 
is further supported with the macro quantitative analysis focussing on the size of the informal tourism economy, which was introduced in section 1.1. Here the available statistics are analysed with an emphasis on the tourism development, political events, and other macroeconomic indicators with their relations to the informal tourism economy.

\subsection{Thailand as Context}

Thailand is chosen as a context in this research because it is one of the top 10 tourist destinations in the world rankings and it is the second largest economy in Southeast Asia, yet with the highest ratio of revenue arising out of the informal economic sector (Bloomberg Business, 2015; Tourism Authority of Thailand, 2018). Thailand's geographical position and its relatively developed infrastructure - in comparison to its neighbours - make it an important tourism hub in mainland Southeast Asia. In the last two decades, the tourism sector in Thailand experienced a five-fold increase in international tourist arrivals from 7 million in 1997 to 35 million in 2017. A recent study argues that the fast growth in tourism will continue and the number of international visitors will record 79 million by 2030. This would make Thailand the fifth biggest tourist destination in the world (Euromonitor International, 2018).

Informal economic activities in Thailand are spread out over many sectors, including tourism, agriculture, construction, manufacturing, transportation, retail and services. Since 1990s, the relatively fast economic growth in Thailand - in particular the fast growth in the tourism sector - has increased the flow of people from rural regions in the country and from the neighbouring countries to major Thai cities (De Jong, 2000). However, there is a limit to the ability of formal (tourism) businesses to absorb this high number of people and in addition both domestic and foreign groups of migrants have few opportunities to obtain employment in the formal sectors (Nakanishi, 1996). To this end, the number of informal actors working at tourism destinations is consistently increasing together with the growth of tourism in Thailand. This growth in informal tourism economies stimulated national and local authorities to design several policies to control the process and activities of informal tourism actors. All in all, to date, national and local authorities do not know the size of the informal tourism economy in Thailand. 
Four different tourist destinations are chosen for the primary data collection of this study, namely Chiang Mai, which is the second largest city of country, and the top three most popular tourist islands - Koh Samui, Koh Phangan, and Koh Tao - located in the south of Thailand (Lonely Planet, 2014). Chiang Mai is a popular backpacker centre for international tourists with a unique cultural heritage and a provincial capital city for migrants from surrounding rural areas as well as neighbouring countries like Myanmar and Laos. Because of the high elasticity in the supply of rural labour, there is a continuous flow from the agricultural sector into manufacturing and service sectors in the major cities of Thailand (Nakanishi, 1996). However, the formal economy in Chiang Mai lacks capacity to absorb this new labour force, and its informal tourism economy - which often requires minimal education and formal qualifications, has relative low entry barriers, is labour intensive - attracts these unemployed people and absorbs the labour surplus. In the other three tourist islands, tourism has developed rapidly in the last two decades, and this has affected the local communities' lives significantly (Pongponrat, 2011). While these islands were categorized as Thailand's marginal paradises in earlier studies (Cohen, 1982), after just two decades, environmental changes have occurred as a result of the rapid expansion of tourism and its associated developments (Green, 2005; Wong, 1998). The current tourism businesses are very dynamic, and many different types of informal tourism entrepreneurs exist on these islands. As a result, the different perspectives and practices of stakeholders involved in the informal tourism economy can be analysed in this mix of urban and touristic areas in Thailand.

The governance of tourism is very important for the policy makers in Thailand, since tourism accounts for about $6 \%$ of the national gross domestic product (GDP), provides massive employment (12.4\% of total) and is a significant foreign exchange earner (WTTC, 2017). Despite several regional and global crises (e.g., 1997 Asian economic crisis, 9/11 attacks in 2001 , the outbreak of contagious diseases in 2003, Indian ocean earthquake and tsunami in 2004, and several riots and political uncertainty including coups) the Thai tourism industry has shown high resilience and recovered much faster from crises than its neighbouring countries (Beirman, 2016). The Thai government's support for tourism started in 1960 with establishing the Tourist Organisation of Thailand (TOT) which evolved into the Tourism Authority of Thailand (TAT) in 1979. 
Whilst TOT's focus was only on the promotion of tourism, TAT has a broader scope of managing tourism and is responsible for its growth, direction and development and the conservation of resources in Thailand (Peleggi, 1996). TAT is a public entity and its structure, objectives and functions are set out in the Act B.E. 2522 (1979) with a revision in 2007 in the same Act. Under this Act, the TAT is given broad powers to function including the right to designate places as tourist sites, to provide loans, advise, train and educate tourism stakeholders, to access and compile data from both private and public sectors, and to construct on and lease real estate in Thailand and abroad (Suthisarnsuntorn, 2013). While the TAT is under the ministerial supervision of the Ministry of Tourism and Sports, the TAT Board plays an essential role in determining the directions and policies for tourism in Thailand. The Board appoints the governor and s/he is responsible for all TAT's operations and implementing its rules, regulations and the law. In addition to TAT, the Department of Tourism of the Ministry of Tourism and Sports is responsible for providing tourism-related licenses, permits and registrations. Yet, the Thai government develops, supports and promotes tourism in Thailand through a top-down approach (Pongajarn, 2017).

Following the establishment of TAT tourism has grown very rapidly in Thailand and by 1982 it had become the top foreign exchange earner and has surpassed the leading export commodity of rice. This rapid growth in tourism development brought challenges such as environmental pollution, damage to monuments and sex tourism. The practices of tourism stakeholders have been becoming much more complex and the individuals have adopted their roles in the structure. For instance, people involved in sex tourism play multiple roles, for instance women and transsexual prostitutes also work as cheap or unpaid tourist guides, interpreters and maids (Green, 2001). However, contrary to all these challenges, the Thai government is constantly investing in general tourism infrastructure by expanding airports, roads, ports and railways. In addition, significant national and international key players continue to invest in the hotel and transport sectors.

\subsection{Overview PhD-thesis}

The goals set out in Section 1.1 imply four building blocks, which uniquely define each chapter in this $\mathrm{PhD}$-thesis. Three chapters in the $\mathrm{PhD}$-thesis (Chapters 2, 3 and 4) relate to practices (field, capital, and habitus) of 
informal tourism entrepreneurs in Thailand. The fourth chapter (Chapter 5) addresses the measurement of the size of the informal tourism economy in Thailand. The overview of the four chapters is visualized in Figure 1 at the end of this section.

Figure 1: Overview of the PhD-thesis

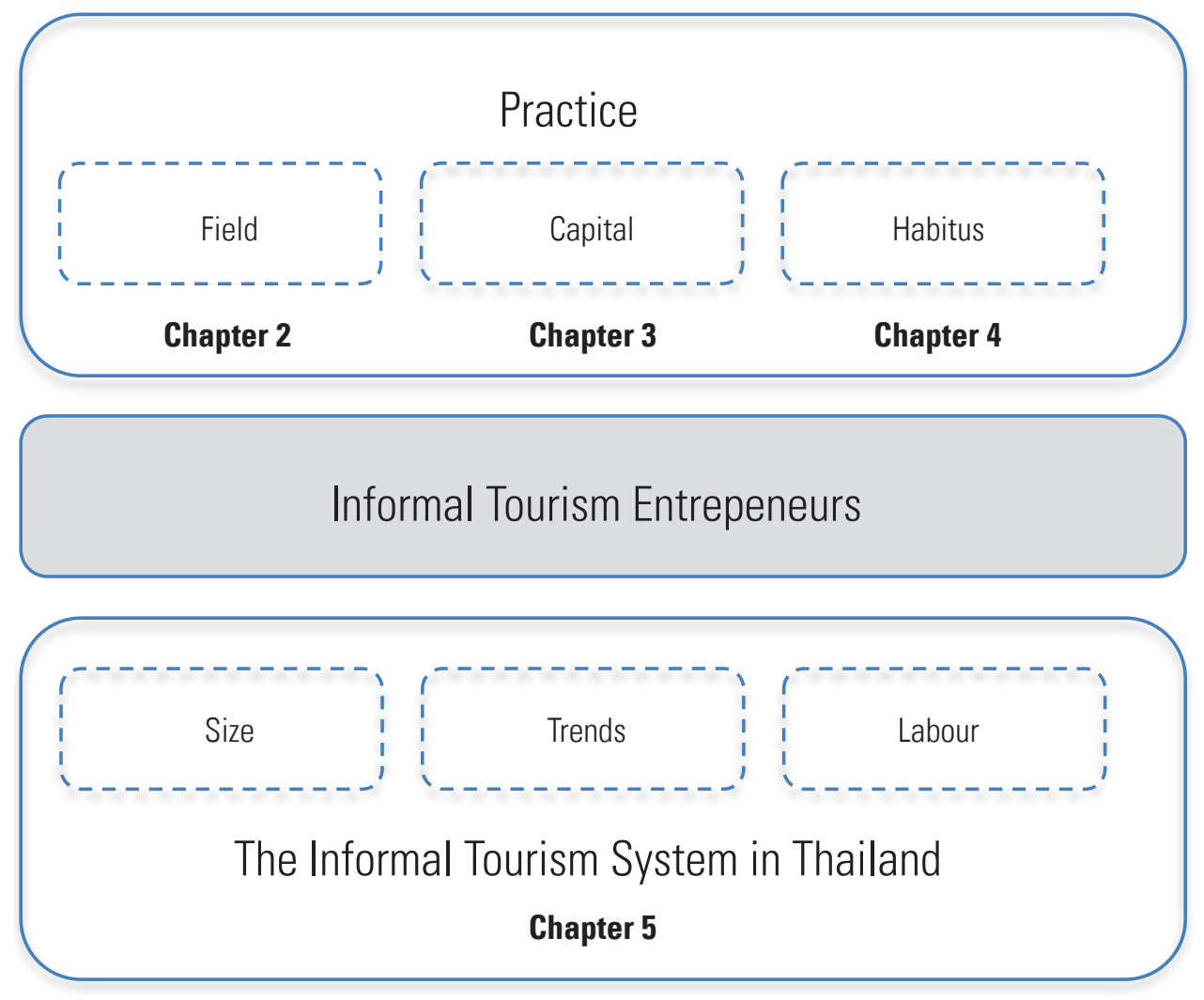

In addition to the overview provided in Figure 1, an overview listing the research questions, the type of research and methodological approach, the theoretical instrument(s), the data source(s) and the keywords for each chapter is provided in Table 1.

Given the pivotal role of field in explaining practice, Chapter 2, "Reframing Informal Tourism Entrepreneurial Practices: Capital and Field Relations Structuring the Informal Tourism Economy of Chiang Mai”, focusses on the positions of actors (with an emphasis on informal tourism entrepreneurs) and their structural relations in the tourism system. When one comes to think about the field, one needs to focus on all the struggles and/or manoeuvres of actors taking place over resources, stakes and access (Bourdieu, 1990). The study presented in Chapter 2 sheds light on the determination of relevant actors and the nexus of their interconnected 
relations to informal tourism entrepreneurs. The two questions guiding the research are (a) How do informal tourism entrepreneurs position themselves in the tourism system and (b) Which structural field relations exist in the (in)formal tourism system? In order to answer these questions, this study first demonstrates the basic capitals of informal tourism entrepreneurs, stresses the misfit between the field conditions and their possessed capitals, and, based on this analysis, maps out their positions in relation to other dominating tourism stakeholders' positions in the social fields of power, value and culture. In fact, these boundless changes and struggles make fields different than systems, which postulate more common function, internal cohesion and self-regulation (Everett, 2002).

Further this study reveals the extent to which informal entrepreneurs are excluded from policy actions, which particularly aim at supporting entrepreneurialism in tourism, and highlights the missed opportunity in increasing entrepreneurial activities in combining resources and or improving processes. The focus of much research in tourism studies has been on the formal tourism economy and the role of informal entrepreneurs has been neglected (Wahnschaft, 1982; Crick, 1992). Often these studies consider informal tourism activities as temporary and do not address their participants' needs or sometimes even acknowledge their existence (Cukier-Snow \& Wall, 1993; Dahles \& Brass, 1999; Timothy \& Wall, 1997). With similar intentions, non-governmental agencies see informal tourism actors either as a pool of labour for the formal economy and needing to update their skills and competences or as micro entrepreneurs who may be involved in community-based tourism in rural or remote areas. Implicitly both approaches aim to formalise informal activities and add them as workers into the tourism economic system in developing countries. To this end, the formal tourism economy has been treated generally as the dominant priority (Kermath \& Thomas, 1992; Henderson \& Smith, 2009) and in some cases formal tourism agents have used their power to force informal enterprises out of principal tourist sites (Tan, 2004).

In Chapter 2, it is argued that while informal tourism entrepreneurs have limited access to common property resources, they have important skills, resources, qualities and attributes that could be utilized more successfully to enable them to contribute to broader economic development initiatives. Moreover, this study argues that examining the different types of fields and their relations with tourism offers great potential to explore social practices 
by means of responding to the challenge in tourism studies to engage more fully with practice-based approaches to tourism (de Souze Bispo 2016; Lammers, van der Duim \& Spaargaren 2017). To achieve this aim, this study has adopted a qualitative method including 32 narrative interviews, media analysis, policy documents analysis, and non-participant observation of informal tourism entrepreneurs over three periods between 2015 and 2016 in Chiang Mai, Thailand. The analysis of data is performed through a narrative analysis that categorised stories as small, intermediate and big stories illustrating insights, understandings and interpretations of different layers of stakeholder's fields. Narratives of informal entrepreneurs contributed to the small stories, reflections by NGO executives and private sector organisations based on the semi-structured interviews and document analysis resulted in the intermediate stories and perspectives of the macro-level government and policy makers - derived from interviews and policy document and media analyses - generated the big stories. Overall, it is found that informal tourism entrepreneurs need to mobilise and utilise their connections with other stakeholders to improve their social position in these fields.

\section{In Chapter 3, "Informal Tourism Entrepreneurs' Capital Usage and} Conversion", the focus is on the species and volumes of capital held by the informal tourism entrepreneurs. Identifying the role of different types of capital in creating competitive tactics has received substantial attention in the tourism studies. Yet few studies have offered an integrated view across these capitals and compared them to each other to ascertain which types of capital are salient for informal entrepreneurs to survive. The study presented in Chapter 3 sheds light on this issue by demonstrating the adoption of capital portfolio by informal tourism entrepreneurs at different stages of their enterprises and in this way influencing the structure of the field. The question that guided the research was "Which forms and sizes of capitals do the informal entrepreneurs use and convert at different stages of their enterprises' development processes?"

The dominant view in pro-poor and poverty alleviation approaches considers tourism as a catalyst to stimulate marginalized communities' livelihoods and mostly neglect people's strengths (e.g. skills, capacities, good health) in favour of a focus on the stimulation of entrepreneurial activities (Mitchell \& Ashley, 2010; Roe \& Khanya, 2001). In such approaches, an informal entrepreneur's capital portfolio is often underestimated and not well understood. For that reason there is little sense of the potential posi- 
tive contributions offered by their activities to tourism development in the broader context. However, informal entrepreneurs enter into the tourism economy with specific types of capital and fill out the product and service gaps in the formal tourism economy. Moreover, previous research on capital has tended to do so from a single, static viewpoint - typically economic, social or cultural - serving to overlook the ways in which entrepreneurs use them separately.

In Chapter 3, the claim is that capitals are interconnected. Each stakeholder on the field preserves their capital, aims to acquire new capital or increase its value. Each field favours different combination of capital and it is not only the volume of capital that is important but also its liquidity, convertibility and susceptibility to attrition. Therefore it is argued that informal tourism entrepreneurs strategize their capital portfolio in relation to their enterprises' development process and the field's requirements. This study further investigated informal entrepreneurs' complex capital conversion in tourism economies. The data was obtained by fieldwork on the top three tourist islands in Thailand, where a total of 78 filmed interviews and 426 photographs were collected. Visual documentation (e.g. taking photos, analysing maps, and shooting interviews) and non-participant observation constituted the information gathering methods in this study. A qualitative thematic data analysis was applied to this visual dataset in order to generate a multifaceted analysis of informal entrepreneurs' capital mix and to observe the conversion of these different forms of capital within their complex networks. The results demonstrated the species and volume of capital held by informal tourism entrepreneurs at their development stages (i.e. freelancer, small size, mid size and large size). In addition, Bourdieu's forms of capital (i.e. economic, cultural, social and symbolic) has been extended by adding a new form of capital, labelled as dream capital, which acts as a catalyst to convert other types of capital to economic capital at all entrepreneur development stages.

\section{In Chapter 4, "Habitus Adaptation of Informal Tourism Entrepre-} neurs", the habitus of informal tourism entrepreneurs has been studied guided by the question "How does habitus adapt under the influence of major and minor individual and social structural change?".

Recent research on habitus has advanced our understanding on the role of habitus in exploring social reproduction, yet much less research exists 
regarding how habitus actually adapts under the influence of individual and social structural change (Aarseth, Layton \& Nielsen, 2016; Green, 2008; Lau, 2004). Moreover, in tourism studies habitus has been often been examined in relation to lifestyles, in particular taste formation (Ahmad, 2014; Lee, Scott, \& Packer, 2014) and only a few studies have used social agents' habitus to understand processes of change at tourism destinations (Edensor, 2001; Jaworski \& Turlow, 2010). This chapter seeks to obtain a more complete view of what influences habitus adaptation by informal tourism entrepreneurs by considering social changes as well as individual changes.

The analysis is based on an ethnographic study containing 53 semi structured in-depth interviews with informal tourism entrepreneurs, observing informal tourism entrepreneurs in their work, participating in social activities with informal entrepreneurs and taking photographs. Frequent research visits to the same destinations (Koh Samui, Koh Phangan, and Koh Tao) in three consecutive years (2013, 2014 and 2015) were undertaken. The results identified the existence of a classification of four modes of habitual behaviour: (1) Understanding and appreciating the field and its conditions, (2) Challenging core beliefs systems, (3) Applying a practical sense to 'objective possibilities', and, (4) Challenging non-reflective dispositions.

\section{Chapter 5, "Measuring the Size of the Informal Tourism Economy", is} the first study done to estimate the size of the informal tourism economy and empirically studies the dynamic interplay between trends in the (in) formal tourism economy and the labour market.

Previous chapters in this $\mathrm{PhD}$-thesis demonstrated that formal and informal tourism economies are dynamically linked to each other and many enterprises from both sides have production and distribution relations (e.g. sub-contracting arrangements). In this way informal and formal tourism economies influence the labour mobility and gender gap in the labour market. However, little is known about the size of the informal tourism economy and its contribution to the national economy in aggregate (Kedir, Williams \& Altınay, 2018). It is not possible to calculate the total contribution of the tourism sector to the national economy without knowing the size of the informal tourism economy. Moreover, only examining concepts in the formal economy provides just a very partial representation of the nature of economies and labour markets (Williams \& Horodnic, 2018). Chapter 5 empirically studies the informal and formal tourism economies' 
influence on several features of the labour market rather than only focussing on impacts of the formal sectors. The analysis is based on a dynamic general equilibrium model that allows us to understand how informal and formal tourism economies evolve over time and behave during the economic and political up- and down-turns, and how their developments relate to (un) employment, labour force participation, self-employment in the service sector and gender. This approach offers a highly flexible means for assessing the multiple-causes and multiple-indicators in estimating the size of the informal economy. The model is used by combining the detailed data set from the World Development Indicators (WDI) compiled by the World Bank over the period 1974-2014 and GDP data over the period 19502014 retrieved from the Penn World Table (PWT) version 9. The results suggest that while the relationship between formal and informal economies is negative in the aggregate, they do not move into the same direction in particular sectors, for example this relationship is positive in the tourism sector.

The final Chapter $\mathbf{6}$ summarizes and synthesises the findings of the four studies in this PhD-thesis and draws implications for academicians and practitioners. A description of several future research topics based on the themes which emerged during the entire research process is also provided here. 
Table 1: Overview of Chapters

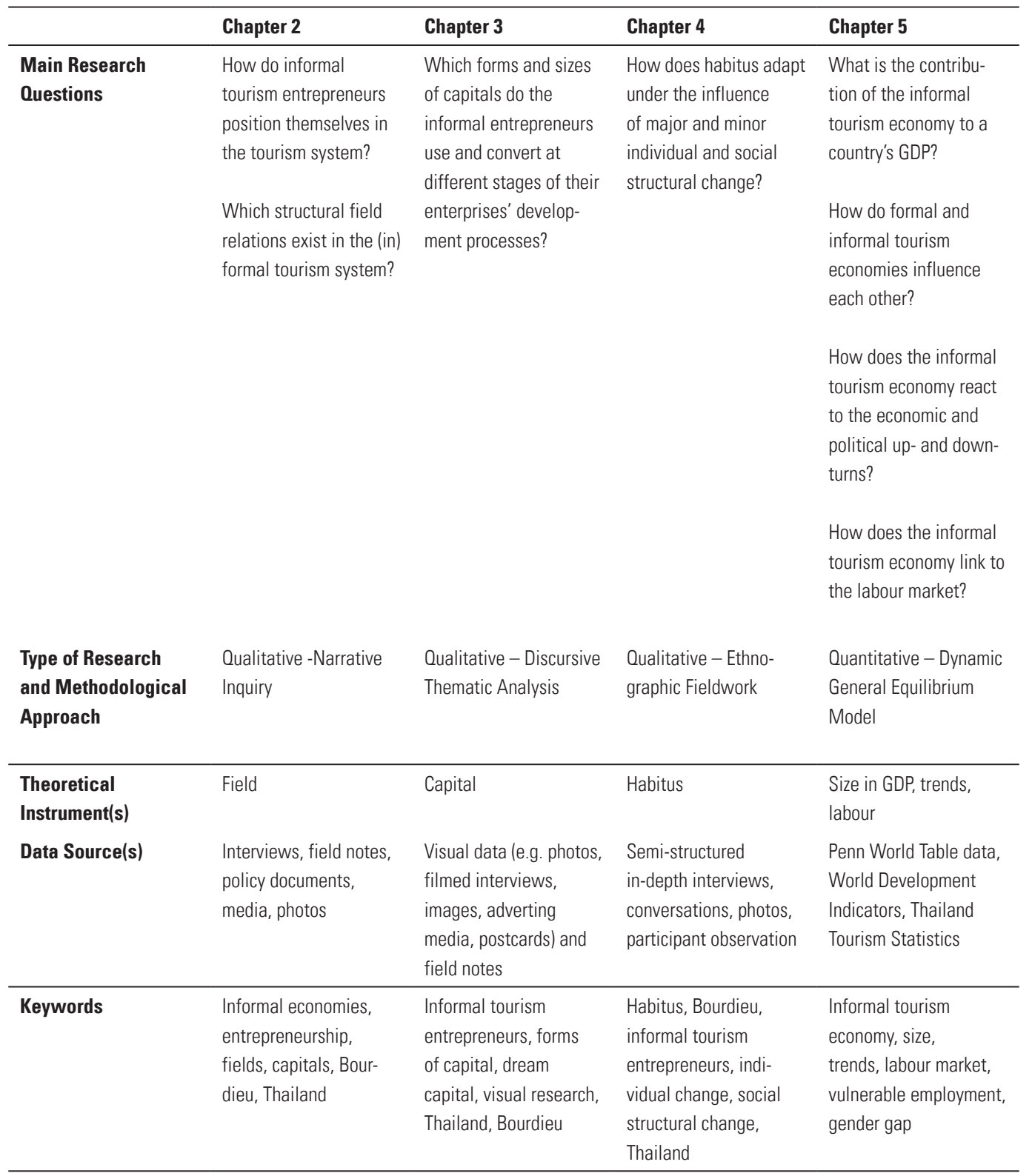




\section{Chapter 2}

\section{Reframing Informal Tourism}

\section{Entrepreneurial Practices: Capital and}

Field Relations Structuring the Informal

Tourism Economy of Chiang Mai.

Erdinç Çakmaka, ${ }^{a, b}$ Rico Lie ${ }^{b}$, Scott McCabe

(The article presented in this chapter is published in Annals of Tourism Research, 2018, Vol. 72, pp. 37-47.)

a Breda University of Applied Sciences, the Netherlands

b Knowledge, Technology and Innovation, Wageningen University \& Research, the Netherlands

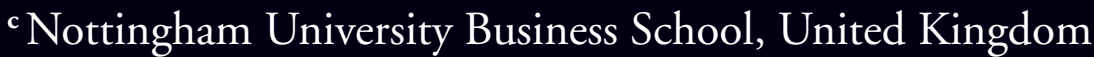




\section{Abstract}

This article examines the types of capitals possessed by informal tourism entrepreneurs and locates their value within the field relations that orders their contribution to the tourism system. Bourdieu's theory on fields and capitals was applied to ethnographic narrative accounts of stakeholders in tourism in Chiang Mai, Thailand to assess these roles. Informal entrepreneurs have limited access to resources and their perspectives are excluded from academic debates and policy initiatives. The paper identifies the dynamism, positive social capital, flexibility, and symbolic capital of informal entrepreneurs. These are related to the field conditions that determine and structure their contribution to tourism destinations. The analysis reveals the importance of collaboration between informal entrepreneurs and other stakeholders, concluding with recommendations for policy makers.

\section{Keywords}

Informal tourism economy; entrepreneurship; fields; capitals; Bourdieu; Thailand 


\subsection{Introduction}

The informal economy provides essential products and services, and generates employment, particularly in developing countries (Chen, 2006). Informal entrepreneurs enhance the competitiveness of regional economies through their input in the provision of tourism goods and services, and their involvement in strategic networks and supply chains (Jones, Mondar $\&$ Edwards, 2006). Yet while the formal economy is represented as a positive force in the economy, characterised as modern, developed or advanced, the informal economy is denoted mostly in negative terms, as traditional, underdeveloped and backward (Williams, 2008). Therefore, often, the views of informal entrepreneurs have been marginalized. The issues affecting informal entrepreneurs are frequently unobserved in academic or professional discussions.

The aim of this article is to explore informal tourism entrepreneurs' positions in the tourism system through an analysis of the 'structural fields' in which they operate. It focuses on an investigation into the range of capitals they possess and explores how these are determined by the actions of a range of other actors in the system (the formal tourism industry sector, NGOs and Government), which represent the 'structural field' relations. The paper examines the extent that informal entrepreneurs are excluded from policy actions, particularly those processes aimed at developing entrepreneurialism in tourism, to highlight the missed opportunity this represents for growing entrepreneurial activity. Through a focus on these issues, the paper seeks to contribute in number of ways. Firstly, it aims to highlight the complexity of political and socio-economic issues in tourism governance of informal economic activity, particularly in a developing country context, to inform policy development to support entrepreneurial activities.

Secondly, recognizing the unequal power relations among stakeholders in the sector, the paper applies Bourdieu's theory of fields and capitals to better understand the mechanisms of inclusion and exclusion within the system. Whilst Bourdieu's theory of capital has been successfully applied to explain tourism phenomena, the extension of the theory into fields of power has yet to be undertaken. Bourdieu's concepts of fields of power helps us to go beyond the identification of the types of capitals possessed by people working in the informal tourism sector. We develop a conceptual model of the linkages between informal entrepreneurs and other stakeholders and, 
suggest ways to learn from and connect the different fields and capitals to benefit society and economy as a whole.

The context for this study is Thailand, which is Southeast Asia's second largest economy, yet with the highest ratio of revenue evolving out of the informal economic sector (Bloomberg Business, 2015). Chiang Mai (literally meaning new city) is the second largest city of Thailand. The city has a fortunate location near to many cultural attractions, which appeal to international tourists. It is also a transfer hub to northern destinations and a popular backpacker centre with a unique cultural heritage. Chiang Mai is the provincial capital city and attracts many migrants from surrounding rural areas as well as neighbouring countries. In addition, due to high elasticity in the supply of rural labour in Thailand, there is a continuous movement from the agricultural sector into manufacturing and service sectors (Nakanishi, 1996). However, the formal economy in Chiang Mai lacks capacity to absorb them. The attractive characteristics of the informal economy such as, relative low entry barriers, labour intensive, small-scale activities, pull unemployed workers towards the sector (Todaro, 2000). In particular, the tourism industry offers low/semi-skilled jobs, a variety of indirect positions, and often requires minimal education and formal qualifications. As a result, the informal tourism economy has absorbed much of the labour surplus in Chiang Mai, presenting an interesting location to analyse these perspectives and practices.

\subsection{Informal Entrepreneurship}

The informal economy is a complex phenomenon and one that has attracted interdisciplinary attention from a range of perspectives including, sociology of work and economic sociology, anthropology, geography and development studies and entrepreneurship. There are many different terms used to describe it, including the 'black' economy, invisible or shadow economy and the irregular economy (Losby, Else, Kingslow, Edgcomb, Malm, \& Kao 2002). Whilst the different approaches have led to contrasting emphases on varying aspects of the informal economy, they share some common defining characteristics including, that exchange activities are undertaken, which are unrecorded in government auditing and accounting systems. The breadth of cash or non-cash economic activities is very broad, including, paid but not taxed, unpaid exchanges, and both legal and/or illegal activities, in addi- 
tion to varying types of labour market conditions. Although the informal economy concept emerged in the context of less developed countries, more recently, research has focused on the phenomenon in advanced economies (cf Sassen 1997). Economic restructuring to tertiary, service economies, the extension of neoliberal labour market policies, and the effects of the global financial crisis, are some of the reasons behind an expansion in informal economic activities.

From a management studies perspective, much of the research on the informal economy activities emerged in the context of entrepreneurship. Entrepreneurship enhances economic growth (Carree \& Thurik, 2010), creates jobs (Hitt, Ireland \& Hoskisson, 2001) and fosters innovation (Luke, Verreynne $\&$ Kearins, 2007). Nevertheless, a substantial amount of entrepreneurship appears informally outside state regulatory systems (Williams $\&$ Nadin, 2010). In a recent review, Williams $\&$ Youssef identify four main schools of thought emerging (2013): the modernization perspective that views informal entrepreneurship as a historical legacy, which is expected to rapidly disappear with the advent of the modern formal economy (Geertz, 1963). Secondly, the structuralist perspective, which positions informal entrepreneurship as a necessity-driven endeavour arising when people are excluded from the formal economy (Sassen, 1997; Gallin, 2001). Thirdly, the neoliberal perspective that considers informal entrepreneurs as voluntary entrants taking rational economic decisions to escape from the high costs and bureaucracy of the formal economy (de Soto, 1989). Finally, the poststructuralist perspective views informal entrepreneurship as a lifestyle choice (Chakrabarty, 2000; Getz \& Petersen, 2005), and is often based on an examination of the 'sharing economy' business models (Guttentag, 2015).

This discussion points to a number of salient issues. Firstly, the informal economy encompasses a range of positions, activities and motivations, rendering it a complex and multi-dimensional field. Secondly, the binary distinctions between formal/informal entrepreneurship represent a false logic, as increasingly, entrepreneurs can be seen to engage in some less formal or informal activities alongside their role in the formal, structural economy (e.g. Al-Mataani, Wainwright, \& Demirel, 2017; Çakmak, Lie, $\&$ Selwyn, 2018), blurring the distinctions between formal and informal economic practices. Thirdly, recent debates on the sharing economy show that the rhetoric around informal economic activity is shifting towards a 
more positive characterisation, and yet in the less developed world such informal activities are still primarily constructed as pejorative.

Informal economy issues in tourism have been studied using all four perspectives outlined above. Some have focused on vendors (Wahnschaft, 1982; Tan, 2004), poverty reduction and pro-poor tourism (Slocum, Backman \& Robinson, 2011), beach resorts (Henderson \& Smith, 2009), and resilience of informal entrepreneurs (Biggs, Hall \& Stoeckl, 2012). Others have examined informal business travellers (Timothy \& Teye, 2005), human resource development and employment (Liu \& Wall, 2006), and coopetitive behaviours between cabdrivers and vendors (Damayanti, Scott \& Ruhanen, 2017). Yet others have focused on macro issues such as, 'sharing economy' business models such as Uber and Airbnb (Guttentag, 2015), and on informal micro-finance institutions (Ngoasong \& Kimbu, 2016).

In these studies, tourism has often been constructed as a catalyst for the economic development of the global South (Truong, 2014). However, the focus of much research has been on the formal tourism economy and somewhat hopeful that informal activities will ultimately diminish through improvements in developing countries' economies (Wahnschaft, 1982; Crick, 1992). With similar intentions, international agencies have undertaken considerable initiatives to formalise the tourism economic system in developing countries. However, the focus on pro-poor approaches to informal labour market activities in developing world contexts has led to a situation whereby people's strengths (e.g. skills, capacities, good health) have been largely neglected in favour of a focus on the stimulation of entrepreneurial activities. Thus, informal entrepreneur's capital is not well understood, and so we have little sense of the potential positive contributions offered by their activities to tourism development in the broader context.

The role of international agencies and national governments also presents a limitation in terms of understanding informal entrepreneur's capital. The formal tourism economy has been treated generally as the dominant priority (Kermath \& Thomas, 1992; Henderson \& Smith, 2009) and formal tourism agents have been able to use their power to force informal enterprises out of principal tourist sites (Tan, 2004). Despite the acknowledged contribution of informal enterprises to national economies, governments have largely supported formal enterprises (Robson \& Obeng, 2008), with fewer finan- 
cial or legal actions offered to support informal entrepreneurs. In practice, (inter)national non-governmental organisation (NGO's) undertake some of the activity not provided by national governments, acting as intermediaries between governments and the informal sector, and delivering training programmes.

However, informal entrepreneurs are often not involved in designing these programmes. The omission of the preferences and priorities of informal entrepreneurs has resulted in being excluded as key stakeholders in these activities. Whilst we might argue that informal entrepreneurs have limited access to common property resources, they may have important skills, resources, qualities and attributes that could be utilized more successfully to enable them to contribute to broader economic development initiatives. In this sense Bourdieu's notions of fields and capitals offers a useful framework to investigate these issues.

\subsubsection{Fields and Capitals}

Bourdieu's primarily concern was to elucidate a "theory of practice". To understand a social phenomenon or to explain interactions between people, Bourdieu argued it is not enough to look only at outcomes (what happened) but also to examine the field in which interactions, transactions and events occurred (Bourdieu, 2005). Further, he suggests a three-level approach to study the field of the phenomenon.

First, it is necessary to examine the field in relation with other fields, in particular the field of power. Bourdieu (1998) defines the field of power as the social space that consists of multiple fields such as the economic, political, bureaucratic, scientific, cultural and others. In these fields, different actors and stakeholder groups operate and interact with each other to obtain a position in which they possess a sufficient amount of different forms of capital to dominate the corresponding social space. Ultimately, in the field of power, political power derived by government, and other mediating institutions such as the monarchy, international business and so on are the most powerful actors (Grenfell, 2008).

Secondly, it is necessary to map out the objective structure of relations between the positions occupied by social actors who compete for the legitimate forms of specific authority within the field. The positioning of 
actors is related to the capitals they hold. Bourdieu (1986) extends the term 'capital' into four different forms: economic, social, cultural, and symbolic. Economic capital refers to accumulated wealth in financial assets; social capital to durable networks of relationships through which individuals can mobilize power and resources (Bourdieu \& Wacquant 1992, p. 119). Cultural capital consists of cultural attributes incorporated into a disposition expressed in mental and physical features (an embodied form), possession of esteemed cultural material objects (an objectified form), and formal qualification and credentials provided by educational institutions showing skills and knowledge (an institutional form). Finally, symbolic capital to a "degree of accumulated prestige, celebrity or honour and is founded on a dialectic of knowledge (connaissance) and recognition (reconnaissance)" (Bourdieu, 1993, p. 7). As a result, capital is the main medium through which the field operates and is used by actors to vie for a position in the field.

However, it is insufficient to study a field as an aggregate of individuals' capital possessions, because the power that capital provides depends on the structure of the field in which it is activated (Sallaz \& Zavisca, 2007). Thus, a capitals value is elicited from the related field where it is recognized, acknowledged and attributed as a 'currency' of exchange and, affords its owner a position within the field according to its defining principles (Grenfell, 2008). These principles have their own logic of practice, defined by what is thinkable and achievable within the field. Finally, as a third step, Bourdieu suggests analysing the habitus of social agents, the characteristics of individuals including their background, life- and professional worlds in conjunction with their relationship to the field and its logic of practice.

Thus, the field is a multi-dimensional concept denoting the world in which social actors are embedded, and toward which they orient their actions. Martin (2003) suggests three points of a field, namely a cartographic map of positions, relational forces of social actors, and the contest among them as they vie for position within it. Although, Bourdieu mentions all these aspects, the contestation is most significant, as illustrated by his frequent use of a football game metaphor. When a football game is visualized, a field has a square form with internal divisions and external borders. The players have pre-set positions. In order to play a game it is not simply enough for a player to know the specific rules but s/he needs to possess basic skills in addition. Each player decides on his/her actions (e.g. where to go and what to do) with regard to his/her position in the field. Also the surface of field 
(e.g. grass, artificial turf, weather conditions) determines to an extent what players can do and how the play is played.

Ultimately, Bourdieu suggests, as in football, that a social field consists of positions occupied by social agents (people or institutions) and what happens in the field depends upon its conditions and boundaries. Social agents not only act in one particular field, rather they occupy different positions in different fields at the same time. He suggests that while there are some relationships and transference between these fields, each field possesses its own logics, rules, and principles. Bourdieu further suggested "... a field is a structured social space, a field of forces, a force field. It contains people who dominate and others who are dominated. Constant, permanent relationships of inequality operate inside this space, which at the same time becomes a space in which various actors struggle for the transformation or preservation of the field" (Bourdieu, 1998: p.40). This power dimension defines the strategies of social actors and the positions occupied in one field and across fields.

In tourism studies, the idea of the field has mainly been applied to knowledge production, the intellectual field (Bourdieu, 1969). With the "knowledge force field", Tribe (2006) described the path from tourism to tourism knowledge, and how positionality, personhood of a researcher, disciplinary norms, and societal ideologies mediate this path (further developed by Belhassen and Caton 2009). Whilst researchers have recently called for tourism studies to engage more fully with practice-based approaches to tourism (de Souze Bispo 2016; Lammers, van der Duim \& Spaargaren 2017), there are few examples. Pappalepore, Maitland \& Smith (2014) is an exception of an analysis of creative fields in urban contexts through the application of Bourdieu's notion of distinction.

Therefore, the different types of fields and their relations with tourism offer great potential to explore social practices, and examine which fundamental and specialized forms of capitals are active in fields, and the positions of social agents within them.

In a very recent study, Ahmad (2017) argues, "organizational analysis in the tourism industry within a broader sociological framework has largely received scant scholarly attention" (p.47). He examines power struggles and contestations within and between travel agencies in India using Bourdieu's framework of relational analysis. In Ahmad's study, travel agencies import 
capital and habitus from their previous social and professional arenas to organizational fields to form and shape their habitus in the tourism field. It is clear that Bourdieu's theory of practice offers great potential to tourism research, and in particular the relational structures in the field of the informal economy, to which we now turn.

\subsection{Methods}

A multiple method, qualitative approach was adopted to understand the interactions of informal entrepreneurs in the tourism economy, and to situate their status in the field within the wider contexts of the relational fields of other actors in the system. The approach combined ethnographic fieldwork with narrative interviews and policy analysis to gain an understanding of the field and insights into how individuals made sense of their positions, in relation to others, and of the situations they encountered.

Ethnographic fieldwork (including a non-participant observation of informal entrepreneurs during their work) was conducted in Chiang Mai, Thailand over three periods between 2015 and 2016. This included the following; observing informal entrepreneurs in their fields, acting as a tourist in interactions with tourism professionals, participating in training sessions offered by non-governmental organisations and analysing media sources about informal entrepreneurship with the assistance of Thai sociology scholars (see table 2 for details).

Table 2: Fieldwork overview

\begin{tabular}{lcllc}
\hline $\begin{array}{l}\text { Ethnographic } \\
\text { research }\end{array}$ & $\begin{array}{c}\text { Narrative } \\
\text { interviews }\end{array}$ & Participant observations & Media analysis & $\begin{array}{l}\text { Participating } \\
\text { training sessions }\end{array}$ \\
\hline March 2015 & 8 & Street observations & $\begin{array}{l}\text { Yes (of minor } \\
\text { significance) }\end{array}$ & With local NG0 \\
March - April 2016 & 18 & $\begin{array}{l}\text { Participation in the tours } \\
\text { Weekly participation in } \\
\text { professional meetings } \\
\text { with local NGOs, informal } \\
\text { entrepreneurs }\end{array}$ & Yes \\
Total & & Street observation & Yes \\
\end{tabular}


Narratives, which individuals use to make sense of past, current and future events, provide insights into people's interests and agenda's (Cobb, 2006). Narrative approaches have been used widely in tourism studies to explore people's lived experiences and their identities (McCabe \& Foster, 2006). People express their positions, interpretations of others and objects, and emotions through storied experiences (Mishler, 1995). As a result, narratives are an essential tool to understand the perspectives of tourism stakeholders and the way they produce social reality (Gergen 1988). Interviewing followed a semi-structured approach whereby respondents were asked to share his/her subjective story of as experience in a chronological sequence of events, often in informal interview contexts. In particular, with informal entrepreneurs, a biographic interview method was used to explore individual experiences, lived situations and life histories.

A judgment sampling method was used to capture a variety of perspectives towards informal entrepreneurship. More precisely, a maximum variation sampling aimed to capture a variation of perspectives towards informal entrepreneurship. Participants were chosen according to their particular characteristics in relation to the aims of the study. To allow participants to express their emotional and personal experiences, the prime challenge was to build a trusting relationship with people in the field. Apart from two interviews (conducted in Thai with a Thai sociology scholar), all the interviews were conducted in English.

The main tranche of data consists of field notes, policy documents from public organisations, handbooks, curricula, and promotion materials from NGOs, travel brochures from tourism enterprises, maps, photos, family stories, media stories, and 32 interviews and conversations collected from informal entrepreneurs, their business partners and relations, from other key informants in the public and private sector and residents. Table 3 outlines participant profiles, some demographic details, the number of interviews, and media analysis conducted across the fieldwork periods. 
Table 3: Participant profiles of narrative interviews

\begin{tabular}{|c|c|c|c|c|}
\hline Period & Participant profiles & Participant demographics & $\begin{array}{c}\text { Nr. of } \\
\text { interviews }\end{array}$ & $\begin{array}{l}\text { Media } \\
\text { analysis }\end{array}$ \\
\hline \multirow[t]{7}{*}{ March - April 2015} & Manager NGO & Female, Thai, 43 years old & 2 & \\
\hline & Field coordinator NGO & Male, expatriate, 36 years old & 1 & \\
\hline & Informal entrepreneur & Female, Burmese, 32 years old & 1 & \\
\hline & Sociology scholar & Female, Thai, 41 years old & 1 & 1 \\
\hline & Tour operator & Male, expatriate, 57 years old & 1 & \\
\hline & Tour operator & Male, expatriate, 31 years old & 1 & \\
\hline & $\begin{array}{l}\text { Business partner of an } \\
\text { informal entrepreneur }\end{array}$ & Male, Thai, 35 years old & 1 & \\
\hline \multirow[t]{6}{*}{ March - April 2016} & Sociology scholar & Female, Thai, 42 years old & 1 & 3 \\
\hline & $\begin{array}{l}\text { Region manager Royal } \\
\text { institution }\end{array}$ & Male, Thai, 35 years old & 1 & \\
\hline & Informal entrepreneurs & $\begin{array}{l}\text { Mixed gender, Burmese migrants, age } \\
\text { between } 23-42\end{array}$ & 7 & \\
\hline & Informal entrepreneurs & Mixed gender, Thai, age between 26-44 & 5 & \\
\hline & Residents & Male, Thai, 26, 31, 45 years old & 3 & 1 \\
\hline & Formal business owner & Female, Thai, 49 years old & 1 & \\
\hline \multirow[t]{4}{*}{ May 2016} & $\begin{array}{l}\text { Government officers from } \\
\text { different ministries }\end{array}$ & $\begin{array}{l}\text { Mixed gender, Thai, 26, 33, 46, } 55 \\
\text { years old }\end{array}$ & 4 & \\
\hline & Formal business owner & Male, Thai, 34 years old & 1 & \\
\hline & Sociology scholar & Female, Thai, 42 years old & 1 & 2 \\
\hline & Informal entrepreneur & Male, Thai, 35 years old & 1 & \\
\hline
\end{tabular}

An interpretive approach was taken to analyse the data. The analysis aimed at a holistic perspective to assess how the relations within the field and the various capitals intersected, overlapped or were distinct. To interpret meanings, we analysed the underlining discourse, as well as the context of each story and narrator, focusing on metaphors, symbols and insights. Subsequently, the narratives were compared with the purpose of detecting similarities, contradictions in content and interpretation (Feldman, Sköldberg, Brown, \& Horner, 2004). Finally, the stories were categorised as small, intermediate and big stories illustrating insights, understandings and interpretations of different layers of stakeholder's fields.

Narratives of informal entrepreneurs contributed the small story (Bamberg, 2006), their perceptions of different types of capital, relationships with other stakeholders and field-based perspectives. They were asked questions including; how they see their own capitals, what do they see as the main challenges in their fields and if and how they overcame these issues, what was their strategy to improve their positioning in these fields? The intermediate stories represent reflections from rational and pragmatic activities of NGO 
executives and private sector organisations and were the results of semi-structured interviews (Verloo, 2015). The big stories represent the macro-level government and policy perspectives, which were analysed through policy documents, master and national development plans, and include explanations from public resources and researchers' diagonal analysis of secondary public resources (Freeman, 2006; Bamberg, 2006). Furthermore, interviews with policy makers and analysis of policies towards informal entrepreneurs sought to explore the perceived level of informal entrepreneurs' capitals and the extent these were incorporated into the design of policies.

\subsection{Findings}

\subsubsection{Small stories}

There is a great variety of products and services offered by informal tourism entrepreneurs in Chiang Mai. These include handicrafts (e.g. bamboo hats, silverware, jewellery), semi-finished items, which are supplied to other manufacturers (e.g. wooden cutlery, decoration items), or to hotels and catering firms (semi-finished meals, vegetables). In terms of services, these include; transportation and guiding, entertainment (e.g. dances, music shows), homestays. In many cases, informal entrepreneurs are not competing with formal agents but complementing the product and service portfolio offered in a sub-contractor type of situation. Informal entrepreneurs' backgrounds vary widely across the areas and subsectors they are operating. Some have higher levels of cultural capital holding a graduate level diplomas, and work experience in formal sectors. One officer in the Ministry of Labour said:

"Many people lost their jobs in late 90s. Some moved from urban areas to rural areas, some moved to informal economies. Since then the vendors in Bangkok increased to a quarter million. You can find everything by these vendors, from a snack to a well branded suit sold for 10.000 baht (equals to approximately 300 USD) in the finance district of Bangkok"

There is a range of motivations why informal entrepreneurs are active in the tourism economy of Chiang Mai. While for some this is an option (e.g. a lifestyle choice), for others, mainly immigrants, working in an informal tourism sector is the only available option. 
Chiang Mai attracts many migrants from rural Northern Thailand and as well as from neighbouring countries like Myanmar. Both domestic and foreign groups of migrants have few opportunities to obtain employment in the formal sector. Lacking institutionalized cultural and social capital suitable to the field, such as a diploma from a well-known education institution and/or connection to powerful people or groups, which may enable them to gain access to the formal sector, create barriers to alternatives. And yet, they often have strong community relations, which accumulates internal positive social capital. One domestic migrant said:

"We live and work as of an 'extended' family". (female Burmese homestay owner, March, 2015).

This form of social capital is used extensively in their business models. For instance, if one informal entrepreneur provides a homestay to tourists, another supplies catering items, one organizes tours, another offers transportation, yet another guides tourists during their tours, and so on. This community spirit and solidarity increases the level of information exchange among informal entrepreneurs and strengthens the resilience of their enterprises. Some of the informal entrepreneurs collaborate with formal enterprises (e.g. providing handicrafts to souvenir shops and hotels, catering items to hotels and travel agencies, transport and guiding services to tour operators). Many of them call this collaboration "fortunate" and perceive these ties with the formal sector to be more valuable than those with other informal entrepreneurs. An informal transport provider and tourist guide stated:

"I get almost 60 per cent of my customers from a formal local travel agency. The rest of my customers reach me through the homestay owners in Chiang Mai. I think my good attitude, foreign language knowledge, experience in working with foreign tourists, knowledge about the indigenous cultures (i.e. his cultural capital) help me to stick my customers to my business." (male from Chiang Mai, April, 2016).

Particularly, women are very active in initiating an informal start-up business in tourism in Chiang Mai. They are highly motivated and adaptable to changes in market conditions. A young female vendor said:

"Thai women are not shy and can sell, Thai men are lazy and shy, they can't sell”. (female vendor from Isaan, April, 2016). 
Alongside their domestic labours, women run informal businesses in any spare time. Additionally, children are everywhere in informal enterprises, helping out and undertaking small tasks. Women divide the tasks across family members in accordance with their skills and availability, and they often have to take care of extended family members such as grandparents, nephews and nieces.

Informal entrepreneurs accumulate different forms of cultural capital. One such essential skill is perceived to be experience of the world of work. Time spent in work leads to an accumulation of experience in which one builds up experience in the field and learns about the rules of the system (i.e. logic of practice). Access into the tourism sector is not difficult, and in most cases no registration is needed. One café owner in Chiang Mai said:

"The local administrators would visit a new starter only after a couple of years and corruption is a big issue." (female from Lampang, March 2016).

When informal entrepreneurs meet a Thai person for the first time, their initial response is: "are you a rachakarn (i.e. Thai for governmental official) or are you from a rathabaan (i.e. Thai for a governmental grouping or institution)". Many of the informal entrepreneurs approached were sceptical of public agents and their explanations of rules and regulations regarding business practices. They were also frustrated about endemic corruption throughout the public administration. A female informal tourist guide argued that:

"I miss the legitimization of my work and enterprise by the local government. Many times the tourist police see my enterprise and myself as an annoyance and marginalize me in the sector. In spite that I know much better social issues in the tribes surrounding Chiang Mai than any other formal travel agents and guides. For instance, Chinese traders at the Night Market copy authentic items, which are produced by indigenous tribes and 'good sold' to tourists. They let produce silk fabrics, textiles (e.g. clothes, bags, table turners, plate mates), umbrellas, wood carvings, lacquerware, mulberry products, silver ornaments, ceramics massively in China and supply to the channels those offer them in the night markets andl or in the walking streets of urban areas in Thailand." (female from Changwat Phayao, April 2015).

Increasing competition amongst vendors at the night bazaar and Sunday 
Walking Street market is an important issue for entrepreneurs. Many complain that tourists cannot see the difference between hand-made traditional items produced in the tribal villages around Chiang Mai and mass produced imitation designer labels from China (conversations with several vendors at Sunday Walking Street Market, April 2015). Some types of informal entrepreneurs, specifically local artisans and designers, are not able to protect their intellectual and aesthetic capitals against copying of their products. However, in some cases, informal entrepreneurs benefit from this chaotic situation by competing directly in the open market. Informal entrepreneurs see economic capital as the most essential capital to start-up a business. First they have to save money, or borrow from relatives. It is rarely possible for them to access loans from banks and other financial institutions. One home stay owner said:

"the micro finance institutions in Chiang Mai did not the reach the bottom, that's why they are not successful." (male homestay owner: Chiang Mai, March, 2016).

In their relationships with NGOs, informal entrepreneurs have a mixture of perceptions. While some complained that NGOs are dominated by the state system and want to exert control over the rural people in line with prescribed economic development programmes, others appreciate the training and support provided by development agencies. A male artisan producing silverware to a shop owner on the high street said that:

"I followed a training module provided by a development agency. In this course, a private designer explained us how we can adapt our designs and make them much more demanding by international tourists. After following this course, I have been selling almost twice more silverware to my customers than before." (male: Chiang Mai, March, 2016).

Surprisingly, many of the informal entrepreneurs in this study were less interested in growing their businesses beyond their current form. Public policies such as self-reliance, sufficiency economy and/or the spiritual Buddhist philosophy seem to have a great impact on forming the attitudinal perspectives of people. Only a few of the informal entrepreneurs we spoke to wished to extend their business and sell products to formal businesses at coastal regions for example. 
Informal tourism entrepreneurs in Chiang Mai expressed their need for knowledge and experience from formal actors in the form of support in designing, packaging and marketing, economic capital in the form of financial aid such as credit, social capital in the form of collaboration with formal sector agents, and protection of their symbolic and cultural capitals in the form of patents and copyrights provided by public organisations. In terms of their future worries, they identified national politics, tourism sector developments and the increasing of imitation "good sold" (copied) products by Chinese traders.

\subsubsection{Intermediate stories}

A significant number of development agencies and NGOs are involved in the informal tourism sector in Thailand. In a recent thesis, Hummel (2015) explains broadly the process of NGO activities in the larger context of Southeast Asia. The essential belief of these organizations is that tourism can be a tool for community development in Thailand. A senior manager at one local NGO argued: "...through tourism, communities can speak out their inherent and current problems and these silent voices will be heard by the government agencies". (female from Bangkok, March, 2015).

In general, the Thai government focuses on strategies for economic development through tourism, whereas NGOs focus more on social and environmental issues. This varies extensively, from community development (interview with Community Development Monks in Development of Highland Communities, Chiang Mai, March 2016), rural development (interviews with several scholars from Chiang Mai University in March, April 2015 and 2016), tourism development (CBT-I managers, April 2015), poverty alleviation (Japanese NGO operating in Isan, March 2016), to preserving cultural heritage, natural heritage, sustainability (reported in several NGO's annual activities results from 2012, 2014 and 2015), and resolving conflicts (volunteers of Friend of Woman Foundation in March 2016).. In one case, an NGO articulates its vision as:

“...providing support and facilitate cooperation among stakeholders from grassroots to international levels, in order to strengthen the capacity of Thai communities to manage tourism sustainably" (Community Based Tourism Institute Thailand, 2015). 
In their daily routines, CBT-I workers target the whole community (interview with CBT-I managers, April 2015), help ethnic communities promote their products to visitors with the purpose of increasing informal entrepreneurs' cultural and social capitals, assist tour operators in reaching these communities and in seeking collaboration among tourism stakeholders. However, in many of these projects, the NGO targets the whole community rather than individual entrepreneurs. Informal entrepreneurs do not receive specific individual support. In addition to the provision of workshops and training, some smaller foundations (e.g. a British volunteer who lives with a local tribe) attend Travel Mart (i.e. annual national tourism fair in Bangkok), and promote informal entrepreneurs' products, offer tourist information to individual tourists (e.g. brochures of several volunteer tourism organisations), certify homestays for their accommodation offers (according to a local NGO worker connected to the Ministry of Tourism and Sports, May 2016), collaborate with universities to support them in their research activities within local communities and organizing field trips (examples provided by scholars from Payap University in Chiang Mai and CBT-I managers, April 2015 and 2016). However, tour operators in Chiang Mai complained (e.g. interview with an international Tour operator on March 30 ${ }^{\text {th }}, 2015$ and interviews with local Thai travel agents in April 2016) about tour-operating activities offered by local NGOs that compete for their business.

Access to formal education amongst actors working in the informal economy is very limited, since upper secondary level vocational education is not free in Thailand. Local NGOs offer training to this group and during one of these workshops (March 24h, 2016), the instructor explained the tourism market changes in Thailand, government regulations, and the importance of good communication skills to informal entrepreneurs who operated micro enterprises in the city Chiang Mai and surrounding villages.

For instance, if a tour operator from Chiang Mai wishes to collaborate with an ethnic community consisting of many informal entrepreneurs, it has to first complete a self-assessment "Community Based Tourism Standard Checklist" consisting of hundreds of questions required by the Community Based Tourism Network Association (CBTN Handbook, March, 2015). The checklist defines how a private tour agency must undertake its transactions with these communities. As a result, many formal tour agencies avoid 
these bureaucratic regulatory frameworks and decide against collaboration with informal entrepreneurs in these communities.

Nevertheless, the formal private sector actors in Chiang Mai believe that informal entrepreneurs can increase diversity in the tourism network system and strengthen formal sector supply chains. According to a formal travel agent:

"...informal entrepreneurs can contribute to a tourism value chain and collaborate with other formal private tourism stakeholders. However, many of these informal entrepreneurs miss foreign language skills, organization, marketing and customer relations skills, which are essential to work in a tourism sector. Due to these reasons, no any informal enterprise is able to provide a whole tour and guide tourists alone." (International male tour operator, Chiang Mai, April, 2015.)

Nevertheless, the formal sector agents see the role of informal tourism entrepreneurs as limited and argue the conditions in the tourism field are too complicated for an informal entrepreneur to organize all aspects of business independently. Another formal local travel agent said:

"...informal entrepreneurs may, for instance, provide transportation, trekking trails, and homestays but they cannot answer all questions of tourists and solve problems if occur. Moreover, they have no standard in the service they offer. They have to collaborate with other formal tourism enterprises." (Male tour operator, Chiang Mai, April, 2015.)

As a result, although the private sector stakeholders recognize the importance of informal entrepreneurs' capitals, and their contribution to tourism value chains, they believe informal entrepreneurs cannot function alone without collaborating with formal tourism sector entrepreneurs.

\subsubsection{Big stories}

The political system of Thailand is complex and this influences policy towards business and entrepreneurialism. Thailand is a constitutional monarchy where governmental power is distributed to departments in the public sector. Some state agencies are established by the constitution and autonomous, some are in the formal structure of government, and others 
are directly or indirectly liable to the executives of the Royal family. As Bourdieu, Wacquant \& Farage (1994) suggest, these agencies construct the state as a "bureaucratic field" where it successfully claims the monopoly of the legitimate use of physical and symbolic violence over the people. However, underpinning all policymaking is religious practice and beliefs. A Thai political scientist working at a public department financed by the Royal family said:

"Buddhism is very influential on the Thai's thinking and behaviour, and you can see Buddhism's influence in every corner of governmental organizations."

The Thai state exerts its legitimate power by introducing specific organizational mechanisms and rules. For instance, registration of tourism businesses, tour guides, tour leaders, related fees, responsibilities and penalties (policy document: Tourism Business and Guide Act, BE 2551, 2008). An earlier document (Tourism Business and Guide Act, BE 2535) prescribes Tourism Authority of Thailand (TAT) the authority to license all tourism businesses throughout the country. In addition, other institutions under ministries of Interior, Labour, and Commerce determine the locations for vendor sites, or policing the total prohibition of hawking at tourism destinations. However, many informal enterprises operate at the margins of these laws and frequently outside them. Although it is not always explicitly mentioned, almost all the public institutions aim to formalize informal enterprises and to control them through public ordinances. According to a senior manager at a governmental institution:

"... society cannot be left uncontrolled and individuals cannot be left in their ways of doing business in the markets."

This desire to bring the informal sector under control has created a plethora of rules and regulations, allowing almost every public institution to intervene in the informal economy. Often this consists of long explanations of the government's expectations, codes of conduct, and how to exercise social rights in daily lives (i.e. being aware of possible socio-cultural impacts of tourism on these communities). The burden of regulation creates barriers for informal entrepreneurs to access resources to build their business. It creates barriers to collaboration, limits their access to capital requirements, and brings extra costs to informal entrepreneurs operations. 
These 'top-down' rules and policies, which are defined by central government institutions, are static and inflexible, offering little scope to other stakeholders and requiring compliance. Whilst the government requires informal actors to be sustainable by means of maintaining their traditions, simultaneously, through several master plans, it pushes for modernization. As a result, these plans and development programmes do not induce commitment and produce high failure rates. Another important issue is the scope for official corruption. Throughout, corruption was mentioned by almost all the stakeholders as a frustration, leading to a lack of trust of public agents.

The Thai state determines ideal attitudes and behaviours. For instance, promoting policies based on traits such as self-reliance to the poor encourages them to be self-sufficient in tough social and economic conditions. However, these policies have received criticism as Walker noted; "sufficiency economy became the moral underpinning of 'sufficiency democracy' - a system in which elite morality would triumph over populism and money politics" (Walker, 2010, p. 262). This symbolic violence becomes natural over time as Bourdieu et al (1994) suggest; "by realizing itself in social structures and in the mental structures adapted to them, the instituted institution makes us forget that it issues out of a long series of acts of institution (in the active sense) and hence has all the appearances of the natural" (p.4).

\subsection{Discussion}

Informal entrepreneurs enter into tourism markets with economic, social, cultural, and symbolic capitals, though they are not often acknowledged by state agents (Bourdieu, 1986). Additionally, there needs to be a fit between an informal entrepreneur's capital and the field in which s/he is operating (Grenfell, 2008). A misfit between the conditions of a field and the capitals possessed by an individual, such as; lack of formal job market information, negative social capital such as racial discrimination in the job market, forces individuals towards the informal sector. Our analysis reveals how this misalignment constrains the activities of informal entrepreneurs in tourism. However, some forms of capital act as stimuli for entrepreneurialism (Bour- 
dieu \& Wacquant, 1992), including; cultural capital in embodied and objectified form, easing access to the field in a sector; positive social capital; economic capital in the form of start-up loans from family and community members.

The findings stress the importance of relationships between informal entrepreneurs and other stakeholders. Any stakeholder on their own can hardly be expected to possess all the necessary capitals to achieve success. Therefore, collaboration is the sine qua non for every stakeholder in tourism. The analysis revealed the importance of collaboration between formal and informal entrepreneurs and the benefits yielded to all parties. Firstly, informal entrepreneurs are usually highly motivated and adaptable to changes in the market. Secondly, through collaboration, formal entrepreneurs can increase diversity in their network and strengthen the supply chain, which can lead to process or product innovation (Williams \& Shaw, 2011). Thirdly, collaboration can lead to more inclusive value chains in tourism (Zhang, Song $\&$ Huang, 2009). Formal organizations gain trust from local communities and appreciation from their customers through a perceived greater social responsibility (Park, Lee \& Kim, 2014). Finally, collaboration between multiple stakeholders including informal entrepreneurs may lead to public-private partnerships wherein the skills and expertise of informal entrepreneurs can be integrated and upskilled.

Having studied the field-based and thus socially conditioned interactions, the focus can now turn to model the social fields using economic and cultural capitals in order to map the structural relations of stakeholders in the fields of power, value and culture (Bourdieu, 1998). According to Bourdieu (1998), social fields could be plotted as made of opposing forces, which is chiasmatic. In such a diagram, he suggests "as one pole the economically or temporally dominant and culturally dominated positions, and at the other, the culturally dominant and economically dominated positions" (Bourdieu, 1998, p. 270). Applying Bourdieu's fields and capitals, the following model captures the position of informal entrepreneurs in relation to other stakeholders. In Figure 2, the economic capital axis is shown as vertical, since it brings more status and power to its holder than the cultural capital, though both are highly important in a social field. In such a figurative expression of fields, the level of forces (i.e. from plus to minus) does not show the amount the actors hold but their effects on the actors' positioning (e.g. how advantageous is holding cultural capital in a specific field). 
Figure 2: Fields, capitals and stakeholders

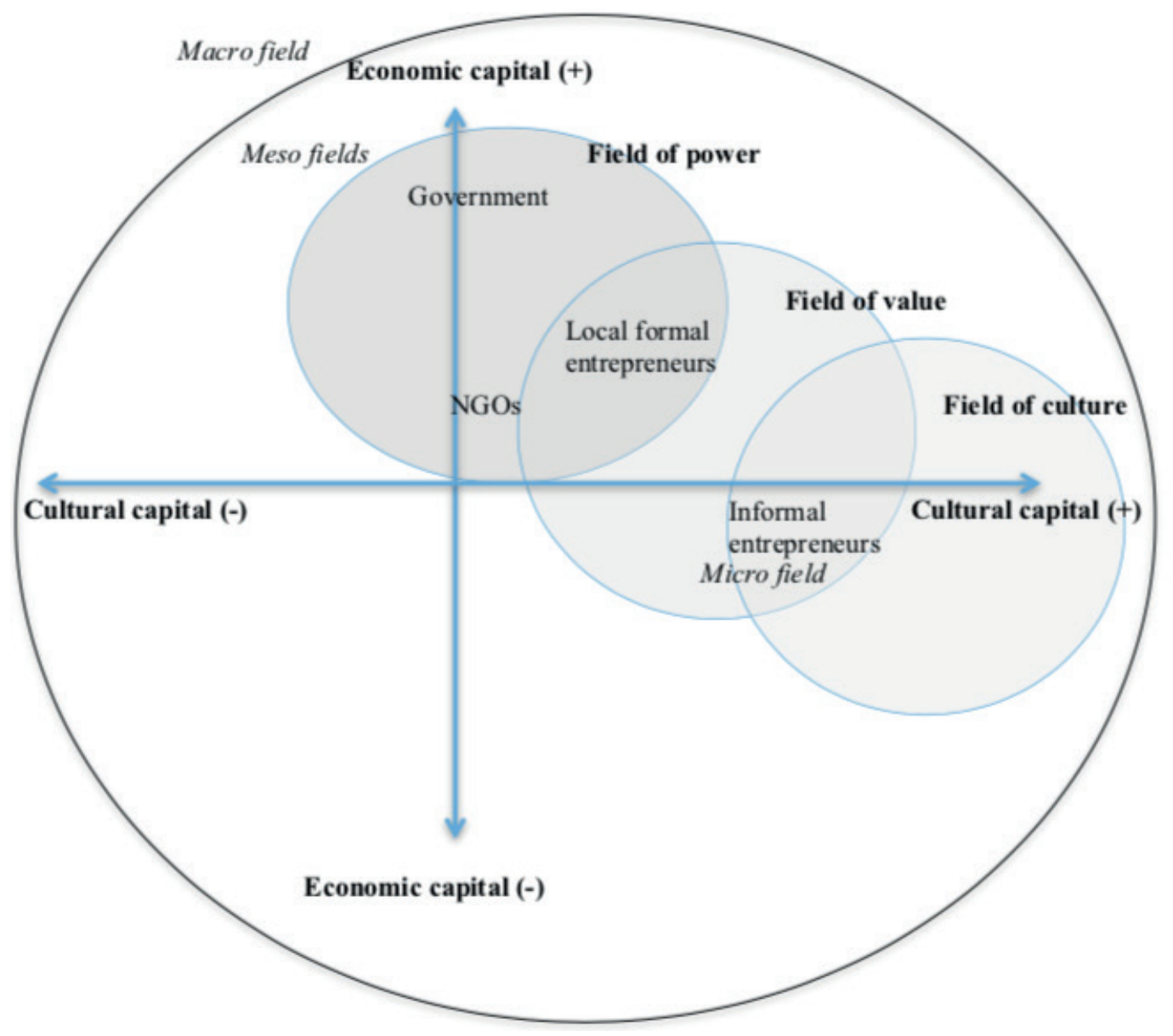

The model develops Bourdieu's (1988) theory in which cultural capital (e.g. skills, knowledge, qualifications) is something that one acquires for equipping oneself and is reproduced by economic capital (e.g. all the financial assets one may possess). This model first articulates society as the macro field, shaped through the interactions among organized and unorganized power groups acting in the meso field. Each agent defines its positioning (micro field) within larger fields, and aims to establish valuable and legitimate capitals within that micro space.

In the field of power, governmental institutions dominate the organized power structure and legitimize it for its purposes (Bourdieu, Wacquant \& Farage, 1994). This allows governmental institutions to accumulate economic capital through collection of taxes and makes it the decisive authority on defining the values of cultural capital. Thus, governments operate within the field of the formal private sector aiming to support their activities. However, in relation to the cultural field, government agencies 
need other actors (e.g. NGOs) to implement modernization policies downstream through society (Bourdieu, 1993).

The field of value is the field in which social actors such as private sector stakeholders and NGOs create value. The perspective of private sector stakeholders is clear and relevant to their aims. They wish their businesses to survive and achieve success and to accumulate capitals to gain more power, status, and profit. Nevertheless, they recognize that through stronger collaborations in the meso field, they could become more innovative by incorporating tacit knowledge from local people. Additionally, including informal sector workers would decrease costs, which would help them position themselves more competitively. Thus, private sector agents collaborate across fields of value, power and culture with stakeholders such as government, NGOs, local formal agents and informal tourism entrepreneurs.

NGOs, having various levels of economic and cultural capitals, struggle with defining their position in the meso field. Some NGOs (e.g. development agencies), which receive mainly international funding, have a broad focus and aim to increase impact in several fields through their operations in the tourism sector. However, in many cases they are sub-optimal, one of the important reasons is due to the lack of awareness of social conditions (e.g. logic of practice) in the communities they operate (Bourdieu, 1969). Other NGOs, which are familiar with social conditions, intervene in the markets with the aim of improving the position of informal tourism entrepreneurs in all fields. In these cases, they act as formal private sector stakeholders (e.g. organizing and selling tours), which leads to problems, particularly in the value field. They call for collaboration between formal and informal entrepreneurs. Additionally, the higher the number of NGO's actions in all these fields, the more complex the fields become.

The positioning of informal tourism entrepreneurs is spread at the bottom in the value field. To illustrate this point, a group of informal entrepreneurs (e.g. designer, artisans) enters into the value field with high levels of cultural capital (e.g. designers) but different levels of economic capital (e.g. lower for artisans). They are able to offer more competitive products and services than other entrepreneurs. However, this group's position is not fixed at a certain point in the field model. In relation to market conditions, informal entrepreneurs may adapt their strategies and levels of economic and cultural capital. Consequently, their positioning 
swings like a pendulum from the bottom of the value field to a higher level in the culture field (Sallaz \& Zavisca, 2007). If a group of informal entrepreneurs acts collaboratively with formal private sector stakeholders, this decreases their transaction costs, complements their products and services, and increases their position in the market, but leaves them little independent power in determining their own positioning in the fields. As a result, the informal tourism entrepreneur who has a high level of cultural capital, has to collaborate with a stakeholder in the value field to assist in the transformation of cultural capital into economic capital (Bourdieu, 2005).

\subsection{Conclusions}

A better understanding of the practical logic of fields and the structural relations within them can contribute to policy debates about how to integrate and optimize both formal and informal tourism economies for development (Williams and Yousseff, 2013). Informal entrepreneurs are more flexible than formal entrepreneurs and keen to collaborate with other stakeholders in the value field to achieve success, yet their capabilities have been neglected in academic debates as well as in the actions of governments and NGOs (Henderson \& Smith, 2009). Their flexibility (e.g. adapting fast to the changing conditions in the market and re-positioning), and their portfolio of cultural, symbolic and social capitals, offers important assets to tourism stakeholder networks, the analysis of which extends our understanding of the contributions made by informal entrepreneurs to the wider economy (Chen, 2006).

Our study demonstrates that informal entrepreneurs in tourism possess a noteworthy level of cultural and social capitals. Public agents mostly underestimate the value of these exotica capitals. However, through possible collaborations between informal and formal entrepreneurs, these capitals may increase the value of existing capitals in the network and enhance the competitive positioning of stakeholders, bringing greater dynamism to the fields (Sassen, 2007). Such collaboration would help informal entrepreneurs to increase their knowledge in marketing, planning, and monitoring, which are organizational strengths of the formal sector (Ahmad, 2017; Damayanti et al., 2017). 
The study responds to recent calls for practice-based approaches that examine complex social structures in tourism (de Souza Bispo, 2016; Lammers et al., 2017), and we show how Bourdieu's theory of fields can elaborate such practices. The model proposed offers scope for further research to understand how practices and actors are constrained or facilitated by complex, multi-dimensional interactions with interlocking actors in the field in which they operate (Ahmad, 2017). Future research could consider examination of informal entrepreneurs' habitus, including their background, professional and subjective life-worlds in conjunction with their relationship to the fields and their logic of practice. This can help us to understand the structuring elements of informal entrepreneurs's social actions in these fields, since habitus also operates within fields.

At the practical level, public organisations and NGOs need to encourage formal and informal entrepreneurs to collaborate more freely in the widest possible number of fields by allowing them to work in a hybrid form. In addition, government policies ought to shift in focus towards increasing the productivity of informal entrepreneurs by means of monitoring the value chains in the tourism sector, where informal entrepreneurs are effectively active. Successful informal entrepreneurs may possibly become more aware of the social value of their cultural and natural heritage and consequently become more concerned with preserving these resources. In this way a more sustainable tourism development may be realized in these communities over the long term. 


\section{Chapter 3}

\section{Informal Tourism Entrepreneurs' Capital Usage and Conversion}

Erdinç Çakmak ${ }^{\mathrm{a}, \mathrm{b}}$, Rico Lie ${ }^{\mathrm{b}}$, Tom Selwyn ${ }^{\mathrm{c}}$

(The article presented in this chapter is published in Current Issues in Tourism, 2019, Vol. 22(19), pp. 2250-2265.)

a Breda University of Applied Sciences, the Netherlands

b Knowledge, Technology and Innovation, Wageningen University \& Research, the Netherlands

'SOAS University of London, United Kingdom 


\section{Abstract}

This article examines informal entrepreneurs' capital usage and conversion in the Thai tourism sector. On the Bourdieusian assumption that people perpetually transform tangible and intangible forms of capital, this study seeks to answer how informal tourism entrepreneurs transform intangible capital into tangible capital, and vice versa, at different stages of their development process. A visual dataset of 78 filmed interviews and of 426 photographs of informal entrepreneurs in three tourist-island destinations in Thailand was compiled and analysed using thematic qualitative analysis. The results show the importance of diversification of capital mix at informal entrepreneurs' different development stages. Whereas cultural and symbolic capital are more salient for freelancers and small-size entrepreneurs, economic and social capital are more important for mid-size and large informal entrepreneurs. Furthermore, this study introduces dream capital as a new form of capital. Developing countries are recommended to introduce a policy on profiling informal tourism entrepreneurs so that the appropriate level of regulation can be applied in order to maintain or increase their benefits to society.

\section{Keywords}

Informal tourism entrepreneurs, forms of capital, dream capital, visual research, Thailand, Bourdieu 


\subsection{Introduction}

An informal economy consists of various economic activities that are not declared to the state for tax, social security, or labour law purposes, but are legal in all other aspects (Evans, Syrett, \& Williams, 2006; Williams, 2006). Although the tax law is violated, authorities generally tolerate informal economic activities in developing countries (Dana, 2013). In tourism economies, typically, informal entrepreneurs provide tailor-made products and services to visitors at budget prices, absorb excess labour, and mitigate unemployment. Notwithstanding the tourism studies in the 1990s that extensively examined small enterprises in the informal economy (Dahles \& Bras, 1999; Harrison, 1992), informal economic relations have often been neglected in this literature (Thomas, Shaw \& Page, 2011), until very recent publications on coopetition (simultaneous cooperative and competitive activities) among informal economy actors (Damayanti, Scott, \& Ruhanen, 2017). In earlier tourism-related studies, informal economic activities are often associated with poverty alleviation, and tourism is considered as a tool to stimulate marginalized communities' livelihoods (Ashley \& Roe, 2002; Scheyvens, 2007), without focusing on entrepreneurship development in these communities. However, entrepreneurship is central to the emergence of tourism economies, and informal enterprises grew at an unprecedented rate in the last two decades in South East Asian tourism destinations (cf. Hall \& Williams, 2008).

The aim of this study is to investigate informal entrepreneurs' complex capital conversion in tourism economies. It examines how informal entrepreneurs transform economic capital into social, cultural, and symbolic capital, and vice versa, and which types of capital are more salient at different stages of their development process. Combining sociology and economics perspectives, this study investigates the interplay between social, economic, symbolic, and cultural capital. It contributes to tourism practice and research in a number of ways. Firstly, Bourdieu's (1986) capital theory is applied to observe and examine the capital mix of informal entrepreneurs at their different development stages in order to make recommendations to policymakers in developing countries on how informal entrepreneurs can be profiled effectively and regulated in order to increase benefits to society. Secondly, blending sociology and economics, this study addresses informal entrepreneurs' uncovered latent opportunities and challenges to better understand their positioning in tourism economies, and it intro- 
duces a new form of capital: dream capital. The study context is Thailand. Informal tourism entrepreneurs working on the top three tourist islands were investigated, and a total of 78 filmed interviews and 426 photographs were collected. A qualitative data analysis was applied to this visual dataset in order to generate a multifaceted analysis of informal entrepreneurs' capital mix and to observe the conversion of these different forms of capital within their complex networks.

\subsection{Theoretical Framework}

\subsubsection{The Entrepreneurship Context in Tourism Economies}

Schumpeter (1934, p. 354) defined entrepreneurs as "individuals whose function is to carry out new combinations of means of production", focusing on the entrepreneurship process. There is no universally accepted definition of entrepreneurship (Spencer, Kirchhoff, \& White, 2008), but two concepts are considered fundamental to entrepreneurship. Firstly, entrepreneurs identify opportunities that arise out of market dynamics and/or inefficiencies within an economic system (Edelman \& Yli-Renko, 2010; Penrose, 1980). An entrepreneurial opportunity is defined as the potential to create more efficient or effective ways in which new goods, services, distribution can be organized and sold at more than their cost of production (Casson, 1982). In recognizing and exploiting these opportunities, entrepreneurs take risks, evaluate various options, and deal under uncertain conditions. Secondly, entrepreneurs innovate by combining these opportunities with available resources into a new product, method, market, and organization in an industry (Schumpeter, 1934). Tourism entrepreneurs follow the same path and shape places into tourism destinations. Koh and Hatten (2002, p. 22) called tourism entrepreneurs the persona causa of tourism development and posited: "only when tourism entrepreneurs are present, do a community's climate, landforms, flora and fauna, historic vestiges, and ethno-cultural enclaves become tourism resources that may be transformed into tourist attractions". They supply all the goods and services required to meet the needs and wants of travellers, and thus they contribute to the economic growth of national economies and provide employment opportunities.

However, the tourism sector has some specific features such as smallness, informality, and flexibility, which challenge tourism entrepreneurs 
in seizing opportunities (Power, di Domenico, \& Miller, 2017). Tourism is inherently composed of many small entities, and the sector's backbone consists of small to medium-size enterprises (SMEs) (Lashley \& Rowson, 2010). These SMEs form the local businesses in a region and help to prevent economic leakages at destinations (Andriotis, 2002). Despite their greater impact on local economic and tourism development, SMEs have less power or inadequate access to the decision-making procedures in the tourism system (Jamal \& Camargo, 2014). In addition, this smallness often leads to informal economic activities in developing countries (Morrison \& Teixeira, 2004).

Flexibility is another important feature of the tourism sector, which is labour intensive, service oriented, and seasonality tied. Flexibility offers many opportunities to entrepreneurs, but it leads to a diversification of entrepreneurship types (i.e. commercial, social, ethnic, informal, woman, lifestyle) in the tourism sector (Cooper \& Hall, 2008). Seasonality is another important characteristic of the tourism sector. Tourism demand is variable at destinations, and tourism enterprises do not have customers regularly throughout the year. In his seminal work on seasonality, Butler (2001, p. 5) depicts seasonality as a "temporal imbalance in the phenomenon of tourism, which may be expressed in terms of dimensions of such elements as numbers of visitors, expenditure of visitors, traffic on highways, and other forms of transportation, employment, and admissions to attractions". Seasonality in tourism requires a different dynamic adaptation of business structure than other sectors. For instance, tourism entrepreneurs have to deal with flexible employment consisting of many part-time jobs and seasonal labour. Although seasonality poses a threat to formal entrepreneurs' planning activities, it may offer more opportunities to informal entrepreneurs because of their greater flexibility.

In this study, an informal entrepreneur is defined as an individual who does not register his/her enterprise with public organizations and uses labour provided by family and friends without offering them an official work contract. Typically, an informal entrepreneur does not have a business plan that leads to a specific structure in his/her enterprise. In some cases, this issue may lead to some confusion about the planning of activities. Yet, this does not mean that informal entrepreneurs lack knowledge or management expertise (Ateljevic, 2007). Another aspect is the legitimacy of informal entrepreneurship. Some economics scholars perceive informal economic 
activities as illegal and consider how to formalize these transactions for taxation purposes, but sociology and anthropology scholars see these activities as legitimate (Feige, 2007; Webb, Tihanyi, Ireland, \& Sirmon, 2009). Suchman (1995, p. 574) depicted legitimacy as a "generalized perception or assumption that the actions of an entity are desirable, proper, or appropriate within some socially constructed system of norms, values, beliefs, and definitions". According to his definition, an informal enterprise may diverge dramatically from societal norms, but it may be legitimate if the divergence goes unnoticed.

Informal entrepreneurs use different forms of capital and convert those perpetually to create competitive tactics in seizing opportunities in the tourism sector. Although capital is widely discussed in tourism studies, informal entrepreneurs' capital possession and usage are not examined (Macbeth, Carson, \& Northcote, 2004). The fact that informal entrepreneurs have relatively limited options to operate in formal markets (e.g. limited access to financial sources, labour markets, benefits and protections of formal networks) might lead tourism scholars to have some misperceptions of informal entrepreneurs' capital mix. However, in other disciplines, for instance sociology and development economics, scholars have produced important results and highlighted the entrepreneurial process in informal economies (Bhatt, 2006; Webb et al., 2009), the reasons for informal entrepreneurship (see Williams \& Youssef, 2013 for further details), and the characteristics of entrepreneurship in the informal economy and its differentiation from that in the formal economy (Hipsher, 2010); and many case studies examine the nature of informal entrepreneurship (Gallin, 2001; Williams, 2008). Because of tourism's specific features and characteristics, it is expected that informal entrepreneurs adapt their capital mix differently across their development stages and that no single capital alone is sufficient for survival in tourism markets.

In this research, the respondents are real people, informal tourism entrepreneurs, who recognize and exploit an entrepreneurial opportunity in tourism markets with the intention to establish and run a profit-driven commercial enterprise in a responsible way (Wempe, 2005). However, their enterprises are not declared, registered, regulated, and protected by the existing legal organizations. To classify informal entrepreneurs, the International Labour Organization's (ILO) definition is adopted (ILO, 2009). ILO takes a dualist approach and uses the criterion of enterprise type in which informal employ- 
ment operates. Consequently, there are four types of informal entrepreneurs in this study, namely, (1) freelancers (e.g. designers and performers, who are selling work or service by the hour, day, and are not employees of an organization), (2) small informal entrepreneurs (e.g. own account entrepreneur without employees), (3) mid-size informal entrepreneurs (e.g. own account entrepreneur with up to six employees, who are family and friends), (4) large informal entrepreneurs (e.g. own account entrepreneur with more than seven employees, hired on the labour market).

\subsubsection{Forms of Capital}

Bourdieu (1986) relates the term capital to all forms of power and distinguishes its form across economic, cultural, social, and symbolic dimensions. An economic capital portfolio consists of financial assets and wealth. People who possess greater amounts of economic capital are more likely to control production and thus have more status and power in the social field. Bourdieu distinguishes three cultural capital forms. In the first form, cultural capital is embodied. A person embodies the principles of a field in the form of mental and physical features, and creates his/her tastes, gestures, and use of language. In the second form, cultural capital is objectified. Here, cultural capital is represented in material objects such as writings, books, art works, paintings, monuments, machines, instruments, and various kinds of artefacts. In the third form, cultural capital is institutionalized. A person obtains qualifications and/or academic credentials from an institution that recognizes his/her specific knowledge, skills, and competence. An important aspect of cultural capital is its transposability. Cultural capital reaches its highest value not when its stock is highest but rather when it is highly transposable (Moore, 2008). For instance, a certificate, an institutionalized form of cultural capital that recognizes the cultural competence of its holder, facilitates its holder in transforming his/her cultural capital into economic capital by guaranteeing a certain monetary value for a certain institutional level of achievement. Furthermore, different from economic capital, the acquisition of cultural capital always demands time. One cannot acquire embodied cultural capital second hand. One has to invest and create cultural capital over time based on the result of this investment.

The third capital, social capital is the network of connectedness, in other words, being a member of more formalized groups. Having a rich social 
capital gives one access to goods and resources, reduces transaction costs, and provides safety nets in the social field. Bourdieu (1985, p. 248) defined social capital as "the aggregate of the actual or potential resources which are linked to possession of a durable network of more or less institutionalized relationships of mutual acquaintance or recognition". Social networks are not a natural given; one has to craft investment strategies oriented to the institutionalization of group relations, which may be usable as a reliable source or benefit (Portes, 1998). This means that the acquisition of social capital requires economic and cultural capital investments. Furthermore, social capital can lead to positive and negative outcomes. Possessing positive social capital brings benefits and access to resources to its holder; having negative social capital results in the exclusion of outsiders, excessive claims on group members, restrictions on individual freedoms, and downward levelling norms (Portes, 1998). In addition, Granovetter (1973) suggested that one could not receive new ideas and information from one's traditional social groups, because such a traditional group is composed of homogeneous (almost identical) units and/or members, what he called weak ties. In other words, the information possessed by one's closest social network is not different from that which one owns oneself. Consequently, in order to be exposed to more valuable information and ideas, one needs to cooperate with various heterogeneous social networks.

Symbolic capital refers to a "degree of accumulated prestige, celebrity or honour and is founded on a dialectic of knowledge (connaissance) and recognition (reconnaissance)" (Bourdieu, 1993, p. 7). The acquisition of symbolic capital requires time, wealth, and energy. However, richness in symbolic capital (e.g. having greater legitimacy, prestige, and value) opens new avenues in social networks. Another more frequently given example of symbolic capital is education, which brings to its holder more advantages and better positions in multiple fields.

From a Bourdieusian perspective, the game that occurs in tourism fields with various tourism stakeholders using diverse strategies to maintain and enhance their positions is competitive. In this game, the main goal of an individual (e.g. an informal tourism entrepreneur) and/or a social group (e.g. a tourism stakeholder group) is the accumulation of different forms of capital. Every individual/group has a capital portfolio, in other words, a particular amount of capital in different forms with a particular composition. Some individuals and/or social groups that have distinctive forms of capital are advantaged in 
the field and accordingly are able to produce capital more easily than others. Such lucky players are able to use their capital advantage to advance further and to be more successful than other players in the field.

\subsection{Methodology}

This research is based on an interpretivist paradigm that adopts a relativist ontology. It follows Bailey's (2007, p. 53) view that "there is no objective social reality but instead multiple realities, and people produce knowledge through lived experiences and interactions with others".

\subsubsection{Field Research Context}

Three famous tourist destinations - the top three most popular islands located in the south of Thailand (Lonely Planet, 2014), namely, Koh Samui, Koh Phangan, and Koh Tao - were chosen for the field research. Tourism developed rapidly in these islands, particularly in the last two decades, and this has affected the local communities' lives significantly (Pongponrat, 2011). In an earlier study, Koh Samui was categorized as one of Thailand's marginal paradises (Cohen, 1982). However, after just two decades, environmental changes have occurred as a result of the rapid expansion of tourism and its associated developments (Green, 2005; Wong, 1998). The current tourism business on the island is very dynamic, and all four types of informal entrepreneur exist. The freelancers work as artists, dancers, musicians, and firework showmen, and appear mostly at night time in several bars and restaurants. The small informal entrepreneurs work as vendors, selling food (e.g. chicken, fruits, nuts, skewers), souvenirs, drinks, clothes (e.g. t-shirts, bags, shoes) in the coastal areas and, as taxi/tuk tuk drivers, occupy all possible touristic spots in the coastal areas and some tourist hotspots on the inland. The medium-size informal entrepreneurs run mobile travel agencies (offering diving and snorkelling trips and selling all types of transportation tickets); and laundries, tattoo shops, art galleries, cafés/bakeries, and so on, are scattered throughout all the back streets of coastal areas. The large informal entrepreneurs - there are a few on the island - operate mostly massage parlours and some catering services.

The second fieldwork location, Koh Phangan, neighbouring Koh Samui, has been a famous fieldwork area for tourism scholars who have examined 
the power relations between hosts and tourists (Malam, 2004), full moon dance parties (Gibson \& Connell, 2003), drugs and risk taking (Uriely \& Belhassen, 2006), poverty (Scheyvens, 2012), and films (Hammons, 2016). The popular full moon party, for which the island is well known, draws approximately 30 thousand domestic and international tourists to the island on one night, before or after every full moon. The full moon party has been featured in Hollywood films such as The Beach and Last Stop for Paul. Although the island has a few luxury resorts and villas, the tourism sector caters mainly to young and active travellers, and informal enterprises provide more nature-related activities. The freelancers work as informal tourist guides, offering services for hiking, trekking, and kayaking trips. The mid-size informal entrepreneurs offer spiritual training in yoga centres, run home stays, small bakeries, taxi boats, and fishing boats.

The third fieldwork location, Koh Tao, known as a dive paradise among divers, attracts all kinds of professional, amateur, and novice divers from all over the world. The large-size informal tourism entrepreneurs are proportionally more represented here than other types and serve mainly the formal enterprises on the island by complementing their services or reducing their transactions. Additionally, informal entrepreneurs provide large numbers of bungalows, souvenir shops, and many other similar informal enterprises, which also exist on the other two fieldwork islands. Tourism staff members on the island are estimated as a mix of 1,042 registered Thai individuals with an additional approximately 5,000 temporary migrant workers, largely from Myanmar and working in low wage positions in hotels and restaurants (Szuster \& Dietrich, 2014).

\subsubsection{Visual Methods and Data Collection}

The use of visual data - encompassing images, photographs, video films, advertising media, graphic representations, and postcards - is gaining ground in the social sciences (Heath, Hindmarsh, \& Luff, 2010; Lie \& Witteveen, 2017; Pauwels, 2010; Pink, 2013; Rose, 2012). In tourism studies in particular, images and visual data can play a central role and allow researchers to access and create knowledge about phenomena that are less accessible by merely using the more traditional non-visual methods (Rakic \& Chambers, 2010). However, "over the last two decades, visual methods in tourism research have been relatively ad-hoc" (Scarles, 2010, p. 908). A potentially rich area that can enhance our understandings of tourism as a 
social construct has been underutilized (Burns \& Lester, 2005). In addition, Scarles (2010) suggested that visuals provide a bridge between researcher and respondent to merge an intersubjective change and explore and challenge existing knowledge of both tourism practice and research.

This study used a visual method in the sense that video-recorded interviews and photographs were used within a broader context of ethnographic fieldwork. A video-recorded interview provides factual information on respondents, with affective elements including reflection of emotions, behaviour, language, and interactions with other participants (Andersen \& Adamsen, 2001). The everyday life of informal entrepreneurs and their social interactions were observed in three different fieldwork periods, namely, March 2013, March-April 2014, and lastly April 2015. Purposive sampling, or more precisely, maximum variation sampling was used to capture a variety of perspectives on informal entrepreneurs' different forms of capital. The participants were chosen on the basis of their particular characteristics - the main focus of this research. It may be considered that the results are not representative of all the informal entrepreneurs in Thailand or in the world. As the findings of this qualitative research concern general structures rather than a single practice and are socially representative as they are generated from extensive observations of the relations between variables, the study results are generalizable in similar social circumstances (Gobo, 2004). In addition, using a purposive sampling is not a weakness; rather, it is a choice that allows us to gain greater insights into the informal entrepreneurship phenomenon by looking at it from various angles. All the interviews were held in English; as the main customers of informal entrepreneurs are international tourists, the participants use English as a second language at their workplaces. The participants were asked questions about their work, their households, their livelihoods, their capital conversion, their social relationships, their aspirations, and their perceptions of their contemporary life.

Regarding the specific collection of visual data, a total of 78 filmed semi-structured interviews with participants were held at their workplaces, and 426 photographs were taken showing their work context, including their clients and the environment. In the analysis of the films, the emphasis is on the participants' capital conversion, whereas, in the analysis of the photographs, the emphasis is on their working environment. Table 1 shows the number of interviews disaggregated by informal entrepreneur type in the three fieldwork destinations. 
Table 4: Number of filmed interviews across three fieldwork destinations by type of entrepreneur

\begin{tabular}{lccc}
\hline Type of entrepreneur/Location & Koh Samui & Koh Phangan & Koh Tao \\
\hline Freelancer & 6 & 12 & 2 \\
Small-size entrepreneur & 19 & 8 & 3 \\
Mid-size entrepreneur & 10 & 4 & 3 \\
Large-size entrepreneur & 2 & 1 & 8 \\
Total & 37 & 25 & 16 \\
\hline
\end{tabular}

In the first fieldwork destination, Koh Samui, most of the informal entrepreneurs run small and mid-size enterprises. Almost half of the interviews (37 films) were conducted on Koh Samui. In the second fieldwork destination, Koh Phangan, the respondents were more specialists and worked mostly as freelancers or owned a small-size enterprise. Twenty-five interviews were conducted on Koh Phangan. In the third fieldwork destination, Koh Tao, informal entrepreneurs owned more large-size enterprises. Consequently, 16 interviews were conducted there.

\subsubsection{Data Analysis}

The visual data together with the interview transcripts were analysed using discursive, thematic, qualitative data analysis (QDA) (Sather-Wagstaff, 2011) in order to reveal multiple, deeper, and symbolic meanings of informal entrepreneurs' capital usage. QDA integrates both visual and discursive data. QDA methods can be deductive, inductive, or a combination of the two. This study used a combination. On the one hand, it followed a deductive approach and focused mainly on different capital forms identified by Bourdieu $(1985,1986)$. On the other hand, it followed an inductive method and the steps described by Braun and Clarke (2006). The latter approach gives more space to recognize themes, propositions, and explanations generated through the data analysis process. First, films, photographs, and field notes were reviewed and examined. Then, the data were deconstructed into fragments through an initial coding using QDA software NVivo10. Thirdly, keywords, similarities, and dissimilarities were clustered into themes (i.e. axial codes), in line with the forms of capital (i.e. economic, cultural, social, symbolic, and dream). 


\section{4 Findings}

\subsubsection{Informal Entrepreneurs' Profiles}

The sample is comprised of $72 \%$ females with an average age of 25 years and $28 \%$ males with an average age of 28 years. The results show that $87 \%$ of the informal entrepreneurs are migrants from other parts of Thailand and from other Asian countries (i.e. Myanmar, Cambodia, Philippines). Only a small number $(13 \%)$ of participants were born and raised on the fieldwork islands. The large group of participants, migrants, mentioned many reasons for their migration to these tourist islands, such as having a lack of land rights, avoiding agricultural jobs, high unemployment and low wages threatening younger generations', future in their hometowns, and so on. On average, they had been working at their current places for six years. However, not all informal entrepreneurs, particularly small informal tourism entrepreneurs, live on the islands year-round. There is some evidence of seasonal migration; in the low season, known also as the wet season, which lasts from May to October, small informal entrepreneurs move from the tourist islands to one of the larger towns on the mainland. This makes it difficult to quantify the exact number of informal entrepreneurs on the fieldwork islands, as most of the domestic migrant participants were registered demographically in their own hometowns in other parts of Thailand.

In general, the participants were simultaneously manager, operator, and owner of their business. A large group ( $90 \%$ of the participants) lived with family members, and $10 \%$ of the participants lived alone. Another communal characteristic was that almost all of them (95\%) had two or more businesses or jobs. For instance, a travel agent owned a small café and a vendor ran a mobile booth in the evening time while working as a gardener in the daytime. Thus, interviewed informal entrepreneurs generated income from more than one source, although they indicated that the work about which they were interviewed was their main income generator.

\subsubsection{Capital Usage and Conversion by Informal Tourism Entrepreneurs}

\subsubsection{Economic Capital}

At the start-up phase of an enterprise, economic capital is the most important resource for an informal entrepreneur. The participants considered the accu- 
mulation of economic capital as the ultimate goal of establishing and running an enterprise. They believed that having strong economic capital would secure their long-term livelihoods and thus improve their quality of life. The informal entrepreneurs accumulated economic capital as cash, financial assets, machines, and property rights. On all three islands, the small informal entrepreneurs had the lowest amount of economic capital.

The participants used their savings as start-up capital for their new enterprise. If their savings were not enough, they borrowed financial assets from their family, friends, and business partners. One café owner in Koh Samui said:

"I had a tapas bar and later opened a tourist information centre next to it. Building up a tapas bar seemed harder than I have expected. You can't know from the start how much investment you need. Fortunately, my brothers helped me financially, my parents lent me some furniture and I got some kitchen material from the guy who supplies me with Spanish food." Female, medium-size informal entrepreneur, March 2014

Participants used their savings to repay these loans in a period of between two and six months. It is worth noting that, in general, informal entrepreneurs repay their loans much faster than formal entrepreneurs do - the latter spread the repayment period over at least 24 months.

The informal entrepreneurs' pricing strategy had an important influence on their economic capital accumulation. Informal entrepreneurs who sell products applied a more rational pricing strategy than those who offer services. For instance, an informal entrepreneur selling a souvenir set the product's price in relation to its demand and shortage in the given market. However, a tuk tuk driver set a ride price intuitively (e.g. in relation to the fanciness of his vehicle). We noticed this pattern during the photograph analysis of the tuk tuk drivers' work environment. The fancier the tuk tuk, the higher the price the driver asked for a ride.

The seasonality of tourism and the irregular competition between informal and formal businesses on the three islands affect informal entrepreneurs' cash flow and consequently their total annual income. However, the participants did not retain a financial buffer in their enterprises but used their savings to support other family members and fellow entrepreneurs. For 
instance, they paid the education costs of extended family members or gave loans to other informal entrepreneurs. A large-size informal entrepreneur from Koh Tao argued that:

"In Thai culture, it is important that you are close with family. We live with our parents until we find a girlfriend and get married. My younger two brothers are studying and I have to pay their school costs. We all do this and we do not know any other way."Male, 26 years, April 2015

Consequently, informal entrepreneurs' economic capital level does not represent their enterprises' solvency: the participants either transformed their economic capital into local social capital or used it to invest in family members' cultural capital. Accordingly, an informal enterprise does not transition easily from a start-up phase to a scaled-up phase, and it takes on average three years to become a medium or a large entrepreneur.

\subsubsection{Local Social Capital}

All the participants recognized the importance of their local social networks for accessing economic capital. All the migrant entrepreneurs reached their current workplace and position through the people from their social networks. Cousins, siblings, tribe members, friends, and people from the same cultural heritage were already working on these tourist islands. These people informed the participants about the local opportunities and in some cases offered their former jobs to them. The following quotes are indicative:

"My cousin lived with his wife on Samui asked me to come and work here to sell fruit (mangos, watermelon, and Durian)."Female, 22 years, small informal entrepreneur, in Koh Samui, April 2014

"When I first arrived, I did not have anything to rely on, until I started networking and I got a job offer from a friend for a resort. I had no experience at all in serving people but learned how to do very rapidly." Female, 31 years, freelancer, in Koh Phangan, April 2014

Domestic migrants followed a rather easier path than diaspora migrants. The former group came directly to the tourist islands and started working immediately, whereas the latter group (e.g. Burmese) came first to a larger city (e.g. Bangkok) and worked there for a while before coming to the tourist islands. The diaspora migrants made contact first with people from their 
own social network, living and working on the outskirts of Bangkok. People from this unofficial network helped them to find a job in one of the manufacturing plants and offered them a place to sleep. The newcomers worked first a couple of years (on average three years) in these factories, made new friends, and then learned from these new social contacts about the opportunities (e.g. easy work, higher pay, working and having holiday at the same time, less crowded places, and higher diversity of working population) on the tourist islands. If a person's cultural capital (i.e. high education, able to speak foreign language, in most cases English, or able to learn a foreign language very fast) is a good fit for the conditions required in the tourism field, then s/he has the chance to switch workplace from the outskirts of Bangkok to one of the tourist islands in the south in order to accumulate more economic capital.

The participants said that they increased their social capital by usage. Different from economic capital, social capital does not exist in objects; it is flexible, and borrowed social capital does not have to be repaid fast (Róna-Tas, 1997). The informal entrepreneurs' social networks were themselves informal, and their members shared commonalities and supported one another regularly, even in some cases every day. For instance, vendors helped one another when they set up their selling booths, gave clients their fellow vendors' business cards, and fought any perceived external threat to their local social network. In particular, lower class people (many small informal entrepreneurs in Koh Samui belong to this group) showed higher mutual solidarity in these social networks.

Freelancers and small informal entrepreneurs saw their social network members not as an accumulation of people or organizations but as human beings and called them family. Receiving support and solidarity from friends meant a lot to them (i.e. learning the logic of practice, rules of the game, support in solving their daily problems, financial loans). A freelance female singer said:

"Friends are everything for us. I can't live here without them. When I get homesick, I call my friends and meet with them. We do things together and have fun. That helps and makes me think less about my family in the Philippines. "Female, 36 years, Koh Samui, April 2014 
The participants recognized also the outcomes of negative social capital in their work environment. They complained about the negative image of informal entrepreneurs in mainstream Thai society. Despite informal entrepreneurs working hard under tough economic and social conditions, people did not always acknowledge their positive contribution to the economy. For instance, a Burmese vendor argued:

"Some of the Thai people are not friendly towards the migrants. They look down on Burmese people and do not buy anything from them. "Female, 32 years, small-size informal entrepreneur, Koh Phangan, March 2013

The informal entrepreneurs increased their positive social capital by building a reputation for their work. Many of their new customers find the informal entrepreneurs via online and offline word-of-mouth. Former customers tell of their experience and interactions with informal entrepreneurs to their friends and/or recommend these informal entrepreneurs' products and services to other tourists on online social platforms such as Facebook and Tripadvisor. A souvenir booth owner in Koh Phangan said:

"Social media is very important for us. All of these businesses here are promoted on Facebook, I do everything by myself and Facebook has helped me to gain more clients throughout the years. "Female, 29 years, smallsize informal enterprise, March 2015

The analysis of the photographs shows that many informal entrepreneurs put Tripadvisor's Recommended on Tripadvisor stickers on their booth or on the front door of their enterprises.

\subsubsection{Cultural Capital}

The informal tourism entrepreneurs considered a foreign language capability as the most important embodied cultural capital. It was seen as key to accessing opportunities in the tourism sector. Whereas domestic migrants can move to a tourist island without any foreign language knowledge, this is not an option for diaspora migrants. People from the latter group can only find a job in the tourism sector if they speak a foreign language, preferably English. A Burmese designer said: 
"You have to speak both Thai and English very well to have a job in tourism. We are better at English than the Thai people. Because their language does not have some sounds like $x$, for example they can't pronounce 'six' correctly and say 'sis'." Freelancer, 29 years, Koh Tao, April 2013

'Learning English from tourists' was mentioned as an important benefit of working in the tourism sector, as it can increase one's cultural capital on one's career ladder. Cultural capital - as a form of knowledge about the natural and cultural environment, heritage, cuisine, handicrafts, customs, and belief systems - was considered highly valuable by freelancers and small-size informal entrepreneurs, who saw this knowledge as a unique competitive asset in their informal enterprises. In some jobs, particular relevant knowledge and experience are essential. For instance, informal tour guides, elephant drivers, chefs, musicians, dancers, and boat drivers used a particular embodied cultural capital (i.e. specific knowledge and experience) to operate and deliver services directly to their customers. Negotiation (i.e. hard selling and bargaining) and communication (i.e. being in a good mood during contact) skills are other important capital sources in an informal entrepreneur's business life. Many of the participants had been learning these skills since a young age selling small items and having contact with international tourists. International tourists appreciate this embodied cultural capital; one international tourist called this interaction the most valuable authentic experience during his stay on the island'. For instance, on boat tours, international passengers appreciate boat staff's communication and good mood. A male German tourist said:

"Taking a full day boat tour can be boring if the boat staff do not entertain the tourists. Today, time passed like the wind." Koh Phangan, March 2014

The participants mentioned cultural understanding as an important soft skill. An informal tour guide (i.e. freelancer) in Koh Tao said:

"You need to know how to treat a Russian or a Chinese tourist when there is a problem." Male, 33 years, March 2013 to treat people from different cultures differently in relation to a similar 
problem) increase a participant's cultural capital in his/her business. This is a part of the logic of practice (i.e. the game rules) in the given informal sector. In other words, this specific cultural capital, acknowledging the game rules, improves an informal entrepreneur's positioning in the field. Thus, one can acquire this advantage only through internalizing a relevant embodied cultural capital, and obviously this takes time and cannot be purchased rapidly with economic capital.

The participants did not often use their institutionalized cultural capital. Although some informal entrepreneurs had legitimate certificates showing their educational level, vocational knowledge, or skills, they did not display these certificates explicitly at their workplaces. For instance, many of the Burmese informal entrepreneurs did not mention anything about their academic degrees to their customers or use such institutionalized capital as an additional asset in their business. A Burmese café owner said:

\section{"I have a degree in biology from Yangon University. I do not think tourists are interested in my degree, what they only want from me is to have tasty fruit juices." Female, 33 years, small informal entrepreneur in Koh Samui, March 2015}

Holding a cultural capital mix that is based on some specific knowledge and skills required in a field increases an informal entrepreneur's business success.

\subsubsection{Symbolic Capital}

The participants expressed their symbolic capital as the honour and pride of being connected to nature and their cultural roots. Wearing specific tattoos, which signify their closeness to nature, was an important symbolic capital for participants. A tattoo design (e.g. flowers, leaves, animals, spiritual Buddhist signs) symbolizes a milestone in a person's life. Among some religious groups, these tattoos even signify holding a high rank in the social community. An informal tourist guide in Koh Phangan said:

"I am very proud of my tattoos on my body; the one on the right arm is a ship that says 'prison ship', representing the fact that I don't want to end up in prison." Male, 23 years, freelancer, March 2015 
Tattoos applied using an ancient traditional method (called hand tapping) have a particularly high symbolic value, because the participants perceived getting a hand-tapped tattoo as a reconnection with the past. A tattoo artist who adopts this traditional method in Koh Phangan said:

\section{"I am glad to see both Thai urban tourists and international tourists} choose Buddhist tattoo designs. They want to wear a symbol from our culture on their body and in this way they feel rooted to something meaningful, spiritual in the rest of their lives." Male, 33 years, freelancer, March 2015

Other informal entrepreneurs who regularly used their symbolic capital in their daily business are yoga teachers, meditation masters, and Buddhist monks, who run workshops and sell souvenirs with Buddhist symbols. This knowledge and these skills were obviously well recognized by the international tourists who attended these workshops and perceived the participants' symbolic capital as a unique and spiritual value.

The participants used the destination's reputation also as a symbolic value. For instance, the island, Koh Phangan, famous with its full moon party, attracts international tourists from all over the world. Not only the informal entrepreneurs but also formal entrepreneurs who run a business on this island benefited from this reputation and used it as a symbolic capital in their enterprises.

Another example of symbolic capital is the emotional bond between people and place. In general, Thai people feel attached to the land in their country. Regardless of its utility, land inherited from the ancestors has a symbolic value and cannot be sold to third parties. Local community members do not show respect to people who have sold land inherited from their ancestors. Those who retain their inherited land over generations receive the most respect and are seen as prestigious people by their community members.

\subsubsection{Dream Capital}

A new type of capital became apparent when we merged the final codes in thematic analysis. We call this dream capital. By definition, dream capital consists of all resources (i.e. passion, ideas, expectations, dreams, wishes, hopes, and emotions) available in an entrepreneur's mind and serves as an important desire, an ambition for work over the course of one's working 
life. In particular, it is necessary at the seed stage of a business life cycle and nudges one to become an entrepreneur. When a person envisions a new different idea (i.e. dream capital), it is not always generated from a risk-averse rational calculation and is non-linear. A person solidifies this dream capital with family and friends (i.e. social capital) to shape it further. If this stage succeeds, then $s /$ he moves it to the design or prototyping stage without establishing an entity. Dream capital is further used to construct concepts, new products, services, and to enter into the relevant networks. An entrepreneur combines his/her dream capital stock with other types of capital to recognize and exploit an opportunity in a market that is receptive to the innovation. Thus, dream capital plays a role in the evolution of an idea through a series of development stages into a business.

The dream capital stock of our informal entrepreneurs varied dramatically depending on their characteristics. Some diaspora entrepreneurs hoped to accumulate economic capital and return to their homeland to start a business. A Burmese small informal entrepreneur on Koh Samui Island said:

"I work five more years here and then go back to my town. It is very different than here. If you have time, go once there, you can see by yourself. The land is pure, the nature is pure there. People are real there. I want to spend the rest of my life there with real people. "Female, 38 years, March 2013

Mid-size informal entrepreneurs aspire to buy a piece of land close to their current workplace in order to build a house with some commercial spaces on it. Freelancers hope to build a reputation for their work. For instance, a young male tattoo designer wished to become a world-renowned artist whose tattoos would be worn by people and travel all over the world. Small informal entrepreneurs, who sell exclusive items, aimed to expand their business throughout the country and even become a franchisor. Regardless of the type and size of informal entrepreneurs, almost all of them wished to travel in Asia and in particular they wanted to visit Japan, which they consider to be the most innovative country. Dream capital is also linked with the nature of self. An informal guide in Koh Tao emphasized the value of dream capital as fortitude:

"If you never try anything new, nothing will change" Female, 28 years, freelancer, March 2015 
Dream capital can be inherited from the ancestors. Participants ascribed emotional value to places that their ancestors wished to visit or had actually visited, in some cases living there temporarily and working as an employee. A Burmese small informal entrepreneur in Koh Phangan said:

"My father always wished to move to the south of Thailand and to start a business here. When he passed away, I decided to move to Thailand." Male, 32 years, April 2014

A female home-stay owner who was born in Koh Samui said:

"I followed my mother's suggestion to have my own business and become financially independent. We (Thai people) have to care after our extended family and only use rest of time for the business." Mid-size informal entrepreneur, 36 years, April 2014

\section{5 Discussion and Conclusions}

In developing countries such as Thailand, the capital mix of informal tourism entrepreneurs is underestimated in official discourse. However, informal tourism entrepreneurs are capable of introducing a convenient (new) product or service, decreasing formal enterprises' production costs, improving production processes, and importantly providing authentic experiences to tourists. Furthermore, they create jobs, absorb labour excess, support and teach skills to one another, and complement generally the supply gaps in the formal economy (Webb et al., 2009). To gain a better understanding of specific strings of capital conversion by informal tourism entrepreneurs, this study has focused on different forms of capital (i.e. economic, social, cultural, symbolic, and dream capital), how they are perpetually transformed from one into another, and which of them are more notable at different stages of informal entrepreneurs' development process. Through introducing and emphasizing the concept of dream capital as a new form of capital, this paper seeks to contribute to the existing literature on capital, and entrepreneurship. At all entrepreneur development stages, dream capital stock acts as a catalyst to convert other types of capital to economic capital. From the seed stage to the growth and scaling stage, dream capital is important for informal entrepreneurs in recognizing an opportunity, envisioning an idea, creating a new product or service, and entering a relevant network. Dream capital stock plays 
a role in the evolution of an entrepreneurial opportunity through a series of development stages into a business.

Table 5 presents the different forms of capital that are distinguishable across the development stages of informal entrepreneurs.

Table 5: Capital distribution among informal entrepreneurs by stage of development

\begin{tabular}{lccccc}
\hline Type of entrepreneur/Capital & Economic & Cultural & Social & Symbolic & Dream \\
\hline Freelancer & LOW & HIGH & HIGH & HIGH & HIGH \\
Small-size entrepreneur & MODERATE & HIGH & HIGH & MODERATE & HIGH \\
Mid-size entrepreneur & HIGH & MODERATE & MODERATE & HIGH & HIGH \\
Large-size entrepreneur & HIGH & MODERATE & MODERATE & MODERATE & HIGH \\
\hline
\end{tabular}

There is not a fixed capital mix that is necessary at all the different development stages of informal entrepreneurs. Economic capital becomes a consideration in the start-up phase and then assumes greater importance as the informal entrepreneur grows. The specific nature of the tourism sector (Power, di Domenico, \& Miller, 2017) dictates that informal entrepreneurs struggle in their accumulation of economic capital. We argue that, when the size of an informal enterprise grows, the need for economic capital grows as well.

Social capital resides largely in families and friends and is used to access economic and cultural capital. Social capital stock increases with usage, and its value reaches its highest level when it is highly heterogeneous. It is most frequently used at lower stages of informal entrepreneurs' development process. Regardless of their development stage, all informal entrepreneurs use online social media to increase their social capital.

Cultural capital is accumulated over time by freelancers and small informal entrepreneurs, and it is not possible to gain it immediately in return for economic capital. The participants use their embodied cultural capital to communicate with international tourists and use their objectified capital (e.g. artworks, performances) to 5tattract customers and convert their cultural capital into economic capital.

Using symbolic capital is more complex than using other forms of capital. Symbolic capital can enhance its holder's cultural and social capital, but it is not convertible, as it is not diminished by its number of holders. 
Two concepts are fundamental to informal entrepreneurs in the strategy and tactics of capital conversion. The first concept is destination attributes; these are evaluated and used by informal entrepreneurs to adapt their capital mix. For instance, if a destination has a notable cultural and natural heritage appreciated by visitors, informal entrepreneurs tend to accumulate more cultural and symbolic capital. The second concept is the conditions in the particular field where informal entrepreneurs position their enterprise and themselves. For instance, if a field (e.g. tourism) requires a foreign language capability, informal entrepreneurs make great efforts to acquire this knowledge.

The scientific contribution of this article further lies in applying Bourdieu's (1986) capital theory using a combination of sociology and economics perspectives in order to gain a better understanding of the phenomenon of informal tourism entrepreneurship. This new combined perspective enriches existing literature by bringing new insights (e.g. addressing unexpected needs, polycentric solutions) into this phenomenon.

The article has also societal and managerial relevance. The informal economy is a tricky phenomenon for destination governors and policymakers, because it is neither fully taxed nor monitored by public organizations, and its contribution is not included in gross domestic product (GDP) statistics (Gerxhani, 2004). However, it generates employment in developing countries and provides essential products and services (Chen, 2006). It also increases labour market flexibility. Consequently, it is important for policymakers to determine the appropriate degree of control in informal economies in order to regulate informal entrepreneurs such that their benefits to society are not lessened (Dana, 2013). The results of this study may help policymakers to profile informal entrepreneurs in municipal, regional, and national policies on tourism development and urban planning. Our study demonstrates the necessity for capital across different stages of informal entrepreneurs' development and how informal entrepreneurs can be profiled effectively and regulated in order to increase benefits to society.

Future research is needed to identify how the three concepts (i.e. capital, habitus, and field) in Bourdieu's (1993) theory relate to one another in informal tourism entrepreneurship. Further insights can be gained by applying these methods to other types of tourism destinations such as urban areas or cultural sites. Additionally, the informal tourism entrepreneurs in 
this study are working in different sub-sectors of the tourism industry. Future research could address specific categories: looking at transport providers, informal tourist guides, or home-stay owners, or focusing on other aspects like the inclusion/exclusion of informal entrepreneurs in the local society and stakeholder conflicts. 


\section{Chapter 4}

\section{Habitus Adaptation of Informal Tourism}

\section{Entrepreneurs}

Erdinç Çakmak ${ }^{\mathrm{a}, \mathrm{b}}$, Rico Lie ${ }^{\mathrm{b}}$, Tom Selwync, Cees Leeuwis ${ }^{\mathrm{b}}$,

a Breda University of Applied Sciences, the Netherlands

b Knowledge, Technology and Innovation, Wageningen University \& Research, the Netherlands

cSOAS University of London, United Kingdom

(The article presented in this chapter will be considered to be submitted to Annals of Tourism Research for publication) 


\section{Abstract}

This article investigates informal tourism entrepreneurs' habitus adaptation in response to changes taking place in their individual life-trajectories and their immediate social structure. Bourdieu's concept of habitus is used here in the sense that it refers to a matrix of perception, appreciation and action as it shapes one's individual positioning in various contexts. Through semi structured in-depth interviews with 53 informal tourism entrepreneurs in Thailand, this paper identifies a classification of four modes of habitus adaptation: (1) Understanding and appreciating the field and its conditions, (2) Challenging core beliefs systems, (3) Applying a practical sense to 'objective possibilities', and, (4) Challenging non-reflective dispositions. The analysis clusters the informal tourism entrepreneurs according to these modes, concluding with recommendations for policy makers.

\section{Keywords}

Habitus, Bourdieu, informal tourism entrepreneurs, individual change, social structural change, Thailand 


\subsection{Introduction}

The tourism sector of the $21^{\text {st }}$ century is experiencing a tremendous growth and is changing the social and cultural structures of the host populations (Çavuş \& Tanrısevdi, 2003). This growth is accompanied by formal and informal tourism entrepreneurs aligning with the new structures and changing their individual behaviour. In explaining such contextual processes of individual adaptation from a social science perspective, habitus is probably one of Bourdieu's most cited concepts (Maton, 2012). Habitus shapes one's individual present and future embodied practices and consists of 'one's mental and corporeal schemata of perception, appreciation, and action' (Bourdieu \& Wacquant, 1992, p. 16). It is a combination of one's deep-structured identity and one's less fixed occupational identity (Meisenhelder, 1997). While deep-structured identity requires a fundamental connection with a group and develops over time through the influence of the group's norms and beliefs (Rousseau, 1998), occupational identity refers to the connection between one's employment and one's sense of identity (Carroll \& Lee, 1990). Although significant consideration has been given to the role of habitus in exploring social reproduction (Hartmann, 2000; Crossley, 2003), how habitus actually adapts under the influence of individual and social structural change is not further addressed by Bourdieu (Aarseth, Layton \& Nielsen, 2016; Green, 2008; Lau, 2004).

Therefore, the central question in this research is: How does habitus adapt under the influence of major and minor individual and social structural change? More precisely, this paper empirically investigates how informal tourism entrepreneurs in Thailand respond to individual and social change by adapting their habitus. As such, it presents the first formal attempt in the tourism literature to empirically show how habitus adapts. It integrates concepts from two bodies of literature: affective psychology and sociology. The study is new in the sense that it not only focusses on the processes of social structural change and how that influences one's habitus but seeks an integration with individual change and aims to understand how the combination of individual and social structural change influences habitus adaptation. Notably, this study incorporates the notion of individual changes together with structural changes in the production of a new worldview through an individual's habitus adaptation. As such it indicates new avenues for research in tourism studies. 
The research context for this study is Thailand, which is one of the top-ten tourist destinations in the world (World Travel and Tourism Council, 2017). Drawing on a longitudinal study, the paper explores the habitus adaptation of informal tourism entrepreneurs using narrative interviews and informal conversations on Koh Samui, Koh Phangan and Koh Tao islands. Due to the rapid expansion of tourism and its associated developments on these islands in the last two decades, the local communities' daily lives have changed significantly (Pongponrat, 2011).

The results of this study reveal an ongoing exchange between the informal entrepreneurs and the environment - or as Bourdieu would probably operationalize it the tourism field conditions - on these islands. When the characteristics of the tourism sector change on the islands, informal entrepreneurs probably adapt their habitus in line with their capital - Bourdieu makes a distinction between several capitals (see for instance Çakmak, Lie \& Selwyn, 2019) - deployment.

The remaining sections of this paper are organised as follows. First, Bourdieu's theory of practice with an emphasis on the concept of habitus is explained. This leads to the necessity of adopting a combined perspective, which values an individual focus on change as well as a social structural focus on change. Next, a review of the informal tourism economy and its entrepreneurship in tourism studies is provided. After the research methods are outlined, the findings section presents the results of the examination of the habitus adaptation of 53 informal tourism entrepreneurs as part of the changes in their life trajectories and surrounding structure. Finally, based on the findings from the empirical study, the paper presents a classification of habitus adaptation that is based on major and minor changes in individuals and in social structures. The presentation of this classification is then followed by a discussion and a brief conclusion.

\subsection{Theoretical Framework}

\subsubsection{Habitus Formation in Bourdieu's Theory of Practice}

Practice - in Bourdieu's own words 'concrete human activity' (Bourdieu, 1990, p.13) - is a central theme in Bourdieu's sociological work and is always directly linked to an individual's social world. In fact, it is within the 
social world as a context that 'social actors' - as Bourdieu sees individuals - give meaning and value to their practices. People develop and conduct their practices in accordance with their past experiences, their habitus, their beliefs and the positions they hold in what Bourdieu calls the 'fields' in which they operate. In conducting their practices people experience the tension between the adaptation to the social world and the singularity of the self, based on past experiences, habitus, and beliefs (Leandre-Gomez, 2010). While social agents develop subjective elements in their own social context, it is possible to see these personal aspects are being embedded in the social context. To this end, the permanent dialectic between opus operatum - structure - and modus operandi - the mode of operating - underpins the main locus of practice in Bourdieu's social theory. Here opus operatum refers to the existing and autonomous structure - or set of a priori cultural and structural rules of a society - while modus operandi refers to how individuals develop and apply their practical strategies in the social world.

Bourdieu developed his theory of practice to illustrate the dialectical and generative relationship between objective and subjective structures (McNay, 2004). He is opposed to the dualistic nature of sociological thinking with oppositions like external versus internal, macro versus micro, and conscious versus unconscious. He argues that the problem with dualisms and antinomies is the exclusive focus on one or another aspect that leads to logical contradictions (Everett, 2002). Bourdieu advocates an anti-positivistic materialism and states that the theory of practice as practice posits that objects of knowledge are constructed and not passively recorded' (Bourdieu \& Wacquant, 1992, p. 121). In this vein, the principle of construction is embedded in the socially constituted systems and practices and refers to social agents' positionings in the field. As a result, to account for one's practice and its logic, Bourdieu focuses on relationships - he differentiates them from interactions in the formative roles of producing social structures - and habitus, which are conditioned by the structure of the field and its context. In contradiction to the idea that the actions of 'human beings' are the result of conscious intentions (Haggard \& Libet, 2001; Libet, Gleason, Wright, \& Pearl, 1983), Bourdieu suggests habitus as 'a pre-reflexive concept, a second nature, durable and largely unconscious to social actors' (ibid. p. 133).

To account for practice, Bourdieu (1990, p.101) formulates the following equation: 


\section{Practice $=[($ Habitus $) \times($ Capital $)]+$ Field}

The dialectic relationships among habitus, capital, and field produce one's social practice. Individuals produce their social practices through habitus (dispositions for action) which are derived from different forms of capital, which in turn, define their evolving positions within the field (their social context) to which they belong and in which they define their positions and stakes. Individuals exchange and accumulate capital in their social interactions based on their lived experiences, with an aim to improve their positioning in their social context. Obviously, habitus plays an important role in this equation to understand how - in combination with capital and field - individuals see the world and operate in it. Bourdieu (1977, p.79) sees social agents as 'virtuosos' who are not dominated by abstract a priori social rules but know the script so well that they can act through improvisation and the elaboration of themes in collaboration with others. For instance, like tennis players, social agents have a 'sense of the game' through having an intimate understanding of the object of the game and the kinds of situations which can occur. They have the practical flexibility to know when and how they should run to the net or into an open space. Bourdieu (1990, p.52) suggests that habitus is the embodied 'durably inculcated system of structured, structuring dispositions' in a social context and 'a feel for or sense of the social game ... a tendency to generate regulated behaviours apart from any reference to rules' (Bourdieu, 1962, p.111).

Habitus is structured because it is shaped by individuals' original conditions (e.g. history, family upbringing, culture, gender, and the social class they belong to). Habitus structures social context, because being involved in a social context (field) means that individuals develop their own perception, appreciation and action of what to do and what not to do. They develop their own understanding of the field's assumptions, rules and principles. They also develop their own understanding of other actors' positions and stakes in the field. Based on these various understandings they practice. According to Bourdieu, habitus is also a structure. It is composed of a chronological series of orders in which a given rank order specifies lower and higher rank orders. For instance, the habitus of a child acquired in the family structures the child's experiences at school, and the habitus adapted by the school experiences is in its turn at the basis of all subsequent experiences (Bourdieu \& Wacquant, 1992). In this way habitus is derived directly from one's structural or socioeconomic position (e.g. gender, age, class, ethnicity, and 
so on). To this end, Bourdieu sees habitus as a mediator between the opus operatum and individuals' practices where they internalize their dispositions, tastes and knowledge in the social context in which they live.

Habitus is not eternal and it changes constantly based upon one's perception of external stimuli (e.g. changes in the field and beyond) and conditioned experiences in the past (Bourdieu \& Wacquant, 1992). The changes in one's habitus are related to the changes to the characteristics of the field and the kinds and proportions of capitals owned by social agents in relation to the changes taking place in the field (Everett, 2002). However, a hysteresis effect can occur if there is a gap between a changed field and habitus (Bourdieu, 2013). This hysteresis effect happens when the habitus lags behind the changes in the social structure and habitus needs to catch up. Although Bourdieu argues that in such circumstances habitus might become dysfunctional leading to failure, he does not provide further explanation on how individuals can respond to this discrepancy (Wimalasena \& Marks, 2019).

\subsubsection{Habitus and Individual and Social Structural Change}

Bourdieu's social theory and in particular habitus has been criticized for implying a degree of social determinism by underplaying the conscious actions of social agents (Archer, 2007; Jenkins, 1992; King, 2000). However, some critical realist scholars have noted that habitus does allow for conscious deliberations in a sense that the actions motivated by the habitus are rooted in doxa (i.e. common sense), which enables social agents to reformat existing structures through changes in habitual behaviour (Elder-Vass, 2007; Sayer, 2010). While Bourdieu uses various psychoanalytical concepts like a feel for the game, unconsciousness, misrecognition, love, taste, libido and so on, some critics claim that habitus is a limited concept as it does not incorporate an intersectionality approach (Wetherell, 2012). Applying intersectionality would mean including one's individual history, subjectivity, and affective practice, which altogether connects the personal to the social world (ibid.). According to Silva (2016) intersectionality is included in Bourdieu's work as for Bourdieu all individual factors (e.g. age, gender, ethnicity) operate through a mechanism of class-based habitus. However, the fact is that the overemphasis on the role of the social structure is a key aspect of habitus that has often been criticized. 
Affective psychological theories argue that one's action and behaviour are determined by emotional dispositions and some basic emotions are rooted in universal cultural categories, and operate unconsciously and automatically (Leys, 2011). For instance, one's personal preferences like preferring tea to coffee, or kebab to fish and chips have no links with one's social class. Bourdieu acknowledged the unconscious part in one's habitus but did not elaborate further on its functioning (Aarseth et al., 2016). In addition, Lahire (1999) posited that individuals often have significant intrapersonal conflicts and identity problems and these are not accounted for in the notion of habitus.

While a universal perspective focuses on determining the effects of one's personal development (i.e. the early years on character formation), a contingent perspective highlights individuals' dependents, conditions and specifics (e.g. divorce, aging, and other crucial human matters) (Layton, 2004). A contingent perspective focuses on unconscious' dynamic relations within the opportunities offered by one's cultural structure (Layton, 2004). To this end, the contingent perspective posits that one's practices within his or her

given options would affect one's unconscious perceptions, appreciation and actions and therefore one's habitus. Following this reasoning it seems logical to adopt a contingent perspective as well as a perspective on social structure and thus address intersectionality. Therefore, this study aims to understand how habitus changes by incorporating an individual perspective as well as a social structural perspective. Taking the above-mentioned critique seriously, the research studies major and minor changes in individuals as well as in social structures in the informal tourism sector in Thailand.

\subsubsection{Informal Entrepreneurs in the Tourism Sector}

Informal entrepreneurship is increasingly recognised by both academic scholars and policymakers as a potential for jobs and a driver of economic growth in developing countries (Autio \& Fu, 2015). More than 60 per cent of the global employed population function in the informal sectors (ILO, 2018). Informal enterprises demonstrate a vast diversity of characteristics regarding their type, size, location, domains of concentration, degree of compliance with laws and regulations, and level of productivity.

Informal tourism entrepreneurs are self-employed agents or business owners, who directly or indirectly engage with tourism, but are often not 
registered by the authorities, formal associations or trade organizations (Slocum, Backman, \& Robinson, 2011). They work on their own account, hire people from their close environments, and the local communities in which they operate benefit from their entrepreneurial activities, especially during an economic crisis (Brata, 2010; Dahles \& Prabawa, 2013). Both formal and informal tourism entrepreneurs consider trade-offs and opportunity costs related with alternative courses of action, collect and converse different types of capital (solid or in any hybrid combination), and improve their positioning in their occupational choices (Çakmak, Lie, \& Selwyn, 2019). In the course of doing this, they unconsciously adapt their habitus regarding their position in the social structure.

Informal entrepreneurship highlights a long-standing debate in the tourism literature, and existing theoretical understandings of informal entrepreneurship demonstrate strong sociological and economics influences. Because entrepreneurs provide people with an income, tourism entrepreneurship is seen as a potential tool for redressing poverty and alleviating income inequality (Bruton, Ketchen, \& Ireland, 2013; Scheyvens, 2007). In some of the developing countries, policy makers are also aware of the positive role of informal entrepreneurs in job creation, risks diversification, and poverty reduction. Bruton (2010) suggested that entrepreneurs provide the poor with opportunities that might otherwise have remained inaccessible.

Tourism on its own is a factor of acculturation affecting attitudes, altering common beliefs, changing mentalities, and spreading new concepts with regard to work, money and human relationship (Kesmanee \& Charoensri, 1995). Informal tourism entrepreneurs, like other individuals, display their own habitus by viewing their own social and physical spaces, and accordingly position themselves in that social world (Silva, 2016). They enter the informal economy not always by their own free choice, but because of a lack of individual capitals and dispositions in the formal economy (Çakmak, Lie, \& McCabe, 2018). Informal entrepreneurs mobilize capitals to run their business in resource-constraints contexts. However, not much is known about their contribution to reconstructing the social spaces and generating social change endogenously. While Bourdieu's theories have been applied sparingly within tourism research (Çakmak et al., 2018; Çakmak et al., 2019; Lee \& Scott, 2017), practice-based research can provide the empirical foundation to analyse habitus adaptation. 
An informal entrepreneur's habitus includes their internalized cultural discourses, perceptions and attitudes, past experiences, transposable dispositions, skills, gestures, and habits of speech. In this vein, an informal entrepreneur's habitus and the entrepreneur's social structural positioning are also dependent on the earlier discussed field. In this field, habitus is hidden, and it is only possible to construct an entrepreneur's habitus based on his/ her history. Therefore, this study adopts a narrative approach, which will be explained in the next section.

\subsection{Methods}

In studying habitus, researchers - using a qualitative approach - focus on three aspects, namely, individuals' patterns of perception, thinking (appreciation), and action in relation to their history (Faubion, 2018; Reay, 2004). These aspects are examined through studying individuals' relations to their social context in everyday life. This study follows the same approach and applies a qualitative study design based on data gathered through ethnographic fieldwork. The field research was conducted in and around informal tourism entrepreneurs' communities in Koh Samui, Koh Phangan and Koh Tao islands, Thailand in three periods between 2013 and 2015. We first sketch the research context, and then detail the research methods regarding data collection and data analysis.

\subsubsection{The Field Research Context}

Koh Samui, Koh Phangan, and Koh Tao were the top-three most popular tourist islands located in the south of Thailand (Lonely Planet, 2014). While Koh Samui was identified as one of Thailand's marginal paradises three decades ago, the rapid tourism development has affected the environment and the daily lives of local communities' members significantly (Cohen, 1982; Green, 2005; Pongponrat, 2011). Koh Samui is marketed as a trendy boutique destination providing high-end accommodations, but it is also catered for in various other forms by international tour operators. The island's economy is dependent on the tourism industry, which can be labelled as very dynamic as it includes various types of formal and informal enterprises. Informal tourism entrepreneurs work for instance as artists, dancers, and musicians in several bars and restaurants, but they also run stalls and sell food, souvenirs, drinks and clothes in the coastal areas and in 
the main streets. Not only mobile businesses but also medium-size stores are not registered and act as informal entrepreneurs. These stores run both directly related tourism enterprises such as travel agencies, car rentals, tattoo shops, art galleries, cafés and indirectly related tourism businesses such as laundry services, souvenir production, grocery stores and so on.

The second island, Koh Phangan, is located close to Koh Samui and has a reputation among backpackers for its full moon dance parties (Gibson \& Connell, 2003). On the monthly full moon nights, the island attracts approximately thirty thousand domestic and international tourists. The well-known Hollywood films The Beach and Last Stop for Paul have used the theme of the full moon party in their scripts. The island is visited mainly by young and active domestic and international tourists, and informal entrepreneurs are involved in nature-related activities offering tourists guidance, hiking, trekking, and kayaking trips. There are also small and mid-size informal enterprises, which offer spiritual training, overnights in home stays, fishing trips and taxi boats rides. In comparison to Koh Samui, this island attracts more migrant workers and entrepreneurs who mainly come from Myanmar and Cambodia.

The last island Koh Tao is known as a dive paradise among divers worldwide. The informal businesses are similar to those found on the other two islands, but there is a main focus on diving and water activities. The informal entrepreneurs provide services to formal dive instructors, and further offer boats, bungalows, souvenirs, jewellery, food and fruits, sea wear and other water related materials and activities. Like Koh Phangan, this island hosts migrant workers and entrepreneurs from northern Thailand and Myanmar.

\subsubsection{Data Collection and Analysis}

Narrative inquiry has been used widely in tourism studies to explore people's lived experiences and their identities (McCabe \& Foster 2006; Çakmak et al., 2018). The narratives in this study were collected in three periods between 2013 and 2015 through semi structured in-depth interviews, which focussed on both the personal lives and the work histories of informants. An interview guide was used, which included broad themes such as personal background, daily work, family relations, social space, future outlooks, and life history. The informants were encouraged to share their thoughts and experiences freely. Additional field research activities included 
the following; observing informal tourism entrepreneurs in their work, acting as a tourist in interactions with tourism professionals, participating in informal entrepreneurs' social activities, conducting informal conversations and taking photographs. Data gathered in this way was used to add information to the material already acquired through the in-depth interviews.

Fifty-three informants, all informal tourism entrepreneurs, were selected through a combination of purposive and snowball sampling techniques. They predominantly represent mainstream informal tourism entrepreneurs such as homestay owners, transport providers, street vendors, operators of food stalls and unofficial tour guides. The informants also represent a cross-section of individuals in terms of age (ranging from 18 to 57), gender (33 women and 20 men), ethnicity (Thai, Burmese, Cambodian, the hill tribes of Northern Thailand), religion (Buddhist, Christian, Hindu, Muslim), class and geographical location. Pseudonyms are used to ensure the anonymity of informants. The interviews were conducted in English, last between 35 minutes to 4 hours, and were mainly held at informants' workplaces. Due to the longitudinal character of this study, multiple visits to an informal tourism entrepreneur were often conducted while some informants were interviewed at different locations.

Narrative inquiry is 'always interpretive at every stage' (Josselson, 2006, p.4) from data collection to data analysis and to reporting research results in order to find narrative meaning (Polkinghorne, 1988). For the data analysis, interview material, field notes, and additional visual data were organised, coded, and analysed using the NVivo 10 software package. The qualitative data analysis approach used by Creswell $\&$ Poth (2007) was employed. The data were condensed through coding and recoding processes in which keywords, similarities and dissimilarities were clustered into themes. These themes then contain different forms of habitual behaviors.

In determining the coding categories for the analysis, deduction and induction, or a combination of the two methods can be used (Boyatzis, 1998; Mayring, 2004). While in a conventional content analysis, categories are derived from the primary data during the data analysis, in a directed content analysis the researcher uses prior research to develop the initial coding scheme (Hsieh \& Shannon, 2005; Kyngas \& Vanhanen, 1999). This study uses a combination of both a deductive approach and an inductive approach in 
determining the coding scheme to identify the categories of habitus adaptation. On the one hand, it conducts a directed content analysis and focuses mainly on the habitus changes as depicted by Lau (2004). He conceptualizes habitus' components into three categories: (a) belief premises, (b) perception and appreciation, (c) a descriptive and prescriptive practical sense of 'objective possibilities'. On the other hand, it conducts a conventional content analysis and uses the steps described by Braun \& Clarke (2006). This latter approach gives a richer understanding of the habitus adaptation of informants in response to major and minor individual and social structural changes. As a result, an additional code is developed, and the initial coding scheme is revised and refined.

Identifying the habitus adaptation of each informant is a primary concern of the data analysis. Therefore, the analysis categorizes the codes and eventually identifies four categories, which capture the various found forms of habitus adaptation. These categories are: (1) Understanding and appreciating the field and its conditions, (2) Challenging core beliefs systems, (3) Applying a practical sense to 'objective possibilities', and, (4) Challenging non-reflective dispositions. These categories can be seen as modes in which informal entrepreneurs adapt their habitus.

Informants are thus clustered according to these four categories and the following section presents the findings following the structure of the four categories. In each category how informal entrepreneurs adapt their habitus in a specific mode as part of the changes taking place in their life-trajectories and in the social structure is described.

\subsection{Findings}

\subsubsection{Understanding and Appreciating the Field and its Conditions}

Eleven informants are identified as a subgroup expressing an understanding and appreciation of the field and its conditions. This subgroup includes nine women and two men with an age range from 23 to 36 originating from Northern Thailand and Myanmar. Roughly half of the informants identified themselves as Buddhist but none of them were practising all the Buddhist rituals in their daily lives. All narratives in this subgroup have in common that they focus primarily on their jobs and are continuously searching for 
new adaptations in their work and daily life. All eleven informants report that working conditions in tourism and hospitality are demanding and characterised by long hours. They believe informal businesses must operate around the clock and informants confirm they work extended hours. Beyond the widespread unusual working time arrangements, seasonal variations in tourism on these islands have created structural problems in the lack of continuous employment and business operations. The wage levels are low, and without holiday and sick leave entitlements. However, the informants believe there is also good practice in the tourism sector. It provides entrylevel jobs for people who are low-skilled and poorly-educated, and part-time jobs for people, mainly women taking care of the children. There is a high proportion of female, low-skilled and migrant workers in the businesses throughout these islands. These female entrepreneurs develop an understanding of the requirements of tourism practices on the islands and do not consider their jobs as tough and difficult. For instance, they compare their current jobs with other possible jobs they would perform, and one says:

'You do not need any education to work in a cafe, everybody can do this job. It is not difficult... Every job is the same, if you have a problem, you solve the problem.' / Sanda (27 years, female, Burmese, café owner - Koh Phangan, April 2015)

Sanda belongs to an ethnic minority (i.e. Shan) in Myanmar and could not operate a café or any small business in her country, as the conditions in Myanmar would have been similar to her current context. The social pressure in Myanmar would not allow Sanda to become a tourism entrepreneur and she considers her life comfortable enough compared to other family and friends working in Myanmar. Furthermore, having migrated to another country far from home is not a strange thing for Sanda. Everyone from her town has a family member living across the border. The Shan language is similar to the northern Thai dialect and people from the both sides are ethnically and historically connected to each other.

Sanda was 18 years old when she left her town in Myanmar - followed her friends - and moved to Chiang Mai to find a job. She stayed together with her friends at their apartment and started working in the restaurant where many other Shan people were part of the staff. Her new conditions in Chiang Mai were challenging but she earned more: 
'I was a home maid in my town and was earning 900 kyat [equals to 0,58 US\$] for a day. It was also not easy [to work as a home maid], but in my first job in Chiang Mai, I took 80 Bath [equals to 2,51 US\$] for a day as a dish washer.'/ Sanda (Koh Phangan, April 2015)

Sanda worked in Chiang Mai for 3 years, she held different positions at the restaurant, worked two shifts (day and night shift) to save money. In those years, she spoke in the Shan language to her friends, often ate fermented beans (a Shan meal), and listened to the Burmese radio. Sanda and her friends continued to follow the Shan traditions in their daily life in Chiang Mai. Some of Sanda's new friends had moved to Koh Phangan and told her about the 'easy work' and 'higher income' opportunities there. She followed her new friends this time and moved to Koh Phangan in 2009. Moving to southern Thailand weakened Sanda's ties with her family. Although she calls her family regularly and sends remittance, she had visited them only once in the previous six years. It is hard to visit the family in Myanmar (i.e. due to travel costs and passport related issues) and Sanda does not feel that she can leave her work. When Sanda listens to the Shan music - she loves the rock icon Sai Sai Mao's songs - she often thinks about 'home' but less about the issues in Myanmar:

'I love to listen to the Shan pop and also rock music from Sai Sai Mao. He reminds me [of] my mother and the beautiful scenery and people from my hometown. Then I wish to go back home and hug my mother but there is no future there for mé. / Sanda (Koh Phangan, April 2015)

Since she moved to Koh Phangan, Sanda has followed the Thai media more in her everyday life and has become a fan of the Thai television soaps. She has more Thai friends on the island and her English has improved. She is proud of her English skills and often holds conversations with international tourists in order to learn about their cultures and eating habits. She works with another two Thai women in the café. Both are from Chiang Mai like Sanda but they did not know each other before and all met on Koh Phangan. All the three women are aware of their own strengths and learning processes and they create an understanding of "others" cultures. Their flexibility and understanding of 'others" ideas and behaviours help them to be successful in their work life and adapt to the changes in their social life. 


\subsubsection{Challenging Core Belief Systems}

Sixteen informants are identified as a subgroup that challenge their core belief systems and experience a paradigm shift in their daily life. This subgroup includes eleven women and five men, who have a mix of ethnicities (i.e. Thai, Burmese, Cambodian) and are aged between 31 and 42 years. The most striking premise in this subgroup is the development of a different 'status of women' resulting in more active businesswomen as informal tourism entrepreneurs. Compared to men who mostly preferred to work as labourers, women work more as entrepreneurs and are well represented in the informal economy. Women's place is not entirely in the home anymore and it is highly acceptable for women to work on these islands. In all sixteen narratives the common aspect in this subgroup is the informants' subconscious awareness of the underlying discourse in their contexts, their abilities, and their self-reflection on their actions. They are critical about their previous lifestyle and observed the changes in their living contexts and shifted their mindset and habits in their daily lives. The new way of living is most likely based on their individual abilities. For instance, Lek (female, 35 years) was a housewife earlier before she started her souvenir shop next to her house. She has 4 children and her mother in law lives with them. Her husband had worked in Suratthani (i.e. province in the mainland Thailand) but he came back and now helps her to buy stones and other materials to produce bracelets, necklaces, earrings and so on. Lek states that she now engages more in decision making in the areas and issues where traditionally males are dominant. She is supporting the extended family:

'Since I am working as a boss, my family consults me for everything. My younger brother was going to start university education, they asked me what study to choose. My mother was ill and they asked me to which hospital to take her to. I was shy before, now I make decisions, this is because I support them now.'/ Lek (35 years, female, souvenir shop owner - Koh Phangan, April 2015)

The number of women entrepreneurs in the tourism sector is remarkably high compared to other sectors on these islands. They do not only contribute to their household finances, but they also become emancipated working in tourism. A perfect example for this finding is Apinya (31 years, Thai, from Suratthani). She has transformed the front of her house into a boutique where she sells unique and distinctive (some were her own designed) silver jewellery. A part of her collection includes the 'Siam Silver Nielloware' - 
charcoal black enamelled silver jewellery depicting characters and scenes from Buddhist and Hindu tales - items, which are sourced from her hometown Nakhon. Apinya had a tough childhood and youth:

'My family was poor, and my parents had to work hard. I was only 8 years old when I was taking care my three siblings and our home. I only went to the primary school and then I had to stop. With the age of thirteen I went to Phuket to find a job in tourism, but I did not have any skills. I ended up working at a chicken stall in the market, fourteen hours a day and six days a week. It was tough. I was eighteen when I met with the father of my daughter. But later, I saw that he was a butterfly guy and was not interested in founding a family. I was pregnant when I had to return home and gave birth and raised up my daughter in Nakhon.' / Apinya (31 years, female, Thai, from Suratthani, boutique owner - Koh Samui, April 2013)

Raising her child alone in the first five years in Nakhon was a difficult period for Apinya though she received support from her family. Apinya was living together with her siblings, parents, grandparents and her daughter under the same roof. Apinya's grandfather was the head of the household and his advice was expected to be followed without any question. Like every other household Apinya had to 'know her place' in the family and in the community. She was cooking, washing everyone's clothes, cleaning the house and taking care of her daughter. A fundamental shift took place in Apinya's world when she had an invitation in 2006 from her cousin asking her to work at her food stall in Koh Samui. When she arrived on the island, the first thing she did was purchase a dictionary and then enrol on an English language course, which she followed in the weekends. A short period later Apinya found a job at a hotel where she met with her current Dutch husband. In the beginning she was scared about having a relation with a farang (i.e. a white race person) since she had heard many stories about them, and she already had a broken relationship in the past. However, she followed her heart and after two years they got married. Her husband works on a ship and is not at home for six months a year. With some financial support from her family in law, Apinya started with her jewellery store. She always liked to draw and began to design her own jewellery. She went to her hometown that was famous for 'Siam Silver Nielloware' in the past and encouraged people to start working again. She gave some orders to produce jewellery based on her design and promoted 'Siam Silver Nielloware' in Koh Samui. Furthermore, she has travelled to several European and Asian destinations to get inspiration in her designs. 
When Apinya looks back at her childhood she becomes sad, but she took her life in her own hands and changed it for the better. Apinya is more realistic now in her choices and actions and no longer believes that she is powerless. She says:

'People always want to have more and they think it will make them happier but it only makes their life more difficult. I am happy with what I have, and my choices, and admire this way of thinking, feeling and living.' I Apinya (Koh Samui, April 2013)

She always wanted to do something for herself, for her daughter, extended family and people from her hometown. She is self-confident, proud of what she did, and flipped the old paradigms from her childhood and youth. Apinya has liberated herself from the control of traditional power structures.

\subsubsection{Applying a Practical Sense to 'Objective Possibilities'}

Seventeen informants are identified as a subgroup that expresses a practical sense of 'objective possibilities'. Max Weber's concept of 'objective possibilities' contends that asking the 'what might have happened if' is not pointless and forces one to consider alternative scenarios and possibilities. In Weber's terms, the informants in this group focus only on the external (i.e. 'objective') and the final result of their actions without considering the internal (e.g. intention, motivation). A central character of this subgroup is that its members strongly reproduce their past experiences and tendencies, which guide informants to think and act in some determinant ways. This finding is in line with Lau's (2004) findings, and often involves some social limits and petrifies one's 'sense of belonging'. For instance, regardless of their individual incomes informal entrepreneurs who belong to this group rarely stay at a hotel when they are on holiday. They prefer to stay at one of their family members' and friends' houses. A taxi driver from Koh Samui says:

'We can't stay with whole family at a hotel. It is not for us'/ Brandit (57 years, male, taxi driver - Koh Samui, April 2015)

Brandit thinks hotels (regardless of their price range) are for rich people and not for people like him. Although he works as a taxi driver, when he is on holiday, he either uses a tuk tuk or rents a scooter rather than using a taxi. Brandit came from Bangkok to Koh Samui 17 years ago. He has six children - all grown up now - living their independent lives but keeping a close 
contact with their parents. One has opened a restaurant on the southern part of the island and two children moved to Bangkok. When he first came to Koh Samui, Brandit was the solo breadwinner in his family and had to work hard. Over the years the children became independent and do not need any more financial support from dad. However, Brandit wants to keep working as a taxi driver. He says:

'I know everything in Koh Samui and this is my job' / Brandit (Koh Samui, April 2015)

Brandit considers other possibilities for his practices but he always aims for the same result as he is used to, and he is less flexible to change. For instance, he has been performing the same job for many years, though from time to time he considers stopping or updating his business, even to move to other places, but in the end he stayed at the same place performing the same job.

The informal entrepreneurs coming from rural areas tend to keep 'traditional' thoughts and experiences for longer periods. Lookpla (31 years old female vendor from Lampang) is a perfect example of this group. Another characteristic of this group, including Lookpla, is that all the Thai and Burmese informants avoid sunbathing. Lookpla says:

'Being white is beautiful. Face can be brown, that is okay but not the body.' / Lookpla (31 years, female, Thai, vendor, from Lampang - Koh Samui, March 2014)

After living on Koh Samui for twelve years, she still believes the countryside's thought - 'whoever does not work on farm has a fair skin' - and considers having pale skin as a status symbol. Contextually, sunbathing may ruin her status in her social life and others might think that she is a farm worker. Unlike the international tourists, who tend to favour tanned skin, informants prefer to have light skin and keep their skin away from direct sun light. Both male and female informants consider the pale white skin colour attractive and want to appear similar to international tourists. As a result, they protect their body from sunlight very carefully and refrain from wearing skimpy clothes.

This subgroup is the only cluster in which the number of men is higher than women (i.e. 10 men, 7 women). The average age of informants in this 
subgroup is higher in comparison to other subgroups' (i.e. 39 years) and in all narratives the past experience of informants is a dominant factor in influencing their way of thinking and acting. They all see changes in their lifeworld as 'usual' and have their own explanations (i.e. reasons and effects) of these changes in their life based on their previous experiences.

\subsubsection{Challenging Non-Reflective Dispositions}

Nine informants (i.e. 6 women and 3 men) are identified as a subgroup that conveyed challenging non-reflective dispositions. This subgroup's age range is between 18 and 32 and the informants are roughly the youngest ones among others. All 9 informants are Thai and 4 of them are from the fieldwork location Koh Samui, and the other 5 informants come from the mainland of Thailand. Jean-Paul Sartre's concept of 'non-reflective consciousness' refers to one's acceptance of a happening as it is - unmediated - and does not attentively inspect or reflectively introspect, but perceives it as just experience on its own. In Sartre's terms, the informants in this group are expected implicitly to be aware of the changes in their social space and do not reflect on them. However, this group is explicitly aware of the individual changes and changes in the social field but they prefer to accept these changes as a random experience and do not reflect on them. For instance, these relatively young informal entrepreneurs, who possess relatively higher intercultural communication competence, use some of the European, American gestures in their daily lives. The vendors in the Chaweng market area in Koh Samui use both thumbs up to say okay or kiss fingertips to say wonderful. One of the vendors in Chaweng market is Eyw (28 years old, female, from Koh Samui) and she says that:

'People [who are working in the market area] wear Western clothes, eat Western food with chop sticks and behave like international tourists. These signs [gestures] are not Thai they are all learned from their European and Australian friends.' / Eyw (28 years, female, from Koh Samui, vendor in the Chaweng market - Koh Samui, March 2014)

These new gestures are not used in the mainstream Thai communication culture, and vendors and workers in this area adopt them from international tourists. Remarkably many vendors use these gestures very often (in some cases very fulsomely) in their daily communications. Another change has been observed in the type of products sold by the vendors in the streets and 
markets during the fieldwork periods. During the first fieldwork period in 2013, mainly domestic people were visiting the local markets in Chaweng and vendors were selling primarily to locals. However, almost one and a half years later, the crowd in the markets turned to tourists and more than the half of the vendors switched their products to souvenirs, t-shirts, and other eye-catching tourist items. While the market area is used now as a shopping street in the morning, it is used as a 'Night Market' after 7 p.m. until midnight. Eyw was selling fresh fruit juice in her stall in 2013 and she was working from 8:00 to 17:00 hours daily. In 2015 she transformed her stall to a mobile bar where she offers cocktails to the low budget international tourists. She profits from the proximity of the market area to bars and nightclubs on the main street. Eyw is hopeful that she will earn more with her adapted products:

'Young tourists came here for pre-drinks before they were actually partying at the Ark bar, Reggae bar, or other places on the beach. They get here cheap food and cocktails from the stalls and prepare for the night. Yes, last time [when we met in 2013] I was selling only fresh fruit juice and some tourists liked it. Last year a friend recommends me adding some alcohol into juices and making cocktails. It was very good idea, now I am selling only cocktails at the Night Market, fresh fruit juice only to other vendors here. I work now only in the evening but I earn much more and work less"' Eyw (Koh Samui, March 2015)

Local people visit the Chaweng market from very early in the morning till $10 \mathrm{a} . \mathrm{m}$. and afterwards leave it to the international tourists and workers. Although the opening hours of the market area are prolonged (now open from 5:30 in the morning till 00:30 at night), the visiting hours of locals have been compressed and the available products have been changed to respond to the demands of international tourists. As a result, vendors are still vendors but their products and customer portfolio have changed over time, and their reactions are not always reflective to these changes.

\subsection{Discussion}

The findings of this study empirically follow Lau (2004) and Elder-Vass (2007) who operationalize habitus as a practical sense emerging from experience. The study demonstrates how major and minor changes in individual life trajectories and in social structure determine habitus adap- 
tation. Acknowledging major and minor changes are context dependent: individuals may perceive the same change either as a major or minor change depending on the context in which they experience the change. Our analysis discloses how habitus is influenced by informal entrepreneur' original conditions (e.g. family upbringings, history, culture, social class) and how these individuals construct habitus through perception, appreciation and action. In addition, they develop their own understanding of the field in which they operate, which again feeds back into the habitus adaptation. Habitus is thus constructed in a chronological ordering (e.g. gaining experience and skills from the practice in a first job and using it in successive positions) (Bourdieu \& Wacquant, 1992).

The findings demonstrate the ongoing exchange between the individual and the field conditions (Everett, 2002). When the characteristics of the field change (e.g. changes in the infrastructure, new tourism markets, disruptive innovations like AirBnB and Uber), the kinds and proportions of one's capital portfolio change (e.g. increasing economic assets, activating one's social network, increasing cultural capital through gaining foreign language skills), and informal tourism entrepreneurs adapt their habitus accordingly. Habitus is thus constructed through 'practicing', understood in relation to the field and the specific capital portfolio of an entrepreneur.

Further analysis reveals how the different modes of habitus adaptation, which are identified in the research and presented in the findings section, relate to (1) individual and social structural changes, and to (2) major and minor changes. Figure 1 shows how these two axes of change - 'individual and social structural change' and 'major and minor change' - form a matrix in which the four modes can be understood. 
Figure 3: Modes of habitus adaptation as they relate to major and minor changes in individual and social structure

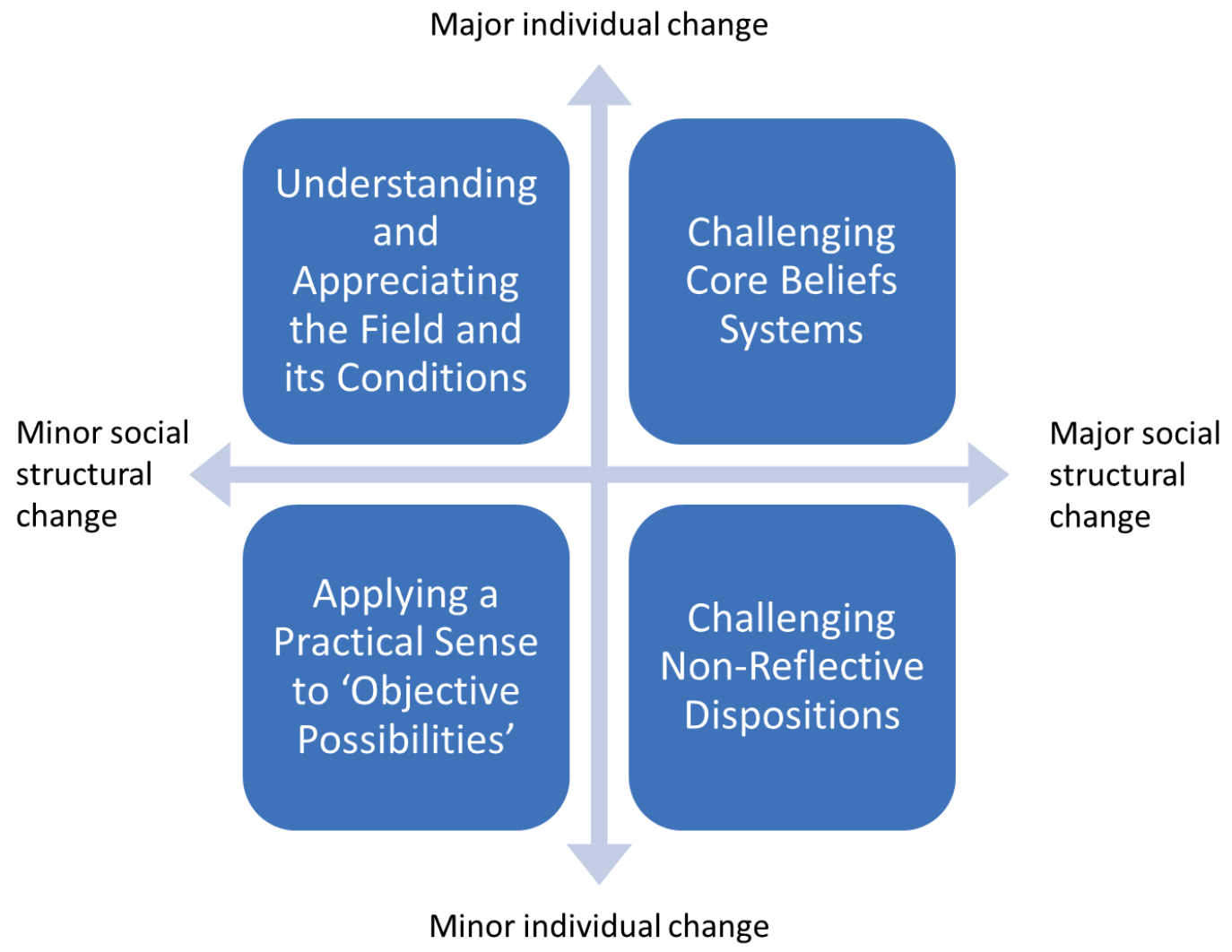

\subsubsection{The Mode of Understanding and Appreciating the Field and its Conditions}

Understanding and appreciation of the field and its conditions reflects a situation where there is a major individual change (e.g. transition to adulthood, emigrating to a new country) and a minor change in the structure (e.g. changes in tourism markets, facilities, governance). Individuals create an understanding and appreciation for the culture of others, for dissimilar roles and forms of communication, for different ideas and behaviours, and at the same time for their own strengths and weaknesses in the field. In this mode individuals become more flexible in adapting to conditions in the field. For instance, Sanda changed her friends and her media consumption in her new home in Koh Phangan. She and her colleagues are continuously attempting to understand their clients' eating habits. The informants in this subgroup become more resilient to major changes in the social structure. For instance, the variety of cultures that exist in the fieldwork locations provides various cues and options to the migrant entrepreneurs to adapt 
their habitus. A constant characteristic of the field is that it is dynamic and new contacts with international tourists push the individual entrepreneurs to negotiate their diasporic habitus continuously.

\subsubsection{The Mode of Challenging Core Beliefs Systems}

Individuals challenge their core belief systems only when they experience a major change in their life trajectories (e.g. losing a loved one, getting married or divorced, becoming a parent) and when at the same time they perceive a major change in the social structure (e.g. a disruptive innovation in the field, political system change, natural disaster, war). A core belief system is about how one perceives oneself and how one perceives other people, the world, and the future. Individuals develop their core belief systems over time, from childhood to being a grandparent, and through significant life events or particular life trajectories. Core belief systems present one's state of mind and are quite resistant to change. Individuals intend to change their core belief systems when major individual changes take place in parallel with major system changes. For instance, Lek did not participate in the household decision making process until she became successful in her business. In another example, Apinya did not comment on her given place in her family and community until she moved to Koh Samui and later got married to a foreigner. In all the narratives, the informants fundamentally intend to modify their perspectives on themselves and on the structure.

\subsubsection{The Mode of Applying a Practical Sense to 'Objective Possibilities'}

Applying a practical sense to 'objective possibilities' happens when individuals experience individual changes as well as social structural changes as minor. Past experiences and tendencies remain dominant and guide the entrepreneurs in how to think and act as they have always done. For this group of individuals, it is practice as usual. This group of individuals brings limits to their practice and social mobility, petrify social limits and deny themselves more deliberate actions (Lau, 2004). They use preconceptions in their encounters and judge new possible experiences in terms of 'that's not for us'. In this mode habitus is least likely to change. 


\subsubsection{The Mode of Challenging Non-Reflective Dispositions}

Individuals challenge their non-reflective dispositions when they perceive a major individual change and a minor change in the social structure. Individuals operating in this mode adapt their habitus almost unconsciously and explain their practice in simple statements like 'I did ...' instead of 'when others behaved in a certain manner, I did ...'. Their actions do not entail reflection and happen on their own, like scratching a part of the body when one has an itch. However, the group which challenges their non-reflective dispositions is aware of the major changes in the social structure and the minor individual changes but prefers not to reflect on these changes. They perceive these changes as random or infrequent.

\subsection{Conclusions}

Understanding informal entrepreneurs' habitus adaptations will help us to comprehend their present and future practices including their mental and corporeal schemata of perceptions, appreciations, and actions (Bourdieu \& Wacquant, 1992). To account for habitus adaptation, it is necessary to apply an individual perspective as well as a social structural perspective. This assures that a change in habitus will not only be interpreted as a result of changes in social structure, but will also reveal that the entrepreneurs' emotional dispositions will also play an essential role in explaining their actions and behaviours. This is in line with what Leys (2011) has argued. Informal entrepreneurs adapt their habitus based on their interpretations of individual and social structural changes and again relate these adaptations to changes in the field in which they operate. Their original individual conditions (e.g. family wealth, social class, culture) kind of form a foundation for habitus adaptation. Habitus adaptation (changes in perceptions, appreciations and actions) in its turn is then dependent on the practices of informal entrepreneurs as they relate to fields and capitals (Practice $=[$ (Habitus) x (Capital) ] + Field) (Bourdieu, 1990, p.101).

Our study demonstrates that there is an ongoing exchange between informal entrepreneurs and the conditions of the tourism destinations in which they live their daily lives. The changes taking place through disruptive innovations, globalization and increasing competition influences informal entrepreneurs' habitus adaptation and the deployment of their capital portfolio. 
It is concluded that major individual changes - in combination with respectively minor and major changes in the social structure - contribute, on the one hand to an understanding and appreciation of the field and its conditions, but on the other hand to challenging radical belief systems. It is also concluded that minor individual changes - in combination with respectively minor and major changes in the social structure - tend to accompany applying a practical sense to 'objective' possibilities and to challenging non-reflective dispositions.

This study responds to the call for empirical examination of habitus by combining an individual and a social structural approach (Aarseth et al., 2016; Green, 2008). It fills a gap in tourism studies by empirically unpacking the habitus of informal entrepreneurs. The identified matrix of major and minor individual and social structural changes offers scope for further research to be directed towards understanding the modes in which other tourism stakeholders (e.g. formal tourism entrepreneurs) adapt their habitus.

In the public domain, public agents and policy makers (at any level of government) can benefit from a habitus analysis in predicting stakeholders' willingness to change and adapt their habitus considering changes taking place. Government policies may shift for instance to explicitly addressing existing belief systems as these are identified as connected to major changes. Entrepreneurs who adapt their habitus quickly and adjust their practices to the changes in the field may detect the gaps and seize the opportunities offered to them in changing markets. 


\section{Chapter 5}

\section{Measuring the Size of the Informal Tourism Economy in Thailand}

\section{Erdinç Çakmak ${ }^{\mathrm{ab}}$, M. Alper Çenesiz}

${ }^{a}$ Breda University of Applied Sciences, the Netherlands

${ }^{b}$ Faculdade de Economia, Universidade do Porto, Portugal

(The article presented in this chapter is currently being revised for the first review in International Journal of Tourism Research.) 


\section{Abstract}

This study is the first to estimate the size of the informal tourism economy. Using a dynamic general equilibrium model, this paper first estimates the size of the informal tourism economy and then assesses its linkages to key labour market variables in Thailand. Empirical results indicate that: i) the informal tourism economy grows faster than the formal tourism and aggregate economy; ii) both formal and informal tourism economies absorb the unemployed; iii) the relationship between formal and informal economies is negative in the aggregate but positive in the tourism sector.

\section{Keywords}

Informal economy, shadow economy, informal tourism economy, size, trends, labour market, vulnerable employment, gender gap, Thailand 


\subsection{Introduction}

Worldwide more than 2 billion people earn their livelihoods in the informal economy and $47 \%$ of those working in the service sector have informal employment (ILO, 2018). Despite the debates and critiques about the informal economy, several studies continued to attest the role of informal entrepreneurs in tourism and travel sector. Albeit they do not register their activities officially to avoid taxes and regulation (Webb, Bruton, Tihanyi \& Ireland, 2013), they create jobs (Webb, Tihanyi, Ireland \& Sirmon, 2009), support and teach skills to one another (Damayanti, Scott \& Ruhanen, 2017), and fill out the product and service gaps in the formal tourism sector (Çakmak, Lie \& Selwyn, 2019). This renewed interest in informal tourism economy stems from the fact that it can provide deeper and detailed information necessary - for instance - in designing effective policies, depicting national employment trends, monitoring informality conditions, and analysing linkages between entrepreneurship and economic growth. Yet little is known about the contribution of the informal tourism economy to the national economy in aggregate and until today there is no study estimated its size (Kedir, Williams \& Altınay, 2018).

The goal of this article is to estimate the size of the informal tourism economy and to reveal the dynamic interplay between the informal tourism economy and the labour market in Thailand. To this end, this paper seeks answers to two interrelated questions. First, what is the relationship between the informal tourism economy and the national economy in aggregate and how they behave during the economic and political up- and downturns? Secondly, how do developments in the size of the informal tourism economy relate to (un)employment, labour force participation, self-employed in the service sector and gender?

This paper contributes to the tourism literature because it is the first to estimate the size of the informal tourism economy and empirically study informal and formal tourism economies' influence on several features of the labour market rather than only focussing on impacts of formal sectors. The informal economy is a permanent and basic component of the total economy, and without knowing the size of the informal tourism economy; it is hardly possible to calculate the total contribution of tourism sector to the national economy. This study's practical importance lies in providing tourism professionals and policy-makers information about labour mobility and gender gap issues in 
the labour market. Such information enables them to reconsider models and prescriptions of the national policies on tourism entrepreneurship and employment. Because the formal and informal tourism economies are dynamically linked to each other and many enterprises from both sides have production and distribution relations (e.g. sub-contracting arrangements), consequently they influence the labour mobility and gender gap in the labour market.

In estimating the size of the informal economy, this paper employs a deterministic two-sector (formal and informal) dynamic general equilibrium model that is applied to Thailand. Being the second largest economy in Southeast Asia, Thailand hosts more than 3 million international migrants and nearly half of these are undocumented and work as informal workers and entrepreneurs throughout the country (Chanwanpen, 2018). In addition, tourism is a fast growing sector and a key to the Thai national economy in creating jobs, decreasing unemployment and providing foreign exchange (Hawkins \& Mann, 2007; Pongajarn, 2017). Though, this study focuses on Thailand, inevitably the used method can easily be applied to other countries as well in order to estimate the size of the informal tourism economy and its role in their labour markets. The paper is structured as follows: first the informal economy in the developing world with relation to the tourism informal economy and labour is reviewed. Next, a contextual study is conducted about the tourism development and dynamics in Thailand. After that the informal economy theory and the estimation methods are reviewed -based on this review- a justification of preferred method is determined. This section is followed by explanation of the models used to estimate the size of the informal tourism economy and benchmarked to the models used in the previous research. Finally, based on the findings from the empirical study, theoretical and practical implications about the size of the informal tourism economy and how it relates to the general economy are provided.

\subsection{Literature Review}

\subsubsection{Informal Economy in the Developing World}

There is a plethora of terms used to describe informal economy such as "undeclared", "black", "shadow", "off-the-books", "hidden", "moonlighting" economy (Williams, 2005). The informal economy includes legal market activities done by firms, workers, enterprises, which are not registered or 
kept hidden to the public authorities for tax, social security and labour law purposes (European Commission, 2007; OECD, 2012; Williams, 2017). In particular, informality is an essential phenomenon in the daily lives of people - especially - in the global South and has received considerable attention from scholars in the last four decades (Perkins, Radelet, Lindauer \& Block, 2012). A voluminous literature from different disciplines exists on the economic, sociological, institutional, and ethnographic aspects of the informal economy (De Soto, 2002; Djankov, Glaeser, La Porta, Lopezde-Silanes \& Shleifer, 2003; Williams, 2008) with a recent few studies in management, which explore the dynamics in informal economy (Godfrey, 2011). Yet, relatively little knowledge exists about the processes underlying value creation and economic dynamism in the informal economy sectors (Estrin \& Mickiewicz, 2012). The reason for the broad interest of policymakers and researchers in the informal economy is its enormous capability in absorbing unemployment and providing jobs: more than $60 \%$ of global workforce aged 15 and over are employed in the informal economy (ILO, 2018). Contrary to the modernization theory, which views the informal economy as a historical legacy that is expected to rapidly disappear with the advent of the modern formal economy (Geertz, 1963; Gilbert, 1998), there is ample evidence of the reality of informal economy that is a fundamental component of developing economies. Examining only the formal economy, therefore, provides only a very partial representation of the nature of economies and labour markets (Williams \& Horodnic, 2018).

Given the importance of the informal economy, there is considerable heterogeneity of its share in countries' gross domestic products (GDP) across regions. For instance, the weighted average size of the informal economy in official GDPs reaches $13.4 \%$ in high-income OECD countries, much higher in Central Asia with a 36.4\%, and in Sub-Saharan Africa with a 37.6\% (Schneider \& Enste, 2013). Some scholars see the informal economy in negative terms due to its negative effects on public finance such as decreasing tax revenues and the provision of public services (De Paula \& Scheinkman, 2007; Levy, 2010). Some others see it in positive terms as the informal economy boosts entrepreneurial talents, provides income for the poor, and promotes flexible labour market initiative during economic downturns (Biggs, Hall \& Stoeckl, 2012; Jones, Mondar \& Edwards, 2006).

In terms of distribution by sectors, agriculture represents almost half of the informal economy in most part of the world, while manufacturing, 
construction, and services account for the other half, specifically service sector represents around $47 \%$ in the Asia (ILO, 2018). Although the South East Asia experienced robust economic growth in the past decade, the share of informal economic activity in GDPs remained persistently high (Ahlstrom \& Ding, 2014). One of the key drivers why informal enterprises have dominated the Asia is the poverty of owners (Young, Ahlstrom, Bruton $\&$ Rubanik, 2011). In Asia and the Pacific region informal entrepreneurship is particularly important to poverty alleviation because of nearly 1.3 billion people live in extreme poverty (defined as a daily income of less than US\$1.25) in these areas (Wan \& Sebastian, 2011).

Despite the vast quantity of research examining the size of the informal economy in aggregate over the last decade, our understanding of country level dynamics is still deficient, mainly because of the dearth of datasets tracking informal economic activities across countries. Another important challenge in measuring the size of the informal economy is the harmonization of concepts at international level. This makes difficult to make systematic and comprehensive comparisons worldwide about the development of informal economy sectors across countries.

\subsubsection{Informal Tourism Economy and Labour}

The informal tourism economy includes all the market activities of agents and businesses engaging with tourism industry directly or indirectly, but often these activities are not registered by the authorities, formal associations or trade organizations (Slocum, Backman \& Robinson, 2011). In most cases, the agents of informal tourism economy consist of street vendors, unofficial tour guides, own account transport providers, handicraft producers, artisans, providers of homestays, holders of food stalls, musicians and dance troupes. Their activities are generally beyond the effective control of authorities (Crick, 1992) but the local community benefits the income from these activities, especially during an economic crisis (Brata, 2010; Cukier, 2002; Dahles \& Prabawa, 2013).

Oppermann (1993) distinguishes the informal tourism economy from its formal counter one through its high integration into the local economic structure that leads to a low leakage and therefore resulting higher multiplier effect on the local economy. Yet, the informal tourism commerce relies more on formal tourism businesses' customers and increases the latter's offers 
through boosting novelty and vibrancy (Henderson \& Smith, 2009). Arguably, tensions exist and the formal economy is considered the dominant party that is protected and supported by government's tourism policy, while the informal economy is subject to rules and regulations in order to assure effective functioning of formal businesses (Meyer, 2006; Wahnschaft, 1982).

It is evident that tourism represents an important sector for many developing countries in their search to reduce poverty and has a strong positive correlation with economic growth (Antonakakis, Dragouni \& Filis, 2015; Tang \& Tan, 2015). Sinclair (1998) suggested that an increase in tourism revenues has significant impacts on developing countries' economies. However, not every tourism destination can experience positive economic impacts such as less leakages and higher tourism competitiveness unless its state moves towards more democratic regime (Antonakakis et al., 2015). In addition, formalising the informal enterprises is not a straightforward intervention for the developing countries' governments. For instance, Slocum et al. (2011) argued that the contemporary policy agendas to formalise the informal economy are negating the economic benefits of tourism development, which were intended to bring growth and prosperity to Tanzania.

Recent research in tourism studies concerning the informal economy focuses on new issues and approaches such as the resilience of informal tourism enterprises to natural disasters (Biggs et al., 2012), street vendors' contribution to tourism development (Yotsumoto, 2013), tourism financing systems and networks (Nogoasong \& Kimbu, 2016), coopetition among the informal tourism service providers (Damayanti et al., 2017), informal women entrepreneurs' role in ethnic tourism (Trupp and Sunanta, 2017), street vendors' perspective towards tourism and poverty alleviation (Truong, 2018), informal business tourism (Rogerson, 2018), and the tales of informal tourism enterprises (Pécot, Gavilanes \& De Viteri, 2018). Given the importance of entrepreneurship for the welfare of a local community in general and for tourism stakeholders in the informal tourism economy in particular, two very recent articles (Çakmak et al. 2019, Çakmak, Lie \& McCabe 2018) examined informal tourism entrepreneurs' capital possession and how tourism stakeholders use these forms of capital in determining their position in tourism field and beyond. Thus far, still, there has been little systematic research into how the informal tourism economy grows and links to national economy in aggregate and the labour market. 


\subsubsection{The Thai Tourism Sector and Dynamics of the Informality}

Thailand is one of the "top ten" tourist destination in the world rankings with 35 million international arrivals (Tourism Authority of Thailand, 2018). A recent study argues that the number of international visitors will record 79 million by 2030 and Thailand will become the fifth biggest tourist destination in the world (Euromonitor International, 2018). The country's geographical position and relatively developed infrastructure in comparison to its neighbours make Thailand an important tourism hub in the mainland Southeast Asia. Tourism is one of the main economic sectors in the country with a 54 billion USD turnover in 2017 and accounts for 6\% of its GDP (Department of Tourism Thailand, 2018). In the last two decades, the tourism sector experienced a five-fold increase in international arrivals from 7 million in 1997 to 35 million in 2017 despite a number of regional and global crises such as the 1997 Asian economic crisis, 9/11 attacks in 2001, the outbreak of contagious diseases in 2003, Indian ocean earthquake and tsunami in 2004, and several riots and political uncertainty including coups. However, the Thai tourism industry has shown high resilience and recovered much faster from a crisis than its neighbouring countries (Beirman, 2016).

The Thai tourism industry is also an important job provider and generated 6 million jobs in 2018 and was responsible for 15,9\% employment nationwide (World Travel and Tourism Council, 2019). Both directly related businesses (e.g., hotels, airlines, tour operators, airports and so on) and indirectly related businesses (e.g., restaurants, souvenir shops and laundries, which supply products and services to the travel and tourism industry) generate jobs in the informal and formal tourism markets.

Informal economy in Thailand encompasses many sectors, including tourism, agriculture, construction, manufacturing, transportation, retail and services. The relatively fast economic growth in Thailand in the region, in particular in the tourism sector, induced the migration from rural areas and from neighbour countries to major Thai cities (De Jong, 2000). As a result, the number of informal entrepreneurs and workers at tourism destinations is consistently increasing with the growth of tourism in Thailand. This growth urged national and local authorities to design several policies to control the process and activities of informal tourism actors. For instance, street vending is not legal in Thailand unless there is a permission granted by authorized local officers (Tangworamongkon, 2014). Arguably, in many 
cases, street vendors claimed that they do not receive any formal receipt for the payment of their vending related fees, or they pay a monthly bribe to local inspectors to operate outside of the designated areas (Tangworamongkon, 2014). All in all, to date, there is no estimate of the size of the informal tourism economy in Thailand.

\subsubsection{The Informal Economy Theory and Measuring its Size}

Researchers have used three prominent methods to estimate the size of the informal economy, namely, direct, indirect, and latent-variables approaches (Schneider \& Enste, 2000). The direct approach basically uses surveys and tax auditing samples in micro econometric estimations of the size of the informal economy (Isachsen \& Strøm, 1985, Pedersen, 2003). The in-detail use of information on the informal economy is an advantage. But the direct approach method is costly (due to implementing surveys) and associated with endogeneity problems (due to measurement errors, selection bias and simultaneity), and does not render a dynamic analysis possible.

The indirect approach uses economic indicators - supposed to contain information about the informal economy - such as the gap between national expenditure and income, the gap between official and actual labour force, the demand for electricity, and the demand for currency (Schneider \& Enste, 2013).

The fundamental critique to the direct and indirect approaches is the assumption, implicit in both methods, that the determinants of the informal economy are unique. To overcome this critique, the latent-variables approach assumes that there are multiple-indicators and multiple-causes, hence the name MIMIC model. The MIMIC model uses a structural econometric model to establish the causes and the effects of the informal economy. This approach, however, lacks a theoretical basis for the inclusion of the indicators as causes and robustness to data transformations, to the units of measurement and to the sample used. To rectify these weaknesses Solomon (2011) uses a dynamic general equilibrium model as a theoretical basis identifying the causes and indicators in estimating the size of the informal economy. The method of Orsi, Raggi \& Turino (2014) and Solis-Garcia \& Xie (2018) relies in this vein. In estimating the size of the informal GDP in Thailand, this study follows the approach of Orsi et al. (2014) and Solis-Garcia \& Xie (2018). Although, this study uses a similar estimation method, yet, neither 
Orsi et al. (2014) nor Solis-Garcia \& Xie (2018) provide an estimation of the size of informal economy in Thailand. For comparison purposes, this study adds also the widely used Schneider, Buehn \& Montenegro (2010) estimate for Thailand and assesses the model's performance.

\subsection{Methods}

\subsubsection{Model}

The model in this study builds on Ihrig \& Moe's (2004) model, thus, its exposition is rather brief. The economy consists of a representative yeoman (consumer-producer) and a government. The government taxes formal production at a rate of $\tau_{t}$ and uses its tax revenue to finance its spending, $g_{t}$. Government spending is of no use to the yeoman. The production technology in the formal sector is given by $y_{f, t}=a_{f, t} k_{t}^{\alpha} l_{f, t}-\alpha$, where $y_{f, t}$ is the formal GDP, $a_{f, t}$ is total factor productivity in the formal sector, $k_{t}$ is the stock of capital, $l_{f, t}$ is hours-worked in the formal sector, and $\alpha$ is the share of capital in the formal GDP. Balanced government budget requires

$$
\tau_{t}=\frac{g_{t}}{y_{f, t}}
$$

The production technology in the informal sector is given by $y_{i, t}=a_{i, t} l_{i, t}^{\gamma}$ , where $y_{i, t}$ is the informal output, $a_{i, t}$ is total factor productivity in the informal sector, $l_{i, t}$ is the hours worked in the informal sector and $\gamma$ measures returns to scale.

The yeoman chooses consumption, $c_{t}$, the stock of capital to be employed in the next period, $k_{t+1}$, hours-worked in the formal sector, $l_{f, t}$ and in the informal sector, $l_{i, t}$ to maximize her utility

subject to

$$
\sum_{t=0}^{\infty} \beta^{t} \log c_{t}
$$

$c_{t}+k_{t+1} \leq\left(1-\tau_{t}\right) a_{f, t} k_{t}^{\alpha} l_{f, t}^{1-\alpha}+\left(1-\rho_{t}\right) a_{i, t} t_{\mathrm{i}, \mathrm{t}}^{\gamma}+(1-\delta) k_{t}$,

$l_{f, t}+l_{i, t} \leq T$, 
where $\beta$ is the discount factor, $\delta$ is the depreciation rate of capital stock, $T$ is the total time devoted to work, and $\rho_{t}$ is the probability of being caught by the tax authority. The term $\rho_{t}$ can also be thought as the indirect taxes to be paid by informal actors when being caught by the authorities. The first order conditions with respect to $l_{f, t}$ and $l_{i, t}$ can be arranged to obtain

$$
\left(1-\tau_{t}\right)(1-\alpha) a_{f, t} k_{t}^{\alpha} l_{f, t}^{-\alpha}=\left(1-\rho_{t}\right) \gamma a_{i, t} l_{i, t}^{\gamma-1}
$$

Equation (4) implies that in equilibrium, marginal product of formal labour equals that of informal labour. It is straightforward to show that the steady state size of informal sector increases when the tax rate in the formal sector $(\tau)$ rises or when the enforcement in the informal sector $(\rho)$ decreases (Ihrig \& Moe, 2004).

\subsubsection{Data}

The estimation data used to estimate the size of informal GDP in Thailand are annual, cover the period 1950-2014 and are retrieved from the Penn World Table (PWT) version 9. Researchers use PWT as a standard source of data on real GDP across countries for over four decades (Feenstra, Inklaar $\&$ Timmer, 2015). Table 6 lists some details of the PWT data used.

Table 6: PWT Data: variables, acronyms, range

\begin{tabular}{llll}
\hline Variable & Acronym & Database & Range \\
\hline Average hours worked & $a v h$ & PWT & $1950-2014$ \\
Capital & $r k n a$ & PWT & $1950-2014$ \\
Consumption & rconna & PWT & $1950-2014$ \\
Depreciation rate & delta & PWT & 1999 \\
Employment & emp & PWT & $1950-2014$ \\
Labour share & labsh & PWT & $1950-2014$ \\
Share of government consumption & chs_g & PWT & $1950-2014$ \\
Total factor productivity & rtfpna & PWT & $1950-2014$ \\
\hline
\end{tabular}

Note: Only the 1999 value of the depreciation rate is needed in the estimation.

The estimation data set also includes variables from the World Development Indicators (WDI) compiled by the World Bank. WDI provides more than 1.600 indicators for 217 national economies worldwide, with time series including 50 years and more. Table 7 lists the employment and tourism related variables from the WDI data used in the analysis. 
Table 7: WDI Data: variables, acronyms, range

\begin{tabular}{|c|c|c|c|}
\hline Variable & Acronym & Database & Range \\
\hline $\begin{array}{l}\text { Employment in services, female } \\
\text { (\% of female employment) }\end{array}$ & SL.SRV.EMPL.FE.ZS & WDI & $1971-2014$ \\
\hline $\begin{array}{l}\text { Employment in services, male } \\
\text { ( } \% \text { of male employment) }\end{array}$ & SL.SRV.EMPL.MA.ZS & WDI & $1971-2014$ \\
\hline $\begin{array}{l}\text { Employment in services } \\
\text { (\% of total employment) }\end{array}$ & SL.SRV.EMPL.ZS & WDI & $1971-2014$ \\
\hline GDP & NY.GDP.MKTP.CD & WDI & 1975-2014 \\
\hline $\begin{array}{l}\text { Labour force participation rate, female } \\
(\% \text { of female population ages } 15+)\end{array}$ & SL.TLF.CACT.FE.NE.ZS & WDI & 1978-2014 \\
\hline $\begin{array}{l}\text { Labour force participation rate, male } \\
\text { (\% of male population ages } 15+\text { ) }\end{array}$ & SL.TLF.CACT.MA.NE.ZS & WDI & 1978-2014 \\
\hline $\begin{array}{l}\text { Labour force participation rate, total } \\
\text { (\% of total population ages } 15+)\end{array}$ & SL.TLF.CACT.NE.ZS & WDI & 1978-2014 \\
\hline $\begin{array}{l}\text { Ratio of female to male labour } \\
\text { force participation rate }\end{array}$ & SL.TLF.TOTL.FE.ZS & WDI & 1978-2014 \\
\hline Service exports & BX.GSR.NFSV.CD & WDI & $1975-2014$ \\
\hline Travel services (\% of service exports) & BX.GSR.TRVL.ZS & WDI & $1975-2014$ \\
\hline $\begin{array}{l}\text { Unemployment, female } \\
\text { (\% of female labour force) }\end{array}$ & SL.UEM.TOTL.FE.NE.ZS & WDI & $1975-2014$ \\
\hline $\begin{array}{l}\text { Unemployment, male } \\
\text { (\% of female labour force) }\end{array}$ & SL.UEM.TOTL.MA.NE.ZS & WDI & $1975-2014$ \\
\hline $\begin{array}{l}\text { Unemployment, total } \\
\text { (\% of total labour force) }\end{array}$ & SL.UEM.TOTL.NE.ZS & WDI & $1975-2014$ \\
\hline $\begin{array}{l}\text { Unemployment, youth female } \\
\text { (\% of female labour force ages 15-24) }\end{array}$ & SL.UEM.1524.FE.NE.ZS & WDI & 1976-2014 \\
\hline $\begin{array}{l}\text { Unemployment, youth male } \\
\text { (\% of male labour force ages 15-24) }\end{array}$ & SL.UEM.1524.MA.NE.ZS & WDI & 1976-2014 \\
\hline $\begin{array}{l}\text { Unemployment, youth total } \\
\text { (\% of total labour force ages 15-24) }\end{array}$ & SL.UEM.1524.NE.ZS & WDI & 1976-2014 \\
\hline $\begin{array}{l}\text { Vulnerable employment, female } \\
\text { (\% of female employment) }\end{array}$ & SL.EMP.VULN.FE.ZS & WDI & $1987-2014$ \\
\hline $\begin{array}{l}\text { Vulnerable employment, female } \\
\text { (\% of female employment) }\end{array}$ & SL.EMP.VULN.MA.ZS & WDI & $1987-2014$ \\
\hline $\begin{array}{l}\text { Vulnerable employment, female } \\
\text { (\% of total employment) }\end{array}$ & SL.EMP.VULN.ZS & WDI & $1987-2014$ \\
\hline $\begin{array}{l}\text { Wage and salaried workers, male } \\
\text { (\% of male employment) }\end{array}$ & SL.EMP.WORK.FE.ZS & WDI & $1987-2014$ \\
\hline $\begin{array}{l}\text { Wage and salaried workers, male } \\
\text { (\% of male employment) }\end{array}$ & SL.EMP.WORK.MA.ZS & WDI & $1987-2014$ \\
\hline $\begin{array}{l}\text { Wage and salaried workers, total } \\
\text { (\% of total employment) }\end{array}$ & SL.EMP.WORK.ZS & WDI & $1987-2014$ \\
\hline
\end{tabular}

Measurement of the size of informal GDP (economy) and tourism output in Thailand

In the first step, a value of the left-hand side (LHS) of equation (4) is obtained for each year. For taxes, $\tau_{t}$, as equation (1) dictates, the data for the share of government consumption, $g_{t} / y_{f, t}$, are used. For labour share, 
$(1-\alpha)$, the average of labour share in our data, which is 0.43 , is used. For total factor productivity, $a_{f, t}$, and capital stock, $k_{t}$, the ones reported as constant 2011 national prices in our data are used. Formal labour, $l_{f, t}$ is specified as the product of the number of people employed and the average annual hours worked.

Now a time series of the LHS of equation (4) is obtained. It shall be used to generate a time series of informal labour, $l_{i, t}$. On the right hand side (RHS) of equation (4), however, there are three other unknowns in addition to informal labour. Hence, three further assumptions are in order. First, the relative size of informal economy in year 1999 in Thailand is assumed to be the same as that reported in Schneider et al. (2010, p.30), i.e. $y_{i, 1999} / y_{f, 1999}$, is set to $53.4 \%$. Second, following Ihrig \& Moe (2004), the enforcement parameter, $\rho_{t}$, is assumed to be zero in all years. Third, the growth rate of total factor productivity in the informal sector is assumed to be the same as that of capital stock.

In the second step, the 1999 value of the LHS of equation (4) is divided by an arbitrary $\gamma$ to get a value for the term $\left(1-\rho_{1999}\right) a_{i, 1999} \gamma_{i, 1999}^{\gamma-1}$. Then, the budget constraint, equation (2), is used to get a value for $\left(1-\rho_{1999}\right) a_{i, 1999} l_{i, 1999}^{\gamma}$. For the depreciation rate, $\delta$ the value 0.0584 reported in PWT is used. Note that

$$
\frac{\left(1-\rho_{1999}\right) a_{i, 1999} l_{i, 1999}^{\gamma}}{\left(1-\rho_{1999}\right) a_{i, 1999} l_{i, 1999}^{\gamma-1}}=l_{i, 1999 .}
$$

Also recall that $y_{i, 1999}=a_{i, 1999} l_{i, 1999}^{\gamma}=0.534 y_{f, 1999}$ Using the same arbitrary $\gamma$, dividing this last expression by the $l_{i, 1999}^{\gamma}$ gets $a_{i, 1999}$. Using the value for $a_{i, 1999}$ and the growth rate of the total factor productivity in informal economy, a series of $a_{i, t}$ is generated. Then the total factor productivity series along with our arbitrary is fed back to the series generated using the LHS of equation (4) to get

$$
l_{i, t}=\left(\frac{\left(1-\tau_{t}\right)(1-\alpha) a_{f, t} k_{t}^{\alpha} l_{f, t}^{-\alpha}}{\left(1-\rho_{t}\right) \gamma a_{i, t}}\right)^{\frac{1}{\gamma-1}} .
$$

Now both series of $a_{i, t}$ and $l_{i, t}$ are a function of our arbitrary $\gamma$. Setting $\gamma=0.33$ so that for $t=1999$, it implies 


$$
\frac{a_{i, t} l_{i, t}^{\gamma}}{a_{f, t} k_{t}^{\alpha} l_{f, t}^{1-\alpha}}=0.534,
$$

i.e., the relative size of informal economy in 1999 equals to the one reported in Schneider et al. (2010).

\subsubsection{Size of the Formal and Informal Tourism Output}

Having obtained the informal GDP series, the (in)formal tourism output can now be set forth. The data of the formal tourism output (FTO) are available in the World Travel and Tourism Council (WTTC) but only for post-1995 and our analysis ends in 2014 as dictated by the PWT database. Thus, there would be only 20 data points had the available tourism data been used, which, in turn, provide rather limited information for the current analysis. Therefore, an estimate of the share of FTO in the GDP of Thailand is first formed using the WDI database. From the WDI database, the data for the service exports, the share of travel services in service exports, and the GDP are used to get a series of the share of travel-services-exports in the GDP. ${ }^{1}$ Then that share is multiplied with i) the formal GDP series that is used above and ii) the informal GDP series that is generated above. This allows us to obtain a series (as a proxy) for the formal and informal tourism outputs starting in 1974 i.e., to double the length of our tourism data. The implicit assumption in obtaining the series for the informal tourism output (ITO) is that the share of the tourism output in the GDP is the same for the formal and informal tourism.

\subsection{Results}

The upper panel in Figure 4 depicts the evolution of the size the informal GDP relative to the formal GDP (solid line, measured in the left axis) and the formal GDP (dashed line, measured in the right axis). 
Figure 4: Informal versus formal GDP
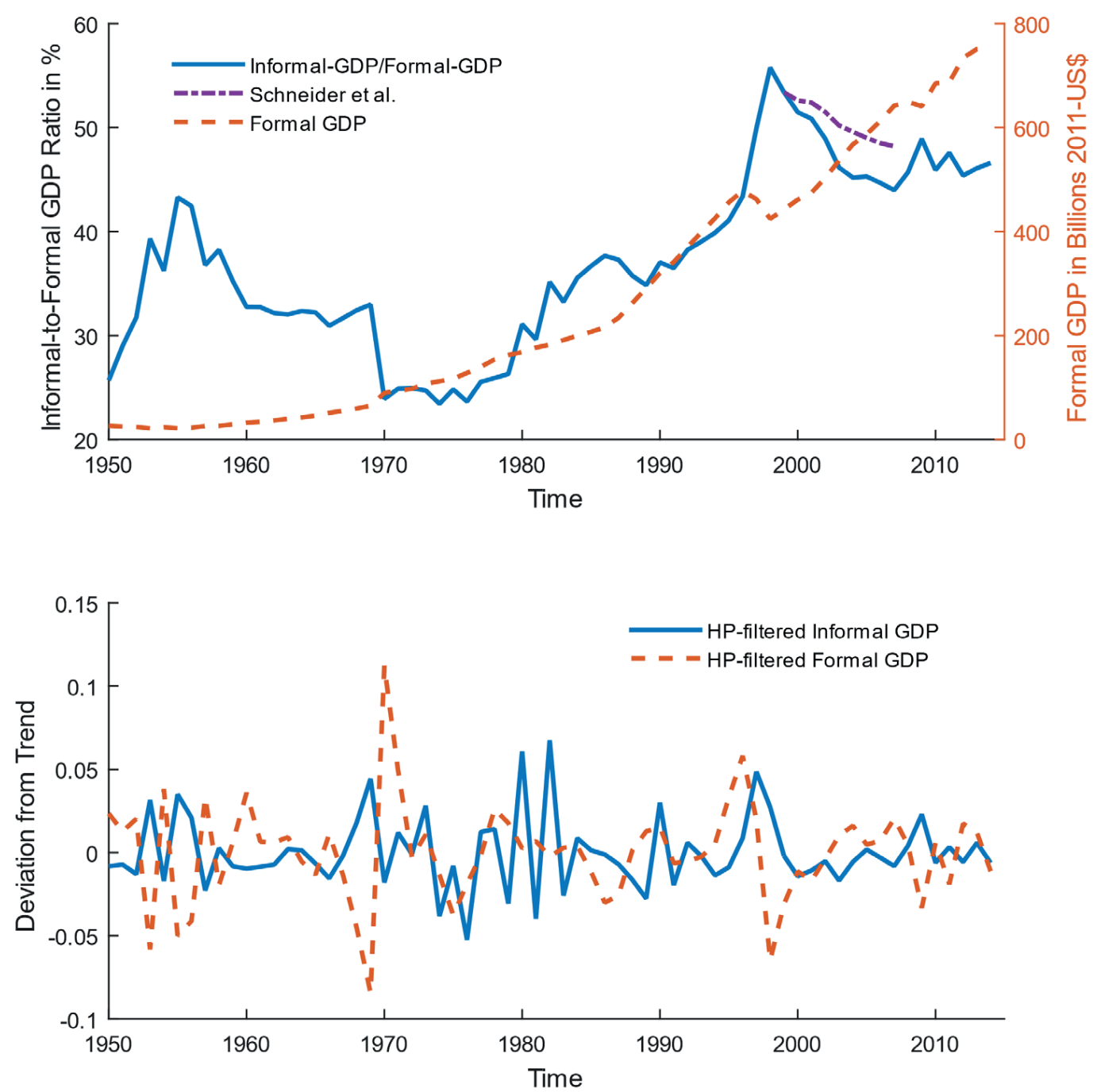

Note: The solid line represents the size of the informal GDP (relative to the formal GDP and measured by left axis and in \% in the upper panel) while the dashed line represents the formal GDP (measured by the right axis and in billions 2011US\$ and at constant 2011 national prices in the upper panel).

It is observed that the relative size of the informal economy reached its lowest point around mid-70's and its highest point in late 90's and overall has an upward trend. Furthermore, in periods when the growth rate of the formal GDP increases, the relative size of the informal GDP starts decreasing. This suggests that when the formal GDP deviates from its trend in one direction, the relative size of the informal GDP deviates from its trend in the other direction.

For comparison, the upper panel in Figure 4 also depicts the relative size of the informal GDP estimated by Schneider et al. (2010) (dotted line, measured in the left axis), which is widely used in the literature of informal 
economies. ${ }^{2}$ Because one parameter in the model, $\gamma$, is set to target the relative size of the informal GDP in 1999 to that reported in Schneider et al. (2010), the two series coincide 1999. The estimated series in our study spans 1950-2014 while that of Schneider et al. (2010) spans only 19992007. The two series between 2000 and 2007 have a correlation coefficient of 0.98 . Both series reveal that the relative size of the informal economy is decreasing between 2000 and 2007. The main difference is that the rate of decrease between 2001 and 2003 is faster in our series than that in Schneider et al. (2010). Importantly, the downward trend appearing series of Schneider et al. (2010) is simply a result of focusing on a short period in time. Interestingly, Solis-Garcia \& Xie (2018) reaches a similar conclusion in their estimation of informal economy in Argentina, Indonesia, Mexico, Turkey, and Vietnam.

The lower panel of Figure 4 depicts the detrended informal and formal GDP series. The detrended series are obtained by employing the HodrickPrescott (HP) filter (Hodrick \& Prescott, 1997) to the natural logarithm of the two GDP series. ${ }^{3}$ For the HP-filter, the smoothing parameter is set to 6.25 as suggested by Ravn \& Uhlig (2002) for data in annual frequencies.

Eyeballing the lower panel of Figure 4 confirms our previous conjecture on the negative relation between formal and informal GDP series. In recessions, the relative size of the informal economy grows and in booms it shrinks. The two series has a correlation coefficient of -0.35 , implying that the relative size of the informal economy is mildly countercyclical.

Next in Figure 5, the evolutions of the informal and formal tourism outputs are depicted, as raw series in the upper panel and as detrended series in lower panel. The fact that in both panels, FTO data compiled in the current study (dashed line) closely matches FTO data compiled by the WTTC (dotted line) verifies the applied methodology in this study. There is some slight difference between the two especially when compared in levels. Notwithstanding this, none of the results reported in this paper do qualitatively change if the WTTC data had been employed. ${ }^{4}$ 
Figure 5: Informal versus formal tourism output
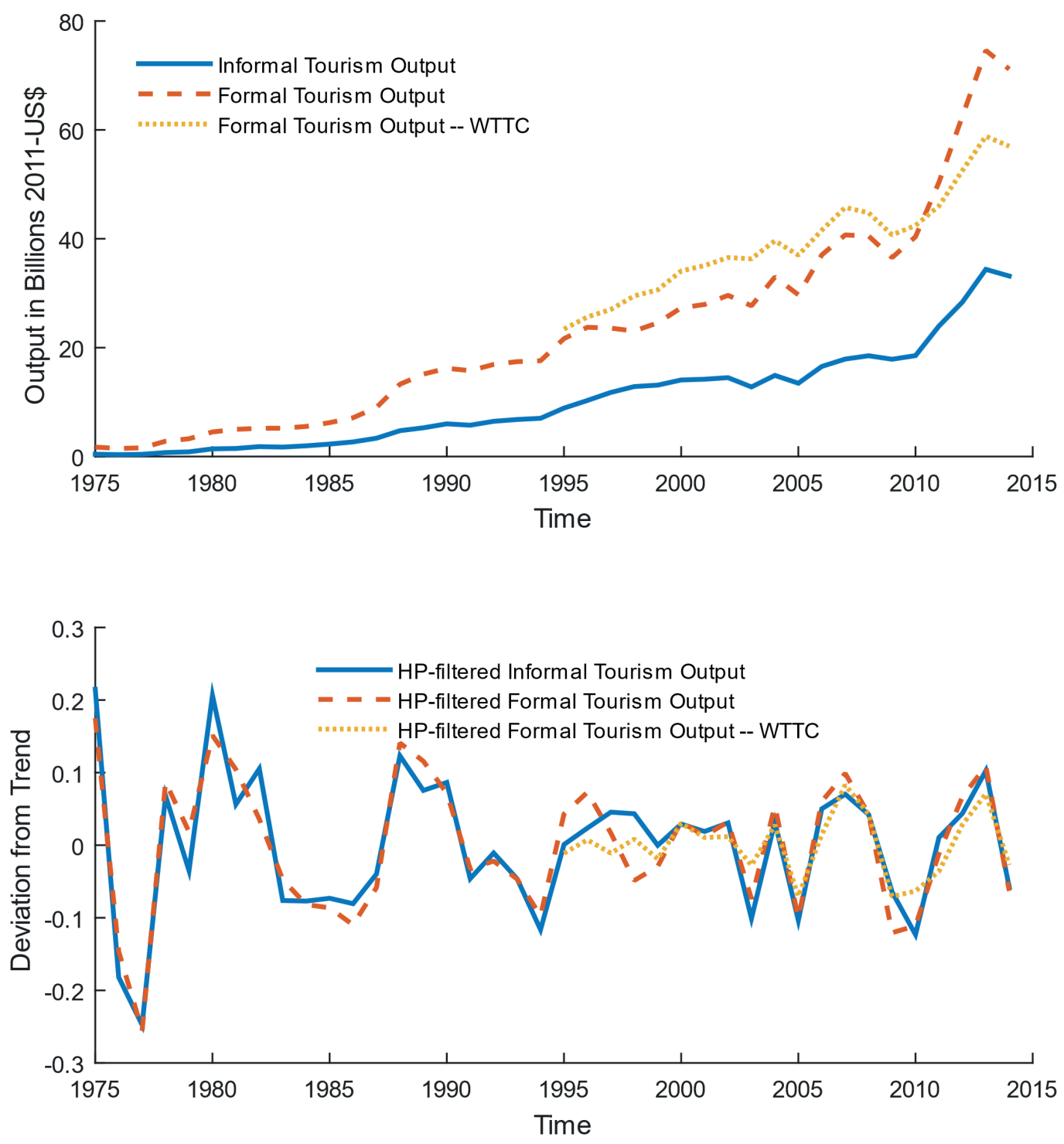

Note: The solid line represents the size of the informal tourism output, the dashed line represents the size formal tourism output, and the dotted line represents the formal tourism output in WTTC database (all in billions 2011US\$ and at constant 2011 national prices in the upper panel).

By looking at the upper panel of Figure 5, one observes that both informal (solid line) and formal tourism outputs steadily increase from 1975 until 2010, after which there is steep increase lasting for three years. The average growth rate of FTO is $11.08 \%$ while that of ITO is $13.08 \%$ between 1975 and 2014. Over the same period, the average growth rates of the formal and informal GDP are $4.96 \%$ and $6.75 \%$, respectively.

In the lower panel of Figure 5, the detrended series of informal and formal tourism outputs move rather in a similar fashion. The informal and formal 
tourism output series between 1975 and 2014 have a correlation coefficient of 0.94 . This strong and positive correlation of informal and formal outputs in tourism sector is in stark contrast to the mildly negative correlation of informal and formal GDPs. This stark contrast, in turn, suggests that the link between informal and formal parts of the economy can be very different across the sectors as compared to the aggregate economy.

Next the link between ITO and a number of important features of employment is analysed. The analysed features are unemployment, youth unemployment, vulnerable employment, labour force participation and the rate of self-employment in the service sector, all across genders as well. The data of these are also retrieved from the WDI.

The panels in the first two rows of Figure 6 show that the general unemployment and youth unemployment rates evolved in a similar way over the 40 years pre-2015 though the youth unemployment rates have been higher than the general unemployment rates.

Figure 6: Informal tourism output versus (un)employment
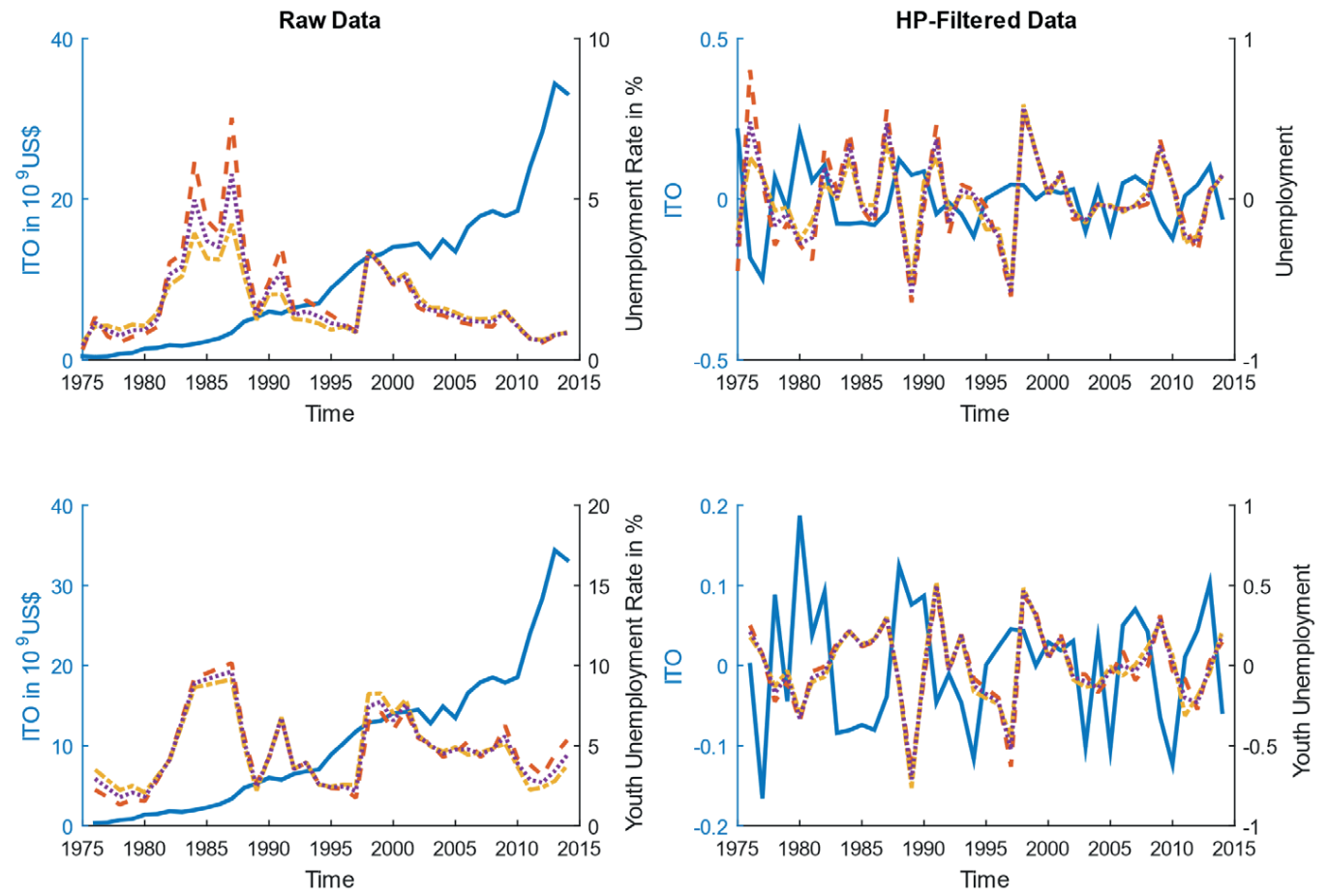

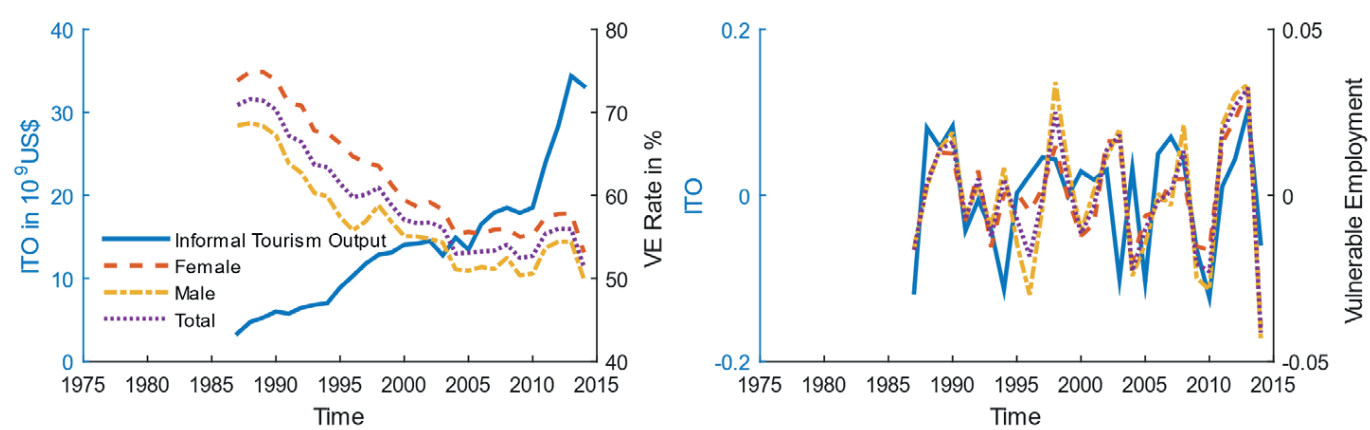

Note: The solid line represents the size of the informal tourism output (left axis in all panels; in billions 2011US\$ at constant 2011 national prices in the panels in the left column). The right axis measures: unemployment in the first row; youth unemployment in the second row; and vulnerable employment in the last row. In all panels, the dashed line represents the corresponding variable for females, the dot-dashed line represents corresponding variable for males, and the dotted line represents the corresponding variable for total.

Both youth and general unemployment rates peaked in 1980's. Male unemployment rates, youth and general, have been higher than female ones. The detrended series reveal that there is a negative correlation between ITO and unemployment rates (both youth and general). This suggests that the informal tourism economy has been absorbing the unemployed people in Thailand.

The panel in the third row left shows that vulnerable employment has been decreasing in a pace similar to that of the increase of ITO in the last 28 years pre-2014. ${ }^{5}$ The vulnerable employment rates are higher for males than females. The relation between detrended ITO and vulnerable employment rates do positively correlate. This implies that the employment generated in the informal tourism economy is a vulnerable one.

As regards the labour force participation (LFP), the upper left panel in Figure 7 shows that the LFP rates have been decreasing over the last 37 years pre-2014 (the decrease is 12.82 percentage-points in females, 8.55 percentage-points for males, and 10.91 percentage points in total). 
Figure 7: Informal tourism output versus labour force participation
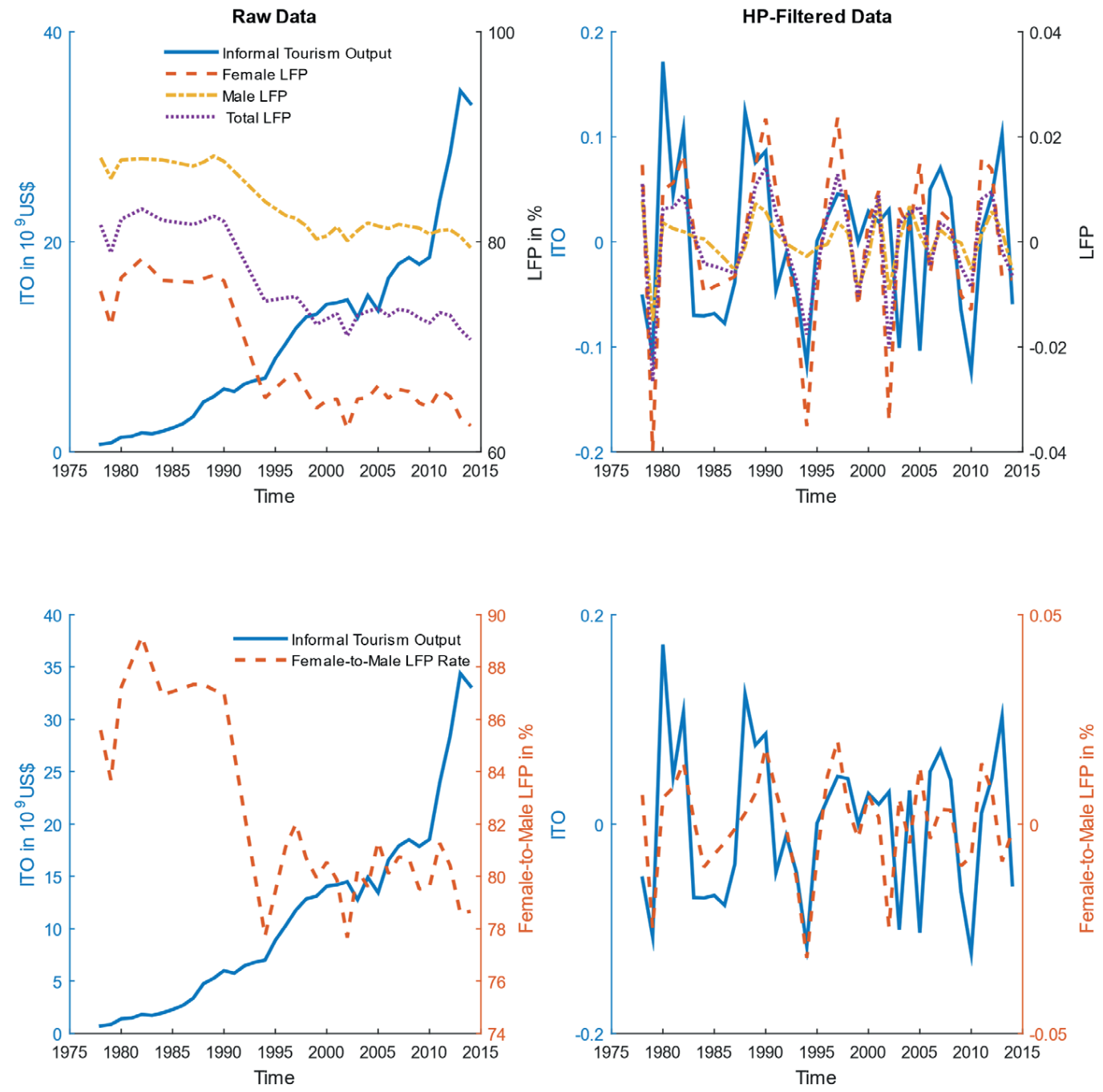

Note: The solid line represents the size of the informal tourism output (left axis in all panels; in billions 2011US\$ at constant 2011 national prices in the panels in the left column). In the upper raw panels, the right axis measures: labour force participation rates of females (dashed line), males (dot-dashed line) and in total (dotted line). In the lower raw panels, the right axis measures the ratio of female-to-male participation rate (dashed line).

Males have been participating more than females in the formal labour market. The upper right panel shows that ITO and the LFP rates positively correlate. Though this is rather difficult to interpret, we believe that a multiplier effect is in play: as ITO and FTO behave very similarly, any development affecting FTO also affects ITO in the same direction.

The lower left panel of Figure 7 shows that the female-to-male LFP rate has been decreasing over the last 37 years pre-2014, implying that the rate of decrease has been higher in female LFP rate than the male LFP rate. The lower right panel shows that ITO and female-to-male LFP rate positively 
correlate, suggesting that informal tourism economy attracts more male workers than female.

Finally, the left panel of Figure 8 shows that the rate of self-employed in the service sector has been increasing in a similar pace as that of ITO over the last 28 years pre-2014.

Figure 8: Informal tourism output versus self-employed in the service sector
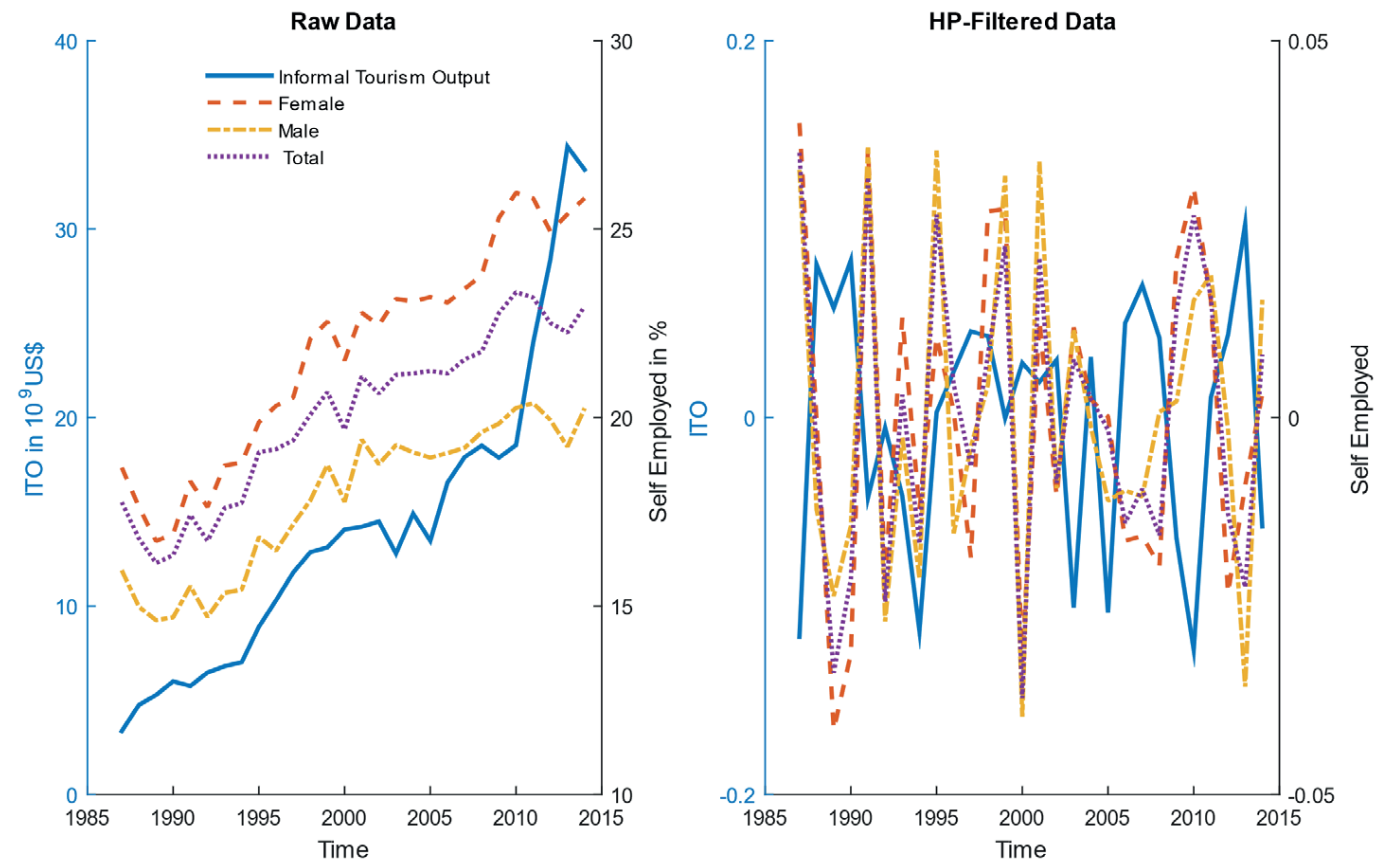

Note: The solid line represents the size of the informal tourism output (left axis in all panels; in billions 2011US\$ at constant 2011 national prices in the panels in the left column). The right axis measures the rate of self-employed people in the service sector. In all panels, the dashed line represents the corresponding variable for females, the dot-dashed line represents corresponding variable for males, and the dotted line represents the corresponding variable for total.

The rate of self-employed is higher for females than for the males. The right panel shows that the rate and ITO negatively correlate, suggesting that self-employed in the formal service sector absorbs the demand that boosts ITO and vice versa.

Table 8 presents the contemporaneous cross-correlations of ITO and FTO with several variables. In a way, the table summarizes the analysis above. The important points that are not detectable in the figures above but in the table are as follows. 
Table 8: Correlations of tourism output

\begin{tabular}{|c|c|c|}
\hline & Informal tourism output & Formal tourism output \\
\hline \multicolumn{3}{|l|}{ Panel A } \\
\hline Formal tourism output & $0.938^{* * *}$ & ----- \\
\hline Informal GDP (\%) & $0.405^{* * *}$ & 0.136 \\
\hline Formal GDP (\%) & 0.112 & $0.364^{* *}$ \\
\hline \multicolumn{3}{|c|}{ Panel B (unemployment) } \\
\hline Female & $-0.452^{* * *}$ & $-0.550^{* * *}$ \\
\hline Male & $-0.349 * *$ & $-0.478^{* * *}$ \\
\hline Total & $-0.409^{* * *}$ & $-0.523^{* * *}$ \\
\hline \multicolumn{3}{|c|}{ Panel C (youth unemployment) } \\
\hline Female & $-0.403^{* *}$ & $-0.521^{* * *}$ \\
\hline Male & $-0.388^{* *}$ & $-0.515^{* * *}$ \\
\hline Total & $-0.402^{* *}$ & $-0.527^{* * *}$ \\
\hline \multicolumn{3}{|c|}{ Panel D (vulnerable employment) } \\
\hline Female & $0.506^{* * *}$ & $0.469^{* *}$ \\
\hline Male & $0.460^{* *}$ & $0.337^{*}$ \\
\hline Total & $0.491^{* * *}$ & $0.400^{* *}$ \\
\hline \multicolumn{3}{|c|}{ Panel E (labour force participation) } \\
\hline Female & $0.464^{* * *}$ & $0.391^{* *}$ \\
\hline Male & $0.414^{* *}$ & $0.378^{* *}$ \\
\hline Female-to-male ratio & $0.431^{* * *}$ & $0.351^{* *}$ \\
\hline Total & $0.475^{* * *}$ & $0.410^{* *}$ \\
\hline \multicolumn{3}{|c|}{ Panel F (self-employed in the service sector) } \\
\hline Female & $-0.554^{* * *}$ & $-0.638^{* * *}$ \\
\hline Male & $-0.391 * *$ & $-0.421^{* *}$ \\
\hline Total & $-0.515^{* * *}$ & $-0.543^{* * *}$ \\
\hline
\end{tabular}

ITO and the formal GDP are not -statistically significantly-correlated. Similarly, FTO and the informal GDP are not -statistically significantlycorrelated. The relation of unemployment rates (general and youth) is stronger with FTO than with ITO. The same also holds for the rate of self employed in the service sector. But the relation of vulnerable employment and that of LFP are stronger with ITO than with FTO. 


\subsection{Conclusions}

Little is known about the informal tourism economy's characteristics in the existing literature and no study has estimated the size of the informal tourism economy (Kedir, Williams \& Altınay, 2018). The present study offers an analysis of 40 years of data on the formal and informal tourism market activities, estimates the size of the informal tourism economy, and presents some historical trends and some major sectorial patterns in Thailand. Research estimating the general size of the informal economy at country level has identified a negative correlation between formal and informal GDPs (Schneider \& Enste, 2010; Solis-Garcia \& Xie, 2018). In other words, when the formal GDP deviates from its trend in one direction, the relative size of the informal GDP deviates from its trend in the other direction. The results of this study support this statement, however, this is not true in the tourism economy: formal and informal tourism outputs move rather in a similar fashion (See lower panel in Figure 2). Both formal and informal parts of tourism economy showed higher growth rates to the "Visit Thailand" promotional campaign year in 1987 and a year after, while both decreased during the SARS outbreak in 2003, after the Asian economic crisis in 1997, and the last coup d'etat took place in Thailand in 2014. Hence, this study reveals that relations between the informal and formal parts of tourism economy are different than in the aggregate economy.

In addition, the empirical results of this study indicate also a significant and positive correlation between the general informal economy and the informal tourism economy. Both show similar reactions to recessions and political instability, while the informal tourism economy is more affected by global crises and regional environmental disasters than the general informal economy.

The argument that the informal economy creates jobs and absorbs unemployed workforce (ILO, 2014; Pongajarn, 2017) is supported by this study. There is a negative correlation between the informal tourism economy and unemployment rates (See panels B and C in Figure 3) that shows the informal tourism economy absorbs unemployed workforce and particularly the female and young unemployed workers. In addition, the informal tourism economy creates jobs primarily for the poor, as it has been noted by Chen (2012), and it correlates positively and significantly with the vulnerable employment. The vulnerable employees include own-account workers, 
their unpaid family members and migrant workers, who have less chance to find a job in the formal labour markets (ILO, 2004).

A recent study shows that the entrepreneurs' percentage to workers in informal employment is much higher in favour for females (ILO, 2018). The results indicate a similar phenomenon. While males participate more as workers in both formal and informal parts in the tourism economy, females prefer more to work as self-employed in the service sector.

The results of this study have significant practical implications. First, the informal tourism economy grows faster than the formal tourism and aggregate economy. Second, both formal and informal tourism economies grow in parallel. Professionals and policy makers ought to shift in focus towards regulating the informal activities and employment in tourism sector separately than the informal economy in aggregate. Policies aiming to reduce the informal tourism activities may reduce the formal tourism output.

The present study offers a first estimation of the size of the informal tourism economy in a developing country. It is limited by the fact that it does not explore all the determinants of the informal tourism economy and its composition. There is a great need to further estimate the size of the informal tourism economy in other countries, and further examine the forces of informal tourism economy that would provide detailed information of process in the informal tourism economy and its relation with the rest of the economy.

\subsection{Endnotes}

1. Note that: export-travel-services/GDP=(export-travel-services/ service-exports) $\mathrm{x}$ (service-exports/GDP).

2. The estimation method of the informal economy applied in the current paper is similar to that in Orsi et al. (2014) and in Solis-Garcia and Xie (2018). Unfortunately, neither Orsi et al. nor Solis-Garcia and Xie provide an estimation for Thailand. We are not aware of any other work besides Schneider et al. (2010) reporting an estimate of the informal economy in Thailand. Hence, we can only contrast our estimation of the informal GDP with the estimation of Schneider et alia. 
3. Instead of HP-filtering the data, the first differences (the growth rates) could also be used. Yet employing the first difference method does not qualitatively alter any of the results reported in this paper. While HP-filtering is the dominant method in the economics literature, the HP-filtering method is opted for here to ease comparability.

4. It is also worth to emphasize that the results reported are mainly derived from detrended series implying that it is the deviations from trend (or the growth rates) that matters in our analysis but not the absolute numbers.

5. The WDI data depicted Figures 3-5 are not uniform; some starts as late as 1987 . 


$$
\text { 告 }
$$




\section{Chapter 6}

Concluding Synthesis and Directions

for Future Research 


\subsection{Introduction}

Understanding the practice of informal tourism entrepreneurs is a complex task in today's highly competitive tourism destinations. This complexity arises due to the dearth of datasets tracking informal economic activities across countries and the harmonisation of concepts at international level. Little is known about the informal tourism economy's characteristics in the existing literature and so far no study has estimated the size of the informal tourism economy (Kedir, Williams \& Altınay, 2018). Contrary to formal entrepreneurs, informal entrepreneurs have limited access to common property resources, and their perspectives have been marginalized and excluded from academic debates and policy initiatives. However, they enter into tourism markets with important skills, qualities, and attributes - in the forms of economic, social, cultural, and dream capitals - which could be utilized more successfully to enable them to contribute to broader economic development initiatives.

This PhD-thesis focuses on how informal tourism entrepreneurs construct their informal tourism sector through their practices. Recent research has advanced our understanding of disruptive innovations in informal tourism accommodation (Guttentag, 2015), coopetition among informal tourism actors (Damayanti, Scott, Ruhanen, 2017), and the resilience of informal tourism entrepreneurs (Biggs, Hall, Stoeckl, 2012). However, no study has departed from Bourdieu's theoretical work on practice and worked with his central concepts (i.e. field, capital, habitus) in order to examine the entire complexity of structural relations in the informal tourism sector. Furthermore, no study has estimated the magnitude of the informal tourism economy with the aim of giving a complete and integrated picture of the practices of informal tourism entrepreneurs. Taking such a social systems perspective on the informal tourism economy, this $\mathrm{PhD}$-thesis investigates how evolving conditions in the tourism field and beyond simultaneously affect the capital deployment and habitus adaptations of informal tourism entrepreneurs and uses the macroeconomic indicators to estimate the size of the informal tourism economy and its relations to the general economy. To this end, this $\mathrm{PhD}$-thesis offers a more complete understanding of the practice of informal tourism entrepreneurs, and the informal tourism economy and its entrepreneurs' contribution to national economies. main research question: How do informal tourism entrepreneurs construct 
their informal tourism economy through their practices? In the second chapter the field relations in the (in)formal tourism system are explored. It investigates the positions of actors (with an emphasis on informal tourism entrepreneurs, and the structural relations in the tourism system. It aims to understand the determination of relevant actors and the nexus of their interconnected relations to informal tourism entrepreneurs. Two research questions are central in this chapter: (a) how do informal tourism entrepreneurs position themselves in the tourism system and (b) which structural field relations exist in the (in)formal tourism system? Further in this chapter the informal entrepreneurs' basic capitals are demonstrated, and their positions mapped out in relation to other dominating stakeholders' positions in the social fields of power, value and culture.

In the third chapter the focus is on the capital deployment strategies of informal entrepreneurs. It seeks to obtain a complete and integrated view of the species and proportions of capital held by the informal tourism entrepreneurs, and answers the research question: Which forms and sizes of capitals do the informal entrepreneurs use and convert at different stages of their enterprises' development processes?

Informal tourism entrepreneurs' capitals are compared to each other to ascertain which types of capital are salient for informal entrepreneurs to survive and how they adopt their capital portfolio at different stages of their enterprises, and through this means influence the structure of the fields.

In the fourth chapter the habitus of informal tourism entrepreneurs is investigated. Here the research question takes the following formulation: How does habitus adapt under the influence of major and minor individual and social structural change? This chapter demonstrates informal tourism entrepreneurs' perceptions of the changes in their individual and social world and their habitus adaptations in response to these changes.

In the fifth chapter the focus is on the economic impact of the informal sector and it is argued that without knowing the size of the informal tourism economy it is scarcely possible to know the total contribution of the tourism sector to the national economy. The following research questions are formulated here: (a) What is the contribution of the informal tourism economy to the national gross domestic product?; (b) how do formal and informal 
tourism economies influence each other?; (c) how does the informal tourism economy react to the economic and political up- and down-turns?; (d) how does the informal tourism economy link to the labour market? This chapter estimates the sizes of both the formal and informal tourism economies, their contributions to general economies, how they influence each other, and evolve over years, and demonstrates, trends, and labour markets in the total Thai tourism economy over the last four decades.

Two methodological approaches are used to provide the overview of practice of informal tourism entrepreneurs, and to estimate the size of the informal tourism economy in Thailand. Chapter 2, 3, and 4 depart from a sociological/anthropological perspective and employ Bourdieu's theory to investigate field, capital and habitus empirically. Chapter 5 departs from a fundamental economic perspective and uses a macroeconomic approach, by generating a data set from three different sources, applying a dynamic general equilibrium model, estimating the size of the informal tourism economy, and demonstrating the dynamic interplay between trends in the (in)formal tourism economy and the labour market.

Next, a summary of the main findings and a is presented, followed by implications for policy makers and research in tourism studies. Finally, several research opportunities are discussed towards the end of this chapter.

\subsection{Overview of main findings}

Altogether these four studies systematically analyse the practices of informal tourism entrepreneurs and the characteristics of the informal tourism economy in Thailand by taking a Bourdieusian perspective. Table 9 lists a summary of the main findings.

Chapter 2 concludes that (a) the informal tourism economy encompasses a range of positions, activities and motivations, rendering it a complex and multi-dimensional field, and informal tourism entrepreneurs positions are not fixed at a certain point in the field. They provide tailor-made products and services to international and domestic tourists at budget prices, decrease formal enterprises' production costs, improve production processes, and importantly provide authentic experiences to tourists; (b) not only an informal tourism entrepreneur but every tourism stakeholder 
Table 9: Summary of the main findings

\begin{tabular}{|c|c|c|c|}
\hline $\begin{array}{c}\text { Field } \\
\text { Chapter } 2\end{array}$ & $\begin{array}{l}\text { Practice } \\
\text { Capital } \\
\text { Chapter } 3\end{array}$ & $\begin{array}{c}\text { Habitus } \\
\text { Chapter } 4\end{array}$ & $\begin{array}{l}\text { The Informal Tourism } \\
\text { System in Thailand } \\
\text { Size, Trends, Labour } \\
\text { Chapter } \mathbf{5}\end{array}$ \\
\hline \multicolumn{4}{|c|}{$\begin{array}{l}\text { The informal tourism economy } \\
\text { encompasses a range of } \\
\text { positions and is a complex and } \\
\text { multi-dimensional field. }\end{array}$} \\
\hline \multicolumn{4}{|c|}{$\begin{array}{l}\text { Collaboration is the sine qua non } \\
\text { for every stakeholder in tourism } \\
\text { related activities. }\end{array}$} \\
\hline \multicolumn{4}{|c|}{$\begin{array}{l}\text { Collaborations between informal } \\
\text { and formal entrepreneurs may } \\
\text { increase the value of existing } \\
\text { capitals in these networks and } \\
\text { bring greater dynamism to the } \\
\text { value chains. }\end{array}$} \\
\hline \multicolumn{4}{|c|}{$\begin{array}{l}\text { The binary distinctions between } \\
\text { formal/informal entrepreneur- } \\
\text { ship represent a false logic. }\end{array}$} \\
\hline \multicolumn{4}{|c|}{$\begin{array}{l}\text { Informal tourism entrepreneurs are more flexible than formal } \\
\text { entrepreneurs in adapting quickly to the changing conditions in } \\
\text { tourism markets. }\end{array}$} \\
\hline & $\begin{array}{l}\text { The capital portfolio of informal } \\
\text { tourism entrepreneurs determine } \\
\text { and structure their contribution } \\
\text { to tourism destinations. }\end{array}$ & & \\
\hline & $\begin{array}{l}\text { From the seed stage to the } \\
\text { growth and scaling stage, dream } \\
\text { capital stock is essential for } \\
\text { informal entrepreneurs. }\end{array}$ & & \\
\hline & & \multicolumn{2}{|l|}{$\begin{array}{l}\text { Habitus is adapted based on } \\
\text { perceptions of the individual } \\
\text { and social changes in their } \\
\text { social field. }\end{array}$} \\
\hline & & \multicolumn{2}{|l|}{$\begin{array}{l}\text { The informal tourism entrepre- } \\
\text { neurs who adapt their habitus } \\
\text { seize the opportunities faster in } \\
\text { the changing markets. }\end{array}$} \\
\hline & & & $\begin{array}{l}\text { A positive and significant } \\
\text { correlation exists between } \\
\text { formal and informal tourism } \\
\text { economies. }\end{array}$ \\
\hline & & & $\begin{array}{l}\text { Both the informal tourism } \\
\text { economy and the general } \\
\text { informal economy grow faster } \\
\text { than their formal } \\
\text { counterparts. }\end{array}$ \\
\hline & & & $\begin{array}{l}\text { The informal tourism economy } \\
\text { is more affected by global crises } \\
\text { and regional environmental } \\
\text { disasters than the general } \\
\text { informal economy. }\end{array}$ \\
\hline & & & $\begin{array}{l}\text { The informal tourism economy } \\
\text { correlates negatively with } \\
\text { the unemployment rates and } \\
\text { positively with vulnerable } \\
\text { employment. }\end{array}$ \\
\hline \multicolumn{4}{|c|}{$\begin{array}{l}\text { Informal tourism entrepreneurs have significant capitals to create jobs, mitigate unemployment, support and teach skills to one another, and } \\
\text { complement the supply gaps in the formal tourism economy. }\end{array}$} \\
\hline
\end{tabular}


on their own can hardly be expected to possess all the necessary capitals to achieve success in these fields. Therefore, collaboration is the sine qua non for every stakeholder in tourism related activities; (c) informal tourism entrepreneurs possess a noteworthy level of cultural and social capitals, and the value of these capitals is underestimated by the public agents. However, through possible collaborations between informal and formal entrepreneurs, these forms of capital may increase the value of existing capitals in these networks, enhance the competitive positioning of formal entrepreneurs and stakeholders at tourism destinations, and bring greater dynamism to the value chains; (d) the binary distinctions between formal/informal entrepreneurship represent a false logic, as increasingly entrepreneurs can be seen to engage in some less formal or informal activities alongside their role in the formal, structural economy, blurring the distinctions between formal and informal economic practices.

Chapter 2 and 3 conclude that informal tourism entrepreneurs are more flexible than formal entrepreneurs in adapting quickly to the changing conditions in tourism markets and re-positioning in these fields. They are keen to collaborate with other stakeholders in the tourism sector to achieve success. In such collaborations, informal entrepreneurs' flexibility and their capital portfolio of cultural, symbolic, social and dream capitals may offer important assets to tourism stakeholder networks.

Chapter 3 concludes that (a) informal tourism entrepreneurs use different forms of capital as stimuli for entrepreneurialism: for instance, cultural capital in embodied and objectified form to ease access to the field in a sector, and economic capital in the form of start-up loans from family and community members. Accordingly, informal tourism entrepreneurs determine the proportions of their capital portfolio based on their perceptions of the field conditions, which determine and structure their contribution to tourism destinations; (b) at all entrepreneur development stages, dream capital stock acts as a catalyst to convert other types of capital to economic capital. From the seed stage to the growth and scaling stage, dream capital stock is essential for informal entrepreneurs in recognizing an opportunity, envisioning an idea, creating a new product or service, and entering a relevant network.

Chapter 4 concludes that (a) informal tourism entrepreneurs adapt their habitus based on their perceptions of the individual and social changes 
in their social field. While major social and individual changes challenge informal entrepreneurs in their core belief systems and non-reflective dispositions, minor changes encourage them to understand and better appreciate the social conditions, and to create a practical sense of objective possibilities; (b) the informal tourism entrepreneurs who adapt their habitus and their practices to the changes in the social field timely seize the opportunities faster in the changing markets and become more successful in their businesses.

Chapter 5 concludes that (a) although it is known there is a negative correlation between general formal and informal economies, this is not true at the sectoral level, at least for the tourism sector. Formal and informal tourism economies move in a rather similar fashion. This means, when the formal tourism economy grows, the informal tourism economy grows as well, vice versa is also true; (b) both the informal tourism economy and the general informal economy grow faster than their formal counterparts; (c) while a significant and positive correlation exists between the informal tourism- and general informal economy, the former one is more affected by global crises and regional environmental disasters than the latter one. However, both show similar reactions to recessions and political instability at a destination; (d) the informal tourism economy correlates negatively with the unemployment rates and positively with vulnerable employment. This means the informal tourism economy mitigates unemployment and creates jobs primarily for the poor but also for women and young unemployed workers.

All four chapters together conclude that informal tourism entrepreneurs have significant capitals to create jobs, mitigate unemployment, support and teach skills to one another, and complement the supply gaps in the formal tourism economy.

In sum, the deepening of our understanding of the practices of informal tourism entrepreneurs as listed above contributes to integrating and optimizing both the formal and informal economies for sustainable development at tourism destinations. 


\subsection{Synthesis of main findings}

This $\mathrm{PhD}$ - thesis adopts a Bourdieusian approach in the research process and uses a transdisciplinary perspective in blending concepts from sociology, anthropology, and economics in order to gain a better understanding of the phenomenon of the informal tourism economy and entrepreneurship. It responds to recent calls for practice-based approaches that examine complex social structures in tourism (de Souza Bispo, 2016; Lammers et al., 2017), and shows how Bourdieu's theory of field, capital, and habitus can explicate such practices. This novel transdisciplinary perspective enriches existing sociology, anthropology, and economic literatures on the understanding of the informal tourism sectors by adding new insights (e.g. addressing unexpected needs, polycentric solutions) on this phenomenon.

This PhD-thesis suggests that the binary distinctions between formal/ informal entrepreneurship represent a false logic for research purposes. A binary distinction or dualism might be useful in the classroom to explain the differences between concepts to students but they are less useful in the research process. Using rigid binary distinctions can lead researchers to focus on one aspect or other exclusively resulting in logical contradictions and/ or false logic in the research design and findings. The practice of informal tourism entrepreneurs includes hybridities in every form and aspect. In particular, actors engaging in activities in the formal sector as well as in the informal sector blur the distinctions between formal and informal economic practices. Using a binary distinction such as formal versus informal does not allow the researcher to understand the deeper and more complex dynamics among agents in the fields and the patterns of changes. In addition, while in the Figure 9, the positioning of informal tourism entrepreneurs is spread at the bottom of the value field, it is not always fixed at a certain point in the field. If an informal tourism entrepreneur increases their social capital through collaborating with a formal entrepreneur, his or her position in the field can move closer to local formal entrepreneurs. 
Figure 9: Fields, capitals and stakeholders

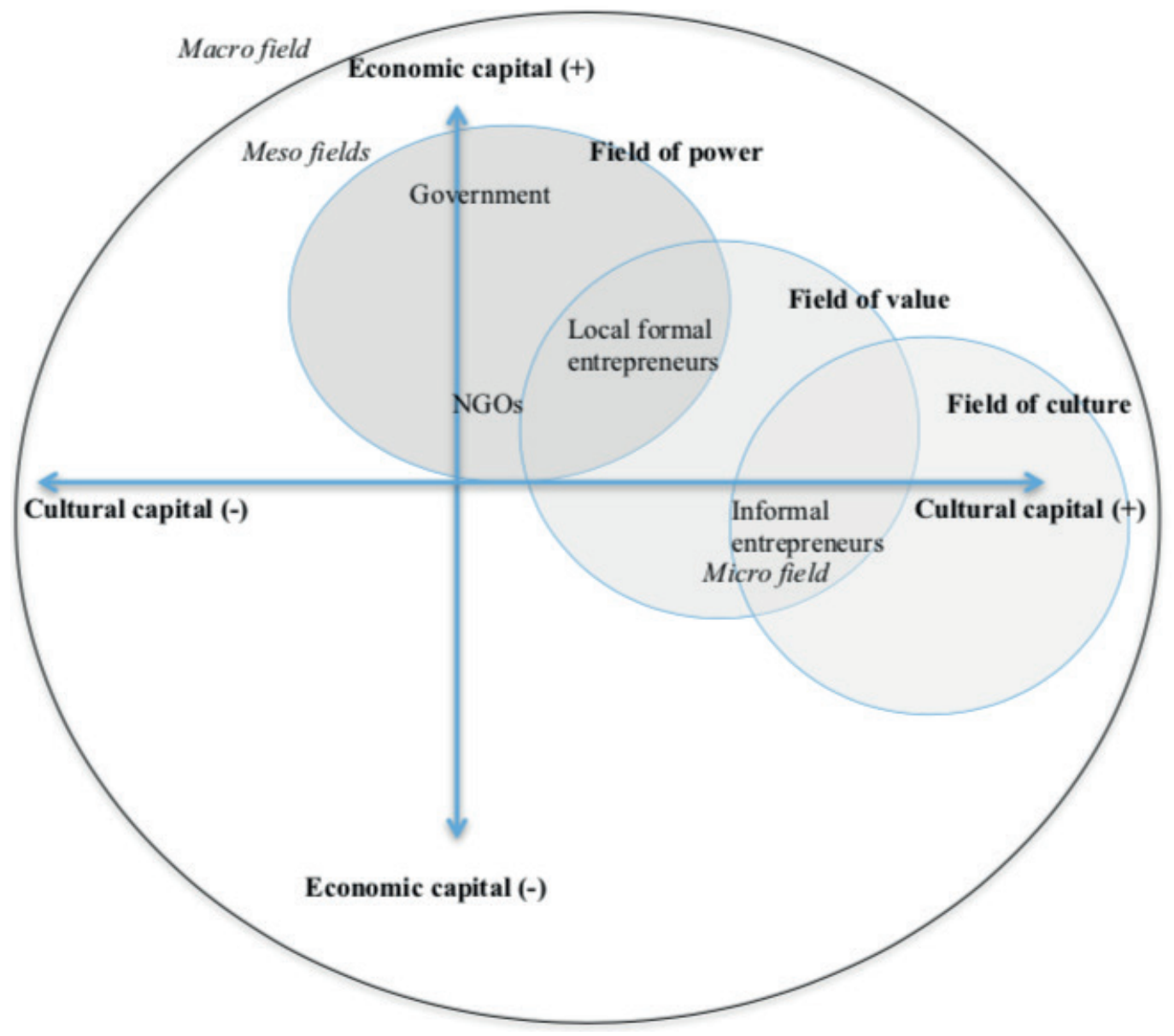

Extant research on the informal tourism economy and its actors is often combined together with poverty alleviation, and often considers tourism as a tool to stimulate marginalized communities' livelihood - a catalyst for the economic development of the global South - (Scheyvens, 2007; Truong, 2014). Here, informal actors are not considered as contributors to the tourism sector but rather as poor people to whom tourism can contribute. In such an approach, people's strengths (e.g. skills, capitals, good health) are neglected in favour of a focus on the stimulation of entrepreneurial activities. However, this assumption is not valid as informal actors enter into the tourism system with a capital portfolio, which is mostly not always understood and recognized by researchers. Furthermore - in comparison to informal actors in other sectors - the informal tourism entrepreneurs cannot be considered as the poorest of the poor as they have tourists, who are relatively wealthier than the domestic people, as end customers. This PhD-thesis argues that informal tourism entrepreneurs have a noteworthy 
capital portfolio. A good determination and recognition of this capital portfolio could provide a positive potential contribution to tourism development in the broader context. In addition, this PhD-thesis introduces and emphasizes a new form of capital, namely dream capital. Every entrepreneur needs a noticeable amount of dream capital stock in order to recognize an opportunity in the markets, and/or to envision an idea that leads to developing a new product or service, and/or to entering a relevant network that supports the entrepreneur in achieving his or her goals. Yet, from shaping an innovative concept to scaling an enterprise, the dream capital stock of an entrepreneur needs to be expressed among the other types of capital resources. The level of dream capital stock would indicate the future perspective of an entrepreneur and how he or she will use other types of capitals in future operations.

While Bourdieu gave significant consideration to the role of habitus in exploring social reproduction, he did not further develop how habitus works out and how one's subjective processes influence his or her habitus adaptation (Aarseth, Layton \& Nielsen, 2016; Lau, 2004). Research in the field of tourism studies that examined habitus has also followed this perceptive, and has often focussed on how habitus constructs one's taste choices in relations to social change processes. This $\mathrm{PhD}$-thesis extends this solo approach and considers both individual and social effects in exploring empirically one's habitus adaptation. As a result, it offers a new sociological avenue for research in tourism studies in examining habitus rather than focusing only on the processes of social changes influencing one's habitus. 
Figure 10: Modes of habitus adaptation as they relate to major and minor changes in individual and social structure

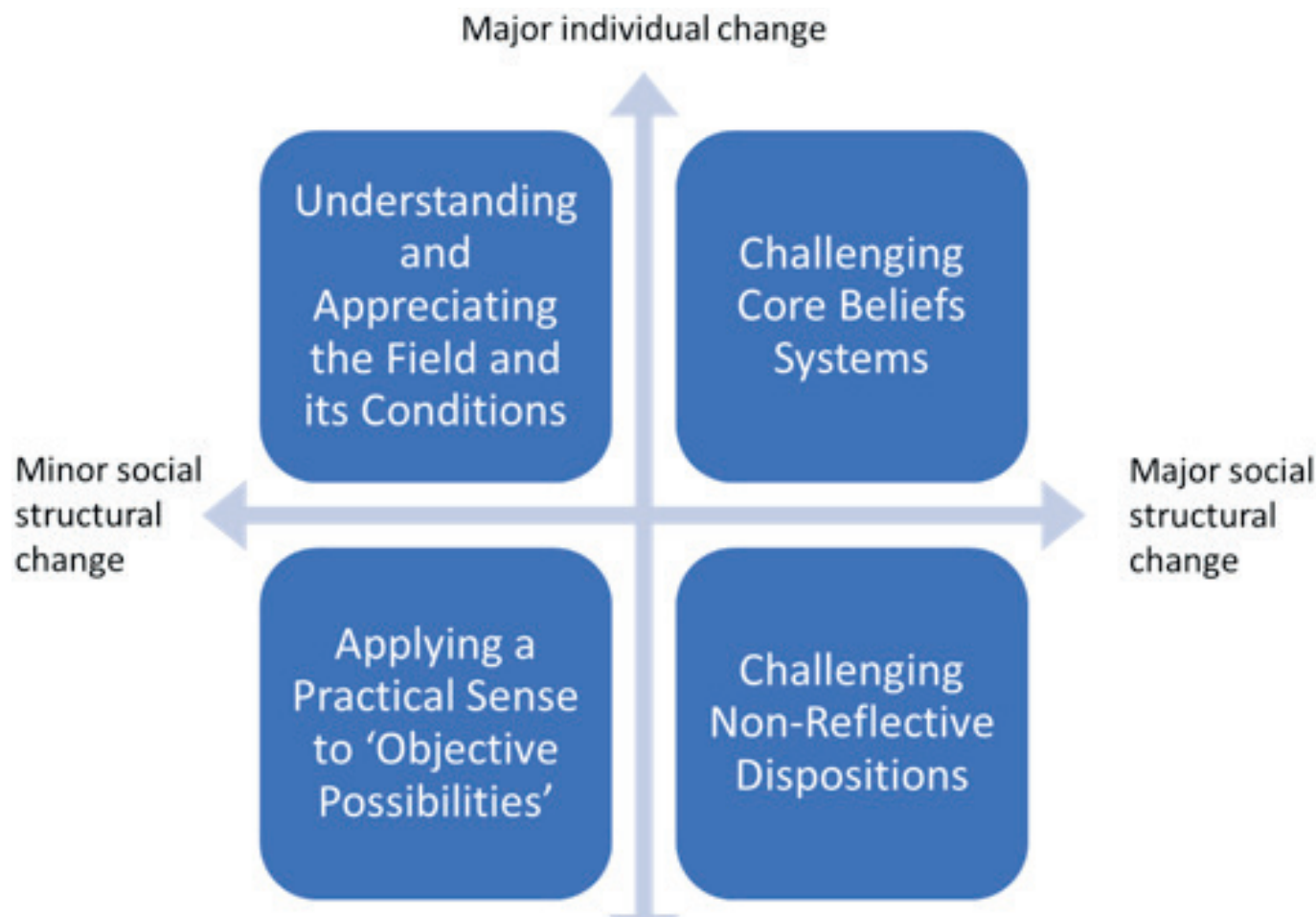

Minor individual change

The model proposed in the Figure 10 offers scope for further research to understand how practices and individuals are constrained or facilitated by complex, multi-dimensional changes, and which group is more likely to adapt their habitus in line with the individual and social changes.

Furthermore this PhD-thesis estimates first the size of the informal tourism economy by offering an analysis of 40 years of data on formal and informal tourism market activities in Thailand. It suggests that both the general informal economy as well as the specific informal tourism economy grow faster than their formal counterparts. In addition, the empirical results of this $\mathrm{PhD}$-thesis indicate a significant and positive correlation between the general informal economy and the informal tourism economy. While both show similar reactions to recessions and political instability, the informal tourism economy is more affected by global crises and regional environmental disasters than the general informal economy. Researchers examining factors influencing informal tourism activities need to also consider global and regional crises rather than only nation specific economic and political instabilities. More interestingly, there is a positive correlation between 
formal and informal tourism economies. This means that the general assumption that a growth in the formal economy leads to a decline in the informal economy is not true at the sectoral level, at least not in the tourism sector. Researchers designing models and policy makers aiming to regulate informal activities and employment in tourism should adapt different strategies for the tourism sector than for the general economy. Finally, this study shows that informal tourism entrepreneurs may decrease the overall unemployment rate by providing job for a vulnerable population.

\subsection{A research agenda}

The following sections discuss several avenues for future research that emerged while the four studies in this $\mathrm{PhD}$-thesis were being conducted.

\subsubsection{Destination capital mix and (mis)fit with entrepreneurs' capital portfolio}

While the importance of entrepreneurial activities as potential triggers in destination development are well addressed in tourism literature, little is said which entrepreneurs influence tourism development at a destination (Ryan, Mottiar, Quinn, 2012). Tourism entrepreneurs are dependent upon the context of a destination they are positioned in. For a sustainable development it is essential to have a good fit between a destination's capital mix and its entrepreneurs' capital portfolio. A good fit may also increase a destination's competitiveness and enhance the quality of life of its residents. Every (tourism) destination has its own capital mix such as economic capital in the form of entrepreneurial assets, employability, and tourism infrastructure; cultural capital including museums, cuisine, street art, reputation, image; social capital as community strength, connected networks, partnerships; symbolic capital along with the vibe of a destination; and dream capital in the form of the hopes, visions, and goals of tourism stakeholders.

This $\mathrm{PhD}$-thesis demonstrated the capital mix of entrepreneurs but did not examine the destination capital mix in order to test a possible (mis) fit between a destination's capital portfolio and its entrepreneurs. Future research could develop a framework for destination capital mix that can be applied to (tourism) destinations, to address possible collaborations with the purpose to increase the fit between a destination's assets and abilities, and 
its entrepreneurs' capital portfolio. Such a framework would help current urban, cultural, and tourism destinations in monitoring the possible gaps and/or misfits between a destination's and its entrepreneurs' capital portfolio, and indicate possible improvements points to achieve their sustainable development goals.

\subsubsection{Dream capital as a new input in the entrepreneurship competence framework}

The dream capital stock level of an entrepreneur assists him or her to identify opportunities to create value and create counter solutions for the challenges existing in his or her social-environmental fields. This capital is embedded in an entrepreneur's cultural and symbolic capitals, and needs to be determined in order to visualise his or her future scenarios and planning. The entrepreneurship competence framework from Bacigalupo, Kampylis, Punie, \& Van den Brande (2016) does not include these items as a specific resource but relates to the areas and competences. As a result, it is scarcely possible for an entrepreneur to estimate the value of his or her ideas using this framework. Yet, including dream capital in such a framework would help an entrepreneur monitor his or her own ideas and the processes, which would need to be followed in order to turn his or her dreams into reality. An additional research topic is that dream capital needs to be further examined not only at individual level but also at organization level in order to indicate how an organisation perceives the opportunities and challenges in its social field, and how different departments share the same vision and strategies of an organisation.

\subsubsection{Symbolic violence and social exclusion practices}

While examining the field conditions and the structural relations in the power field, it was observed that various levels of symbolic violence were enacted on the informal tourism entrepreneurs in their daily practices. Symbolic violence happens when a dominant group signifies what to do and what not to do in a field by means of using non-physical violence manifested in the form of power. Bourdieu et al (1994) suggested that an issue or practice that sourced from a dominant group would be accepted and perceived as 'normal', and become a norm over time by both parties of the supressed and dominant groups. Practices influenced by symbolic violence can be expressed in governance, core belief systems, and as the ideas and 
values of a dominant group. They could be rapidly disseminated through media but also formal and informal education which legitimises a discourse in a society. Symbolic violence would influence the practices of informal tourism entrepreneurs and particularly in their habitus adaptation, for instance in the form of adapting their cultural beliefs, values, and fashion from other groups in the field. A possible analysis of the symbolic violence enacted on informal tourism entrepreneurs contributes to the literature on globalization, authenticity, power, and postcolonialism in tourism studies. To conduct a study on symbolic violence and the suffering it causes requires longitudinal data sets, which may be sourced from long-term participatory observations and these can be analysed by deploying several discourse analyses.

\subsubsection{Contested terrains: doxa and discourses in informality}

In the first and third studies, the examination between field structures and habitus requires knowledge of the doxa in that field and beyond. Doxa expresses what is taken for granted in a particular community or social group (Bourdieu, 1977). It refers to the natural beliefs and opinions, common sense, and popular practices in a field and/or community. Discourse is different than doxa and includes a way of organising knowledge, which structures the construction of social relations through understanding the discursive logic and accepting it as a social fact (Foucault, 1969).

Doxa and discourses limit social mobility, as they petrify social limits, and deprive individuals of more deliberate action and behaviour. While acting as an entrepreneur in the field, one needs to have knowledge about the doxa and discourses in a field. The entrepreneurs take an occupational freedom in the form of challenging conventional habits and addressing new concepts of processes and products. In this sense, it is relevant to investigate entrepreneurs' practices in relation to innovation, doxa and discourses.

\subsubsection{Paradox of fixed/singular entrepreneurship vis-à-vis hybrid entrepreneurship and liquid identities}

The paradox in the tourism sector and in contemporary economic policies is the matter of continually assumed singular entrepreneurship types vis-à-vis the actuality of hybrid entrepreneurship and liquid identities. Informal tourism entrepreneurs could be seen as being at the centre of such 
matters in many destinations around the world, particularly when identity' is linked to such concepts as globalization. While investigating the defining features of informal tourism entrepreneurs, it was observed that they define and redefine their aims and identities continuously. Rather than the linear and simplistic assumptions of fixed and single entrepreneurship and identity, then, entrepreneurs become mixed up with mobility and lifestyle choices, and find themselves with no stable position to aim for in the process of their identity construction (Bauman 2013; Giddens, 1991). Bauman (2013) suggests this formation as the 'liquid modernity' which is happening in the $21^{\text {st }}$ Century, with major economic and social change, including increasing mobility of people, financial assets, ideas and which requires flexibility. Accordingly, we are moving away from singular and fixed ascribed forms of entrepreneurship based on formality towards hybrid and relational entrepreneurship and identities characterised by mobility and flux of people, capitals, and ideas.

States and destination governors need to refrain from choosing some fixed type of entrepreneurs and identities, and allow for hybrid entrepreneurship and recognize the liquid identities of all formal and informal entrepreneurs. To be effective in their work and residential fields the works of informal entrepreneurs need to be recognized by the state and approved by their formal peers. Furthermore they should be treated with the equal rights accorded to every member of their occupation. While in the modern platforms informal economic activities are shifting towards a more positive characterisation in the recent debates on the sharing economy, in the less developed world such informal activities are still primarily constructed as disparaging.

Future research directed on the hybrid entrepreneurship and liquid identities, and how they influence destination development, would lead to inclusive policies for destination governance.

\subsubsection{Sustainable Development Goals (SDGs) and informal tourism actors}

The informal tourism actors can contribute to the SDGs of stakeholders, destinations, and countries. Concrete models and frameworks to realise the aspirations of the sustainable development goals with the contribution of informal tourism actors is under-researched in both the academic and profes- 
sional domains. Future research directed at creating inclusive networks, where all types of stakeholders obtain the chance to interact collectively would help to realize the 1st and 2nd SDGs (i.e. no poverty, zero hunger).

Furthermore ensuring systems to hold tourism stakeholders to account regarding action, investment, fair trade, and outcomes would help to realize the 8th and 10th SDGs (i.e. decent work and economic growth, reduced inequalities). Case studies examining gender gaps, women's empowerment in the informal tourism economy would help to realize the 5th SDG (i.e. gender equality). Field studies on how to increase the awareness of local communities about their impacts on climate change, biodiversity, and ecosystems can contribute to indicating practical ways to realizing 13th, 14th, and 15th SDGs (i.e. climate action, life below water, life on land). Future research on the sustainable production and consumption by informal tourism entrepreneurs acting in urban cities and settlements would help to realize the 11th and 12th SDGs (i.e. sustainable cities and communities, responsible consumption and production).

\subsection{Implications}

The findings in the four studies have a number of societal and managerial implications for stakeholders including public agents (at any level of government), policy makers, NGOs, and destination governors in the tourism sector. Possible implications for both policy and research implications in tourism studies are discussed below in relation to some contemporary social and academic debates.

\subsubsection{Policy implications}

The informal tourism economy is not a desirable phenomenon for destination governors and policy makers, because it is difficult to monitor and not fully taxed by public organizations, and its contribution is not included in the calculation of the nation's gross domestic product. However, its contribution to the labour market is not always excluded in the statistics. For instance, in calculating the unemployment rate, Thailand includes the contribution of informal economies and this results in a country with the lowest unemployment rate (i.e. lower than 1\%) in the world (Trading Economics, 2019). Obviously informal economies generate employment in 
developing countries and provide essential products and services. In particular, informal actors increase labour market flexibility in the service sectors, including the tourism sector. To this end, it is important for policy makers and destination governors to determine the appropriate degree of control in the informal tourism economy in order to regulate informal entrepreneurs such that their benefits to society are not lessened.

\subsubsection{Collaborations including informal tourism entrepreneurs are vital for destinations}

The first study in this $\mathrm{PhD}$-thesis demonstrates the benefits of including informal tourism entrepreneurs in tourism networks. The value chains in the tourism sector are much longer than other sectors and it is hardly possible for a solo stakeholder possessing all the necessary capitals to achieve success alone. Collaborations are essential for all stakeholders operating in the tourism sector and all parties can benefit from the possible collaborations between formal and informal tourism entrepreneurs. Therefore, this $\mathrm{PhD}$ thesis suggests that both public agents and NGOs promote dialogue and encourage formal and informal entrepreneurs to collaborate more freely in the widest possible number of fields by allowing them to work in a hybrid form. First, informal entrepreneurs are highly motivated and more flexible than formal counterparts to adapt to changing conditions in the social environment and tourism markets. Second, through collaboration, formal entrepreneurs can increase diversity in their business network and strengthen their supply chain, which may lead to some process or product innovation. Third, collaborations can lead to more inclusive value chains in the tourism sector. Informal tourism enterprises are highly integrated into local economic structures and a possible collaboration with informal tourism stakeholders would lead to a low leakage, and this may result in a higher multiplier effect on the local economy. Fourth, formal tourism organisations through being a partner with informal tourism entrepreneurs can gain trust from the local communities and appreciation from their customers through a perceived greater social responsibility. Finally, networks consisting of multiple stakeholders from public and private sectors and including informal tourism entrepreneurs may lead to public-private partnerships in which the skills and expertise of informal entrepreneurs can be integrated and upskilled. Attending to these networks, informal tourism entrepreneurs can gain more knowledge and experience in marketing, planning, and monitoring, which are organisational strengths of the formal sector agents. Additionally, having informal tourism entrepreneurs in these 
inclusive networks would decrease the formal entrepreneurs' transaction costs, complement their products and services, and increase their position in the market. Hence, in these networks informal tourism entrepreneurs would act as sub-contractors to formal entrepreneurs and would not compete with them but rather complement their product and service portfolio offered at tourism destinations.

\subsubsection{Align the profiles in the informal tourism economy and informal entrepreneurship}

The second and fourth studies in this PhD-thesis demonstrate the capacities of informal tourism entrepreneurs and how they can contribute to the national economies. Informal tourism entrepreneurs have a noteworthy level of cultural, symbolic, social and dream capitals, which can offer important assets to tourism stakeholder networks and to the wider economy. These capitals may increase the capacities of networks by boosting the value of existing capitals and enhancing the competitive positioning of stakeholders and subsectors, and bringing greater dynamism to the social fields at potential and existing tourism destinations. To this end, it is necessary for policy makers to profile the informal tourism economy and entrepreneurs effectively at municipal, regional, and national levels for tourism development and urban planning. While the informal tourism economy can be profiled by its size, sort of activities, economic relevance and dissemination throughout the country, informal tourism entrepreneurs can be profiled by their demographics, capital portfolio, habitus, gaps in skills, necessities, and psychical localisation.

Informal tourism entrepreneurs possess significant tacit knowledge about the cultural and natural assets in their social space, including narratives and oral history. These assets have a great value for domestic and international tourists in increasing their experience and knowledge about places and people. These narratives and oral history help tourists connect with other people and places, and discover how similar they, and their concerns, ambitions and connections are with these people and places. At these tourism destinations the successful informal tourism entrepreneurs may increase not only tourists' awareness about places and people but also their communities' awareness of the social value of their cultural and natural heritage, and consequently make them all more concerned with preserving these resources. In this way a more sustainable tourism development may be realized in these regions over the long term. 
Profiling the informal tourism actors efficiently at destinations would also help to anticipate movements in social mobility. There is a continuous movement of young migrants from rural areas to urban and tourist destinations that leads to a movement from the agricultural sector into manufacturing and service sectors. This group of people possess various skills, basic capitals and good health and increase the labour elasticity in the supply at urban and tourist destinations. Data sets including the profiles of informal actors would make it possible to calculate the labour elasticity in evaluating tax benefit policy reforms and their effect on employment and tax revenue.

\subsubsection{Dream capital needs to be included into the entrepreneur competence frameworks}

Dream capital, introduced as a new form of capital in the second study in this $\mathrm{PhD}$-thesis, is a key entrepreneurial resource in recognizing an opportunity, envisioning an idea, creating a new product or service, and entering a relevant network. Therefore, its stock level needs to be included in entrepreneur competence frameworks, because the stock of dream capital is related to the future vision of an entrepreneur, who wants to develop a product or service concept, to enter into new tourism markets, and/or to scale up his or her business. Destination governors and policy makers can monitor the variety of tourism products, services, and subsectors offered at their destination through the overall dream capital stock of entrepreneurs operating at their destination.

\subsubsection{Reach and mobilise informal tourism entrepreneurs}

The tourism sector has backward and forward linkages with other supplier and buyer industries in the regions. Therefore, informal entrepreneurs working in the tourism value chains do not only create impacts in the tourism sector but also higher multiplier effects in the national economies. For instance, they distribute income and create opportunities for other stakeholders working as all kinds of buyers and suppliers in the indirect tourism sectors such as food, transport, security, health, and maintenance. This PhD-thesis suggests policy makers approach the informal tourism entrepreneurs and offer them some level of social protection, reduce their challenges, and include them in the networks. Excessive bureaucracy, complicated tax systems, licensing procedures and costs of applications are well-known constraints for informal tourism entrepreneurs and limit their opportunities to move to the formal economy. 
Furthermore an existing possible misfit between the conditions of a tourism field and the capitals held by informal tourism entrepreneurs - in the form of lack of formal job market information, negative social capital in the form of racial discrimination in the job market - forces them towards staying in the informal economies. However, regional and local destination governors can enable them to obtain formal recognition for their work, offer some level of social protection, and open them to the new markets. Decreasing the constraints on informal entrepreneurs and offering them some level of social protection would increase their integration in the whole economic system.

It is also important for public organisations and NGOs to involve informal tourism entrepreneurs in designing their programmes and developing curricula for training purposes. Informal tourism entrepreneurs already develop many skills (e.g. foreign languages, marketing techniques, equipment maintenance skills, social skills in approaching tourists), which directly result from their on-the-job informal education. As a result, informal tourism entrepreneurs already know their own priorities and necessities in order to adapt their capital portfolio for a better positioning in the fields.

Finally, policy makers should pay attention to shaping the policies which aim to reduce the informal tourism activities because they may also reduce formal tourism outputs. The fourth study in this $\mathrm{PhD}$-thesis finds an existing significant and positive correlation between informal and formal tourism economies, which means an increase in formal tourism output causes an increase in informal tourism output. This is also true for the opposite causal direction.

\subsubsection{Conduct a habitus analysis of informal tourism entrepreneurs}

Recognising that social-environmental transformation processes are complex and difficult to be accepted by all stakeholders, governments and professionals are faced with the question of who is ready for change and who is opposing adaptation to the new conditions and/or regulations? Stakeholders experience a social-environmental change in relation to their own individual change and often have different concerns and worldviews. The third study in this PhD-thesis offers a habitus analysis that can be used by public agents (at any level of government) and policy makers to predict relevant stakeholders' willingness to change and adjust their habitus towards the new conditions in their social spaces. Based on the results of a habitus 
analysis of informal tourism actors, a public program - aiming to promote new forms of dialogue and challenges to the old belief systems- may boost communication in the groups which most experience the social and individual changes in their social fields. As a result, these groups are most likely to start changing and adapting their habitus to the new conditions in their social fields.

\subsubsection{Informal tourism entrepreneurs demonstrate hybrid forms of entrepreneurship style and jobs}

Recognising that social-environmental transformation processes are complex and difficult to be accepted by all stakeholders, governments and professionals are faced with the question of who is ready for change and who is opposing adaptation to the new conditions and/or regulations? Stakeholders experience a social-environmental change in relation to their own individual change and often have different concerns and worldviews. The third study in this PhD-thesis offers a habitus analysis that can be used by public agents (at any level of government) and policy makers to predict relevant stakeholders' willingness to change and adjust their habitus towards the new conditions in their social spaces. Based on the results of a habitus analysis of informal tourism actors, a public program - aiming to promote new forms of dialogue and challenges to the old belief systems- may boost communication in the groups which most experience the social and individual changes in their social fields. As a result, these groups are most likely to start changing and adapting their habitus to the new conditions in their social fields.

\subsubsection{Informal tourism entrepreneurs may help stakeholders and governors to make their SDGs (Sustainable Development Goals) a reality}

The sustainable development of a destination requires the active participation of all types of people and sectors of the society. It is already known that networks including multi-stakeholder partnership and engagement for sharing knowledge and expertise would support the achievement of the SDGs. The informal tourism entrepreneurs include different types of people, like indigenous people, migrants, children and youth, farmers, women, and persons with disabilities. They can help stakeholders to achieve their SDGs in multiple areas.

First, for the 1st and 2nd SDGs (i.e. no poverty, zero hunger), informal tourism entrepreneurs create solutions for their own struggles and actively 
stimulate businesses at the base of value chains in the tourism sector. They do not generate income only for themselves and their families, but also for other informal and formal actors in the society. They contribute actively to eradicating poverty at the base of the pyramid.

Second, for the 8th and 10th SDGs (i.e. decent work and economic growth, reduced inequalities) informal tourism entrepreneurs can contribute by disseminating income throughout the country and decreasing the inequality among the regions. They are often connected with the rural areas and they both financially help (e.g. remittance sending) their extended families living in the rural areas and/or work themselves during the off-season at the family owned enterprises in rural areas. In this way, they support their extended families living in the rural areas, and support rural developments by contributing with their physical work and finances. Informal tourism entrepreneurs absorb labour excess and are employers of people from the base of pyramid in a society. They employ not only family members but also vulnerable people who are not skilled or semi-skilled and who have little or no chance of finding a job in the formal economies. In this fashion, informal tourism entrepreneurs increase the social inclusiveness in a society and contribute to the sustainable growth of their communities.

Third, for the 13th, 14th, and 15th SDGs (i.e. climate action, life below water, life on land), informal tourism entrepreneurs can contribute by increasing awareness of communities about their impact on climate change. Informal tourism entrepreneurs have remarkable tacit knowledge about biodiversity and ecosystems of their living areas, which is mostly not documented. If they are included in networks with multi-stakeholder partnerships, informal tourism entrepreneurs can extend the capacities of these networks and encourage communities to preserve/conserve the ecosystems and maintain the biodiversity in their living areas. For instance, in the second and third studies in this $\mathrm{PhD}$ thesis, the fishermen and marine informal tourism entrepreneurs use traditional techniques in their daily lives and see the marine environment as part of their lifeworlds. They are the natural conservers of the oceans and marine environment.

Fourth, for the 5th SDG (i.e. gender equality), informal tourism entrepreneurs empower women and girls in their communities. In general, informal entrepreneurship enhances the status of women in a community and makes it acceptable for women to work in their society. In these places, women's 
place is no longer entirely in the home and they combine their domestic work with their part-time job. Consequently, they contribute to their household finances, and importantly become empowered in the decision-making processes in their household.

Finally, for the 11th and 12th SDGs (i.e. sustainable cities and communities, responsible consumption and production), informal tourism entrepreneurs may help cities and human settlements to become more inclusive, safe, resilient and sustainable. In all the four studies in this $\mathrm{PhD}$ thesis, informal tourism entrepreneurs are active in supporting the local market and population, and consequently they promote sustainable production and consumption throughout the whole society.

\subsection{Limitations}

This thesis also has some limitations. First, the ethnographic fieldwork in the first three studies is not done through a long-term participatory observation but with three different fieldwork time frames each of 3 to 4 weeks at field sites. A longer stay at the field sites, observing and participating in the practices of informal tourism entrepreneurs, would produce a deeper understanding. Second, the dearth of datasets about the informal economy and activities makes it difficult to compare results from different periods and to harmonise concepts at an international level. Therefore many of the results remain contextual, cannot be generalized and are limited to the field conditions. Finally, the fourth study offers a first estimation of the size of the informal tourism economy but is limited by the fact that it does not explore all the determinants of the informal tourism economy and its composition.

\subsection{Epilogue}

This $\mathrm{PhD}$-thesis has conducted a relational and reflexive analysis of the practices of informal tourism entrepreneurs and offered actions and solutions to policy makers and destination governors rather than thinking of the whole phenomenon holistically and/or as a set of significations. It demythologized the common sense that informal entrepreneurs are marginalized, traditional, underdeveloped and backward entities, and shown empirically that informal tourism entrepreneurs have important and relevant capitals 
(e.g. skills, qualities, attributes, and networks), and contribute substantially to the socio-economic world of destinations in achieving their broader sustainable development goals. This $\mathrm{PhD}$-thesis addresses the evolution of informal tourism entrepreneurs from their role in poverty alleviation and as a survival strategy for unemployment in developing countries to their existence as trusted and socio-economically essential entities of the social system. It calls for inclusive frameworks and hybrid solutions in which informal entrepreneurs are recognised in academic and professional debates for their benefits to society. 
옳 
References 
Aarseth, H., Layton, L., \& Nielsen, H. B. (2016). Conflicts in the habitus: the emotional work of becoming modern. The Sociological Review, 64(1), 148-165.

Ahlstrom, D., \& Ding, Z. (2014). Entrepreneurship in China: An overview. International Small Business Journal, 32(6), 610-618.

Ahmad, R. (2014). Habitus, capital, and patterns of taste in tourism consumption: A study of western tourism consumers in India. Journal of Hospitality \& Tourism Research, 38(4), 487-505.

Ahmad, R. (2017). Power Struggles Within and Between Organizations in Tourism Business: A Bourdieusean Approach to Organizational Analysis. Tourism Culture \& Communication, 17(1), 47-59.

Al-Mataani, R., Wainwright, T., and Demirel, P. (2017) Hidden Entrepreneurs: Informal Practices within the Formal Economy. European Management Review, doi: 10.1111/emre.12115.

Andersen, C., \& Adamsen, L. (2001). Continuous video recording: A new clinical research tool for studying the nursing care of cancer patients. Journal of Advanced Nursing, 35(2), 257-267.

Andriotis, K. (2002). Scale of hospitality firms and local economic development-evidence from Crete. Tourism Management, 23(4), 333-341.

Antonakakis, N., Dragouni, M., \& Filis, G. (2015). Tourism and growth: The times they are a-changing. Annals of Tourism Research, 50,165-169.

Archer, M. S. (2007). Making Our Way Through the World: Human Reflexivity and Social Mobility. Cambridge University Press.

Ashley, C., \& Roe, D. (2002). Making tourism work for the poor: Strategies and challenges in Southern Africa. Development Southern Africa, 19(1), 61-82.

Ateljevic, J. (2007). Small tourism firms and management practices in New Zealand: The centre stage macro region. Tourism Management, 28(1), 307-316. 
Autio, E., \& Fu, K. (2015). Economic and political institutions and entry into formal and informal entrepreneurship. Asia Pacific Journal of Management, 32(1), 67-94.

Bailey, C. A. (2007). A guide to qualitative research. California: Pine Forge Press.

Bauman, Z. (2013). 'Liquid modernity'. John Wiley \& Sons.

Bhatt, E. R. (2006). We are poor but so many: The story of self-employed women in India. Oxford University Press on Demand.

Bamberg, M. (2006). Stories: Big or small: Why do we care? Narrative inquiry, 16(1), 139-147.

Beirman, D. (2016). Challenging times for Thai tourism. Retrieved from https://www.newmandala.org/challenging-times-for-thai-tourism/

Biggs, D., Hall, C. M., \& Stoeckl, N. (2012). The resilience of formal and informal tourism enterprises to disasters: reef tourism in Phuket, Thailand. Journal of Sustainable Tourism, 20(5), 645-665.

Bloomberg Business (2015). Thailand's generals don't have an economic plan, August $5^{\text {th }}$ by William Pesek.

Bourdieu, P. (1962). The Algerians. Beacon Press: Boston.

(1969). Intellectual field and creative project. Information (International Social Science Council), 8(2), 89-119.

(1977). Outline of a theory of practice (Vol. 16). Cambridge University Press.

(1985). The genesis of the concepts of habitus and field. Sociocriticism, 2(2), 11-24.

(1986). The Forms of Capital. Republished in Education, Globalisation and Social Change, (2006) H. Lauder, P. Brown, J. A. Dillabough and A. H. Halsey (eds). Oxford: Oxford University Press. 
(1990). The logic of practice. Stanford University Press.

(1993). The Field of Cultural Production: Essays on Art and Literature. New York: Columbia Univ. Press

(1998). Practical Reason. On the Theory of Action. Stanford: Stanford University Press.

(1998). The state nobility: Elite schools in the field of power. Stanford University Press.

(2005). The social structures of the economy. Translated by Chris Turner. Cambridge: Polity Press.

(2013). Distinction: A Social Critique of the Judgement of Taste.

Routledge.

Bourdieu P. \& Wacquant L.J.D. (1992). An Invitation to Reflexive Sociology. Chicago: Univ. Chicago Press

Bourdieu, P., Wacquant, L. J. D., \& Farage, S. (1994). Rethinking the state: genesis and structure of the bureaucratic field. Sociological Theory, 12(1), 1-18.

Boonjubun, C. (2017). Conflicts over streets: The eviction of Bangkok street vendors. Cities, 70, 22-31.

Boyatzis, R. E. (1998). Transforming Qualitative Information: Thematic Analysis and Code Development. Sage: Thousand Oaks.

Brata, A. G. (2010). Vulnerability of urban informal sector: Street vendors in Yogyakarta, Indonesia." Theoretical and Empirical Researches in Urban Management, 5(14), 47-58.

Braun, V., \& Clarke, V. (2006). Using thematic analysis in psychology. Qualitative Research in Psychology, 3(2), 77-101. 
Bromley, R. D. F., \& Mackie, P.K. (2009). Displacement and the new spaces for informal trade in the Latin American city centre. Urban Studies, 46(7). 1485-1506.

Brown, A. (2015). Claiming the streets: Property rights and legal empowerment in the urban informal economy. World Development, 76, 238-248.

Belhassen, Y., \& Caton, K. (2009). Advancing understandings: A linguistic approach to tourism epistemology. Annals of Tourism Research, 36(2), 335-352.

Bruton, G. D. (Ed.). (2010). Business and the world's poorest billionThe need for an expanded examination by management scholars. Academy of Management Perspectives, 24(3), 6-10.

Bruton, G. D., Ketchen Jr, D. J., \& Ireland, R. D. (2013). Entrepreneurship as a solution to poverty. Journal of Business Venturing, 28(6), 683-689.

Burns, P., \& Lester, J. (2005). Using visual evidence: The case of Cannibal tours. In B. W. Ritchie, P. Burns, \& C. Palmer (Ed.), Tourism research methods: Integrating theory with practice, pp. 49-62. Wallingford: CABI.

Butler, R. W. (2001). Seasonality in tourism: Issues and implications. Seasonality in tourism, 5-21.

Çakmak, E., Lie, R., \& McCabe, S. (2018). Reframing informal tourism entrepreneurial practices: Capital and field relations structuring the informal tourism economy of Chiang Mai. Annals of Tourism Research, 72, $37-47$.

Çakmak, E., Lie, R., \& Selwyn, T. (2019). Informal tourism entrepreneurs' capital usage and conversion. Current Issues in Tourism 22(18), 2250-2265.

Carree, M., Thurik A. R. (2010) The impact of entrepreneurship on economic growth. In: Acs Z J, Audretsch D B, editors. Handbook of Entrepreneurship Research. New York and London: Springer. 
Casson, M. (1982). The entrepreneur: An economic theory. Rowman \& Littlefield.

Çavu , S., \& Tanrısevdi, A. (2003). Residents` attitudes toward tourism development: A case study in Ku adası, Turkey. Tourism Analysis, 7(3-4), 259-269.

Chakrabarty, D. (2000). Provincializing Europe: Postcolonial thought and historical difference. New York: Princeton University Press.

Chanwanpen, K. (2018). World Bank report urges Thailand to revisit migrant worker policies to pursue 4.0 Growth Strategy. The Nation, May 17.

Charmes, J. (2012). The informal economy worldwide: Trends and characteristics. Margin: The Journal of Applied Economic Research, 6(2), 103-132.

CBT (Community Based Tourism) - I Thailand (2015). Community based tourism partnerships.http://www.mekongtourism.org/wpcontent/ uploads/CBT_Partnerships_for_Tour_Operators_Handbook_CBT-I_ Distributed.pdf Last retrieved on June $7^{\text {th }}, 2017$.

Chen, M. (2006). Rethinking the informal economy: Linkages with the formal sector and the formal regulatory environment." In Guha-Khasnobis, B., Kanbur, R., and Ostrom, E., (eds.). Linking the Formal and Informal Economy: Concepts and Policies. Oxford University Press, 75-92.

(2012). The informal economy: Definitions, theories and policies. WIEGO Working Paper Series, 1(26), 90141-90167.

Chen, M.A., Vanek, J., \& Heintz, J. (2006). Informality, gender and poverty: A global picture. Economic and Political Weekly, 41 (21), 21312139.

Cobb, S. (2006). A Developmental approach to Turning Points: Irony as an ethics for Negotiation Pragmatics. Harvard Negotiation Law Review. 11, 147-197. 
Cohen, E. (1982). Thai girls and farang men the edge of ambiguity. Annals of Tourism Research, 9(3), 403-428.

Cooper, C., \& Hall, C. M. (2008). Contemporary tourism: an international approach. Routledge.

Crick, M. (1992). Life in the informal sector: Street guides in Kandy, Sri Lanka. In Tourism and Less Developed Countries. D. Harrison (ed.). London: Belhaven Press, 135-147.

Crossley, N. (2003). From reproduction to transformation: Social movement fields and the radical habitus. Theory, Culture \& Society, 20(6), 43-68.

Cukier-Snow, J., \& Wall, G. (1993). Tourism employment: Perspectives from Bali. Tourism Management, 14(3), 195-201.

Cukier, J. (2002). Tourism employment issues in developing countries: Examples from Indonesia. In Tourism and development: Concepts and issues, edited by R. Sharpley \& D. J. Telfer, 165-201. Clevedon: Channel View.

Dahles, H., \& Bras, K. (1999). Entrepreneurs in romance: Tourism in Indonesia. Annals of Tourism Research, 26(2), 267-293.

Dahles, H., \& Prabawa, T.S. (2013). Entrepreneurship in the informal sector. The case of the pedicab drivers of Yogyakarta, Indonesia. Journal of Small Business \& Entrepreneurship, 26(3), 241-259.

Damayanti, M., Scott, N., \& Ruhanen, L. (2017). Coopetitive behaviours in an informal tourism economy. Annals of Tourism Research, 65, 25-35.

(2018). Space for the informal tourism economy. The Service Industries Journal, 38(11-12), 772-788.

Dana, L.P. (2013). Informal economy entrepreneurship and policy implications. In M.T.T. Thai and E. Turkina (Ed) Entrepreneurship in the Informal Economy: Models, Approaches and Prospects for Economic Development, pp. 259-268. London: Taylor and Francis. 
De Jong, G. F. (2000). Expectations, gender, and norms in migration decision-making. Population Studies, 54(3), 307-319.

Department of Tourism Thailand (2018). Tourism revenues 2010-2017. Retrieved from https://www.tourism.go.th

De Paula, A., \& Scheinkman, J.A. (2007). The informal sector (No.13486). National Bureau of Economic Research.

De Soto, H. (2002). The Other Path: The Economic Answer to Terrorism. New York: Basic Books

De Souza Bispo, M. (2016). Tourism as practice. Annals of Tourism Research, 61, 170-179.

Djankov, S., Glaeser, E., La Porta, R., Lopez-de-Silanes, F., \& Shleifer, A. (2003). The new comparative economics. Journal of Comparative Economics, 31(4), 595-619.

Edelman, L., \& Yli-Renko, H. (2010). The impact of environment and entrepreneurial perceptions on venture-creation efforts: Bridging the discovery and creation views of entrepreneurship. Entrepreneurship Theory and Practice, 34, 833-856.

Edensor, T. (2001). Performing tourism, staging tourism: (Re) producing tourist space and practice. Tourist Studies, 1(1), 59-81.

Elder-Vass, D. (2007). Reconciling Archer and Bourdieu in an emergentist theory of action. Sociological Theory, 25(4), 325-346.

Estrin, S., \& Mickiewicz, T. (2011). Entrepreneurship in transition economies: The role of institutions and generational change. In The dynamics of entrepreneurship: Evidence from the global entrepreneurship monitor data, edited by M. Minitti, 181-208, Oxford: Oxford University Press.

(2012). Shadow economy and entrepreneurial entry. Review of Development Economics, 16(4), 559-578. 
Euromonitor International (2018). Travel in Thailand - country report (October 2018). London: UK.

European Commission (2007). Stepping up the fight against undeclared work. Brussels: European Commission.

Evans, M., Syrett, S, \& Williams, C. (2006). Informal Economic Activities and Deprived Neighbourhoods. Department of Communities and Local Government, London.

Everett, J. (2002). Organizational research and the praxeology of Pierre Bourdieu. Organizational Research Methods, 5(1), 56-80.

Faubion, J. (2018). Rethinking the subject: an anthology of contemporary European social thought. Routledge.

Feenstra, R., Inklaar, R., \& Timmer, M. (2015). The next generation of the Penn World Table. American Economic Review, 105(10), 3150-3182.

Feige, E. L. (Ed.). (2007). The underground economies: Tax evasion and information distortion. Cambridge University Press: UK.

Feldman, M.S., Sköldberg, K., Brown, R.N., \& Horner, D. (2004). Making sense of stories: A rhetorical approach to narrative analysis. Journal of Public Administration Research and Theory, 14(2), 147-170.

Freeman, M. (2006). Life "on holiday"? In defence of big stories. Narrative Inquiry, 16, 139-146.

Gallin, D. (2001). Propositions on trade unions and informal employment in time of globalisation. Antipode, 19(4), 531-549.

Geertz, C. (1963). Peddlers and Princes: Social Change and Economic Modernization in Two Indonesian Towns. Chicago: Chicago University Press.

Gergen, M. M. (1988). Narrative structures in social explanation. In Antaki, C. (ed) Analysing Everyday Explanation. London. Sage. 
Gerxhani, K. (2004). The informal sector in developed and less developed countries: A literature survey. Public choice, 120(3-4), 267-300.

Getz, D. \& Petersen, T. (2005). Growth and profit-oriented entrepreneurship among family business owners in the tourism and hospitality industry. International Journal of Hospitality Management, 24, 219-242.

Gibson, C., \& Connell, J. (2003). Bongo Fury: tourism, music and cultural economy at Byron Bay, Australia. Tijdschrift Voor Economische en Sociale Geografie, 94, 164-187.

Giddens, A. (1991). 'Modernity and Self-identity: Self and Society in the Late Modern Age'. Stanford University Press. Stanford, USA.

Gilbert, A. (1998). The Latin American city. London: Latin American Bureau.

Gobo, G. (2004). Sampling, representativeness and generalizability. In Seale, C., Gobo, G., Gubrium, J. F., \& Silverman, D. (Ed.). Qualitative research practice, pp. 405-426. London: Sage Publications.

Godfrey, P. C. (2011). Toward a theory of the informal economy. The Academy of Management Annals, 5(1), 231-277.

Granovetter, M. S. (1973). The strength of weak ties. American Journal of Sociology, 78, 1360-80.

Green, A. I. (2008). Erotic habitus: Toward a sociology of desire. Theory and Society, 37(6), 597-626.

Green, P. (2001). Thailand: Tourism and the sex industry. Rahab Ministries: Thailand.

Green, R. (2005). Community perceptions of environmental and social change and tourism development on the island of Koh Samui, Thailand. Journal of Environmental Psychology, 25(1), 37-56.

Grenfell, M. (2008). Postscript: Methodological principles. Pierre Bourdieu: Key concepts, 219-227. 
Guttentag, D. (2015). Airbnb: disruptive innovation and the rise of an informal tourism accommodation sector. Current Issues in Tourism, 18(12), 1192-1217.

Haggard, P., \& Libet, B. (2001). Conscious intention and brain activity. Journal of Consciousness Studies, 8(11), 47-64.

Hall, C.M., \& Williams, A. M. (2008). Tourism and Innovation. London: Routledge.

Hammons, C. S. (2016). Film and video. General Anthropology, 23, $14-15$.

Harrison, D. (1992). Tourism to less developed countries: The social consequences. In Harrison, D. (Ed.) Tourism to less developed countries: the social consequences, pp. 19-34. London: Belhaven Press.

Hartmann, M. (2000). Class-specific habitus and the social reproduction of the business elite in Germany and France. The Sociological Review, 48(2), 241-261.

Hawkins, D. E., \& Mann, S. (2007). The World Bank's role in tourism development. Annals of Tourism Research, 34(2), 348-363.

Heath, C., Hindmarsh, J., \& Luff, P. (2010). Video Analysis and Qualitative Research. London: Sage.

Henderson, J. C., \& Smith, R. A. (2009). The informal tourism economy at beach resorts: a comparison of Cha-Am and Laguna Phuket in Thailand. Tourism Recreation Research, 34(1), 13-22.

Hipsher, S. (2010). Theoretical view on microenterprise entrepreneurial motivators. In Munoz, J.M. (Ed.), Contemporary micro-enterprise: Concepts and cases, pp. 49-60. Northampton, MA: Edward Elgar.

Hirst, P. H. (1965). Liberal education and the nature of knowledge. In Philosophical analysis and education, R.D. Archambault, ed. Pp. 113-140. Henley: Routledge \& Kegan Paul. 
Hitt, M.A., Ireland, R.D., \& Hoskisson, R.E. (2010). Strategic Management: Concepts \& Cases Competitiveness And Globalization. Wall Street Journal (8th ed.). Canada: South-Western.

Hsieh, H. F., \& Shannon, S. E. (2005). Three approaches to qualitative content analysis. Qualitative Health Research, 15(9), 1277-1288.

Hummel, J. (2015). The rise and fall of tourism for poverty reduction within SNV Netherlands Development Organisation. PhD thesis. Wageningen: Wageningen University.

Ihrig, J., \& Moe, K.S. (2004). Lurking in the shadows: The informal sector and government policy. Journal of Development Economics, 73(2), 541-557.

International Labour Organization (ILO). (2009). Experiences and potential directions: A reflection on employment and decent work in poverty reduction strategies. Geneva.

(2014). Women and men in the informal economy: A statistical picture. 2nd ed. Retrieved from https://www.ilo.org/stat/Publications/ WCMS_234413/lang--en/index.htm

(2018). Women and men in the informal economy: A statistical picture. 3rd ed. Retrieved from https://www.ilo.org/wcmsp5/groups/ public/---dgreports/---dcomm/documents/publication/wcms_626831.pdf Isachsen, A. J., \& Strøm, S. (1985). The size and growth of the hidden economy in Norway. Review of Income and Wealth, 31(1), 21-38.

ITC (International Trade Centre) (2011). Trade facilitation: Women in informal cross-border traders. Facilitating formal exports in East Africa. http://www.intracen.org/layouts/searchresults.aspx?searchtext=informal Last retrieved on July $12^{\text {th }}, 2017$.

Iyer, L., Khanna, T., \& Varshney, A. (2013). Caste and entrepreneurship in India. Economic and Political Weekly, 48(6), 52-60. 
Jamal, T., \& Camargo, B. A. (2014). Sustainable tourism, justice and an ethic of care: Toward the just destination. Journal of Sustainable Tourism, 22(1), 11-30.

Jaworski, A., \& Thurlow, C. (2010). Language and the globalizing habitus of tourism: Toward a sociolinguistics of fleeting relationships. The Handbook of Language and Globalization, 58, 255.

Jenkins, R. (1992). Pierre Bourdieu. Routledge: London.

Jones, T., Mondar, R., \& Edwards, P. (2006). Shades of grey in the informal economy. International Journal of Sociology and Social Policy, 26, 353-373.

Kedir, A. M., Williams, C., \& Altınay, L. (2018). Services industries and the informal economy: An introduction. The Service Industries Journal, 38(11-12), 645-649.

Kermath, B. \& Thomas, R.N. (1992). Spatial dynamics of resorts: Sosúa, Dominican Republic. Annals of Tourism Research, 19(2), 173-190.

Kermath, B. and Thomas, R.N. (1992). "Spatial Dynamics of Resorts: Sosúa, Dominican Republic", Annals of Tourism Research, 19(2), 173-190.

Kesmanee, C., \& Charoensri, K. (1995). Case Study on the Effects of Tourism on Culture and the Environment: Thailand. UNESCO Principal Regional Office for Asia and the Pacific.

King, A. (2000). Thinking with Bourdieu against Bourdieu: A 'practical' critique of the habitus. Sociological Theory, 18(3), 417-433.

Koh, K. Y., \& Hatten, T. S. (2002). The tourism entrepreneur: The overlooked player in tourism development studies. International Journal of Hospitality \& Tourism Administration, 3(1), 21-48.

Kyngas H. \& Vanhanen L. (1999) Content analysis. Hoitotiede, 1(1), $3-12$. 
Lahire, B. (1999). Le travail sociologique de Pierre Bourdieu. Dettes et critiques.Retrieved from https://www.cairn.info/le-travail-sociologique-depierre- bourdieu--2707130869-page-1.htm

Lammers, M., van der Duim, R., \& Spaargaren, G. (2017). The relevance of practice theories for tourism research. Annals of Tourism Research, 62, 54-63.

Lashley, C., \& Rowson, B. (2010). Lifestyle businesses: Insights into Blackpool's hotel sector. International Journal of Hospitality Management, 29(3), 511-519.

Lau, R.W.K. (2004). Habitus and the practical logic of practice: An interpretation. Sociology, 38(2), 369-387.

Layton, L. (2004). A fork in the royal road: On "defining" the unconscious and its stakes for social theory. Psychoanalysis, Culture \& Society, 9(1), 33-51.

Leandre-Gomez, M. (2010). A Bourdieusian perspective on strategizing. Cambridge Handbook of Strategy as Practice, 141-154.

Lee, K. H., Scott, N., \& Packer, J. (2014). Habitus and food lifestyle: In-destination activity participation of Slow Food members. Annals of Tourism Research, 48, 207-220.

Lee, K. J., \& Scott, D. (2017). Racial discrimination and African Americans' travel behavior: The utility of habitus and vignette technique. Journal of Travel Research, 56(3), 381-392.

Levy, S. (2010). Good intentions, bad outcomes: Social policy, informality, and economic growth in Mexico. Washington DC: Brookings Institution Press.

Leys, R. (2011). The turn to affect: A critique. Critical Inquiry, 37(3), 434-472. 
Libet, B., Wright Jr, E. W., \& Gleason, C. A. (1983). Preparation-or intention-to-act, in relation to pre-event potentials recorded at the vertex. Electroencephalography and clinical Neurophysiology, 56(4), 367-372.

Lie, R., \& Witteveen, L. (2017). Visual informed consent: Informed consent without forms. International Journal of Social Research Methodology, 20(1), 63-75.

Light, I. (2013). Foreword in Thai, M.T.T. and Turkina, E., Entrepreneurship in the Informal Economy: models, approaches and prospects for economic development, Taylor and Francis, London, pp. 34-49.

Liu, A. \& Wall, G. (2006). Planning tourism employment: a developing country perspective. Tourism Management, 27, 159-170.

Lonely Planet (2014). Thailand travel guide. $15^{\text {th }}$ edition. ISBN:9781742205809

Losby, J. L., Else, J. F., Kingslow, M. E., Edgcomb, E. L., Malm, E. T., \& Kao, V. (2002). Informal economy literature review. ISED Consulting and Research and Aspen Institute. Washington, DC.

Luke, B., Verreynne, M.L. \& Kearins, K. (2007). Measuring the benefits of entrepreneurship at different levels of analysis, Journal of Management and Organisation, 13, 312-330.

Macbeth, J., Carson, D., \& Northcote, J. (2004). Social capital, tourism and regional development: SPCC as a basis for innovation and sustainability. Current Issues in Tourism, 7(6), 502-522.

Malam, L. (2004). Performing masculinity on the Thai beach scene. Tourism Geographies, 6(4), 455-471.

Martin, J. L. (2003). What is field theory? American Journal of Sociology, 109(1), 1-49.

Maton, K. (2014). Habitus. In Pierre Bourdieu (pp. 60-76). Routledge. 
Mayring, P. (2004). Qualitative content analysis. In A Companion to Qualitative Research, (pp. 159-176). Sage: Thousand Oaks.

McCabe, S., \& Foster, C. (2006). The role and function of narrative in tourist interaction. Journal of Tourism and Cultural Change, 4(3), 194-215.

McNay, L. (2004). Agency and experience: Gender as a lived relation. The Sociological Review, 52(2_suppl), 175-190.

Meisenhelder, T. (1997). Pierre Bourdieu and the call for a reflexive sociology. Current Perspectives in Social Theory, 17, 159-186.

Meyer, G. (2006). Formal institutions and informal politics in central and eastern Europe: Hungary, Poland, Russia and Ukraine. 2nd ed. Opladen: Barbara Budrich.

Mishler, E. G. (1995). Models of narrative analysis: A Typology. Journal of Narrative and life history, 5(2), 87-123.

Mitchell, J., \& Ashley, C. (2010). Tourism and poverty reduction: Pathways to prosperity. London: Earthscan.

Moore, R. (2008). Capital. In M. Grenfell (Ed.) Pierre Bourdieu: Key Concepts, pp. 101-17. Stocksfield: Acumen Publishing.

Morrison, A., \& Teixeira, R. (2004). Small business performance: A tourism sector focus. Journal of Small Business and Enterprise Development, 11(2), 166-173.

Nakanishi, T. (1996). Comparative study of informal labour markets in the urbanization process: The Philippines and Thailand. The Developing Economies, 34(4), 470-496.

Ngoasong, M. Z., \& Kimbu, A. N. (2016). Informal microfinance institutions and development-led tourism entrepreneurship. Tourism Management, 52, 430-439. 
OECD, The Organisation for Economic Co-operation and Development (2012). Reducing Opportunities for tax non-compliance in the underground economy. Paris: OECD.

Oppermann, M. (1993). Tourism space in developing countries. Annals of Tourism Research, 20(3), 535-556.

Orsi, R., Raggi, D., \& Turino, F. (2014). Size, trend, and policy implications of the underground economy. Review of Economic Dynamics, 17(3), 417-436.

Pappalepore, I., Maitland, R., \& Smith, A. (2014). Prosuming creative urban areas. Evidence from East London. Annals of Tourism Research, 44, 227-240.

Park, J., Lee, H., \& Kim, C. (2014). Corporate social responsibilities, consumer trust and corporate reputation: South Korean consumers' perspectives. Journal of Business Research, 67(3), 295-302.

Pauwels, L. (2010). Visual sociology reframed: An analytical synthesis and discussion of visual methods in social and cultural research. Sociological Methods \& Research, 38(4), 545-581.

Pécot, M., Gavilanes, J., \& De Viteri, A.S. (2018). Tales of informality: Tourism development in four Ecuadorian beaches. Tourism Planning and Development, 15(5), 584-599.

Pedersen, S. (2003). The shadow economy in Germany, Great Britain and Scandinavia: A measurement based on questionnaire service. Study No.10. The Rockwoll Foundation Research Unit: Copenhagen.

Peña, S. (2000). Regulating informal markets: Informal commerce in Mexico City. International Journal of Sociology and Social Policy, 20(9-10), 37-67.

Peleggi, M. (1996). National heritage and global tourism in Thailand. Annals of Tourism Research, 23(2), 432-448. 
Penrose, E. (1980). The theory of the growth of a firm. $2^{\text {nd }}$ edition. Oxford: Oxford University Press.

Perkins, D.H., Radelet, S., Block, S.A., \& Lindauer, D.L. (2012). Economics of development. NewYork: W.W. Norton \& Company.

Pink, S. (2013). Doing visual ethnography. London: Sage.

Pongajarn, C. (2017). Tourism destination development in Thailand. $\mathrm{PhD}$ diss., Wageningen University and Research, Wageningen.

Pongponrat, K. (2011). Participatory management process in local tourism development: A case study on fisherman village on Samui Island, Thailand. Asia Pacific Journal of Tourism Research, 16(1), 57-73.

Portes, A. (1998). Social capital: Its origins and applications in modern sociology. Annual Review of Sociology, 24(1), 1-24.

Power, S., Di Domenico, M., \& Miller, G. (2017). The nature of ethical entrepreneurship in tourism. Annals of Tourism Research, 65, 36-48.

Rakić, T., \& Chambers, D. (Ed.). (2011). An introduction to visual research methods in tourism (Vol. 9). London: Routledge.

Robson, P.J.A., \& B.A. Obeng (2008). Barriers to growth in Ghana. Small Business Economics, 30(4), 385-403.

Reay, D. (2004). 'It's all becoming a habitus': Beyond the habitual use of habitus in educational research. British Journal of Sociology of Education, 25(4), 431-444.

Roe, D., \& Khanya, U.P. (2001). Pro-poor tourism: Harnessing the World's largest industry for the World's poor. Retrieved from http://pubs.iied.org/ pdfs/11007IIED.pdf

Rogerson, C. M. (2018). Informal sector city tourism: Cross-border shoppers in Johannesburg. GeoJournal of Tourism and Geosites, 22(2), 381-392. 
Róna-Tas, Á. (1997). Path dependence and capital theory: Sociology of the post-communist economic transformation. East European Politics and Societies, 12(1), 107-131.

Rose, G. (2012). Visual methodologies: An introduction to the interpretation of visual materials. London. Sage.

Sallaz, J., \& Zavisca, J. (2007). Bourdieu in American sociology, 19802004. Annual Review of Sociology, 33, 21-41.

Sassen, S. (1997). Informalization in advanced market economies. Issues in development. Discussion paper 20. Geneva: International Labour Office.

Sather-Wagstaff, J. (2011). Beyond content: Thematic, discourse-centred qualitative methods for analysing visual Data. In T. Raki and D. Chambers (eds). An Introduction to Visual Research Methods in Tourism. (pp. 169-83). Hoboken: Taylor and Francis.

Sayer, A. (2010). Bourdieu, ethics and practice. In Cultural Analysis and Bourdieu's Legacy (pp. 99-113). Routledge.

Scarles, C. (2010). Where words fail, visuals ignite: Opportunities for visual autoethnography in tourism research. Annals of Tourism Research, 37(4), 905-926.

Scheyvens, R. (2007). Exploring the tourism-poverty nexus, Current Issues in Tourism 10(2-3), 231-254.

Scheyvens, R. (2012). Tourism and poverty. London: Routledge.

Schneider, F., Buehn, A., \& Montenegro, C. (2010). Shadow economies all over the World: New estimates for 162 countries from 1999 to 2007. Policy Research Working Paper, 5356. World Bank.

Schneider, F., \& Enste, D.H. (2000). Shadow economies: Size, causes, and consequences. Journal of Economic Literature, 38(1), 77-114.

(2013). The shadow economy: An international survey.

Cambridge: Cambridge University Press. 
Schumpeter, J. (1934). The theory of economic development. An inquiry into profits, capital, credit, invest, and the business cycle. Cambridge: Harvard University Press.

Sinclair, M.T. (1998). Tourism and economic development: A survey. The Journal of Development Studies, 34(5), 1-51.

Silva, E. B. (2016). Habitus: beyond sociology. The Sociological Review, 64(1), 73-92.

Slocum, S. L., Backman, K. F., \& Robinson, K. L. (2011). Tourism pathways to prosperity: Perspectives on the informal economy in Tanzania. Tourism Analysis, 16(1), 43-56.

SNV. (Netherlands Development Organisation). (2002, 2003, 2004, 2006, 2009). SNV Annual Report. The Hague: SNV.

Solis-Garcia, M., \& Xie, Y. (2018). Measuring the size of the shadow economy using a dynamic general equilibrium model with trends. Journal of Macroeconomics, 56, 258-275.

Solomon, O.H. (2011). Accounting for the size of the informal sector in Nigeria. South African Journal of Economics, 79(4), 470-489.

Spencer, A., Kirchhoff, B., \& White, C. (2008). Entrepreneurship, innovation, and wealth distribution. International Small Business Journal, 26(1), $9-26$.

Stones, R. (2005). Structuration theory. Macmillan International Higher Education.

Suthisarnsuntorn (2013). What is the tourism authority of Thailand? Retrieved from http://www.pricesanond.com/knowledge/hotels-and-hospitality/what-is-the-tourism-authority-of-thailand-tat.php ).

Szuster, B.W., \& Dietrich, J. (2014). Small island tourism development plan implementation: The case of Koh Tao, Thailand. Environment Asia 7(2), 124-132. 
Tan, K. (2004). Coastal resort dynamics and the tourism informal sector: case study analysis of Phuket, Thailand. Unpublished postgraduate dissertation. Nanyang Business School, Nanyang Technological University.

Tang, C. F., \& Tan, E.C. (2015). Does tourism effectively stimulate Malaysia's economic growth? Tourism Management, 46, 158-163.

Tangworamongkon, C. (2014). Street vending in Bangkok: Legal and policy frameworks, livelihood challenges and collective responses. WIEGO Law and Informality Resources. Cambridge, MA, USA: WIEGO.

Timothy, D. J., \& Wall, G. (1997). Selling to tourists: Indonesian street vendors. Annals of Tourism Research, 24(2), 322-340.

Timothy, D. J., \& Teye, V. B. (2005). Informal sector business travellers in the developing world: a borderlands perspective. Journal of Tourism Studies, 16(1), 82.

Tourism Authority of Thailand (TAT). 2018. Annual report 2017. Retrieved from https://www.tourismthailand.org/About-Thailand/ About-TAT/TAT-Informative

Thomas, R., Shaw, G., \& Page, S. J. (2011). Understanding small firms in tourism: A perspective on research trends and challenges. Tourism Management, 32(5), 963-976.

Todaro, M. (2000). Economic development. Essex: Pearson education limited.

Tourism Authority of Thailand (TAT). 2018. Annual report 2017. Retrieved from https://www.tourismthailand.org/About-Thailand/ About-TAT/TAT-Informative

Tribe, J. (1997). The indiscipline of tourism. Annals of Tourism Research, 24(3), 638-657.

Tribe, J. (2006). The truth about tourism. Annals of Tourism Research, 33(2), 360-381. 
Truong, V.D. (2014). Pro-poor tourism: looking backward as we move forward. Tourism Planning and Development, 11 (2), pp. 228-242.

Truong, V.D. (2018). Tourism, poverty alleviation, and the informal economy: The street vendors of Hanoi, Vietnam. Tourism Recreation Research, 43, 52-67.

Trupp, A., \& Sunanta, S. (2017). Gendered practices in urban ethnic tourism in Thailand. Annals of Tourism Research, 64, 76-86.

Uriely, N., \& Belhassen, Y. (2006). Drugs and risk-taking in tourism. Annals of Tourism Research, 33(2), 339-359.

Verloo, N. (2015). Develop stories, develop communities: Narrative Practice to analyze and engage in Urban conflict". In E. Gualini (Ed.), Planning/Conflict: Critical Perspectives on Contentious Urban Developments. Routledge Publishing.

Wacquant, L. J. (1989). Towards a reflexive sociology: A workshop with Pierre Bourdieu. Sociological Theory, 26-63.

Wacquant, L. J. (1993). On the Tracks of Symbolic Power: Prefatory Notes to Bourdieu’sState Nobility'. Theory, Culture \& Society, 10(3), 1-17.

Wahnschaft, R. (1982). Formal and informal tourism sectors: A case of Pattaya, Thailand. Annals of Tourism Research, 9, 429-451.

Walker, A. (2010). Royal sufficiency and elite misrepresentation of rural livelihoods. In Ivarsson, S. and Isager, L., Saying the unsayable: Monarchy and democracy in Thailand, NIAS Studies in Asian Topics, Copenhagen, Denmark, 241-265.

Wan, G., \& Sebastian, I. (2011). Poverty in Asia and the Pacific: An update. Asian Development Bank Economics Working Paper No. 267. Retrieved from http://dx.doi.org/10.2139/ssrn.1919973

Webb, J. W., Tihanyi, L., Ireland, R. D., \& Sirmon, D. G. (2009). You say illegal, I say legitimate: Entrepreneurship in the informal economy. Academy of Management Review 34(3), 492-510. 
Webb, J.W., Bruton, G.D., Tihanyi L., \& Ireland, R.D. (2013). Research on entrepreneurship in the informal economy: Framing a research agenda. Journal of Business Venturing, 28(5), 598-614.

Wempe, J. (2005). Ethical entrepreneurship and fair trade. Journal of Business Ethics, 60(3), 211-220.

Wetherell, M. (2012). Affect and emotion: A new social science understanding. Sage Publications.

Williams, A. M., \& Shaw, G. (2011). Internationalization and innovation in tourism. Annals of Tourism Research, 38(1), 27-51.

Williams, C.C. (2005). Spatial variations in the nature of undeclared work and its public policy implications. Space and Polity, 9, 135-147.

(2006). The hidden enterprise culture: Entrepreneurship in the underground economy. Cheltenham: Edward Elgar.

(2008). Beyond necessity-driven versus opportunity-driven entrepreneurship: A study of informal entrepreneurs in England, Russia and Ukraine. International Journal of Entrepreneurship and Innovation, 9 (3), 157-165.

\& Nadin, S. (2010). Entrepreneurship and the informal economy: an overview. Journal of Developmental Entrepreneurship, 15, 361-378.

\& Yousseff, Y. (2013). Evaluating the competing explanations for informal entrepreneurship: some lessons from Brazil. In Thai, M.T.T. and Turkina, E., Entrepreneurship in the Informal Economy: models, approaches and prospects for economic development, Taylor and Francis, London, 34-49.

(2017). Developing a holistic approach for tackling undeclared work. Brussels: European Commission. 
\& Horodnic, I. (2018). Extent and distribution of unregistered employment in the service industries. The Service Industries Journal, 38(11-12), 856-874.

Wimalasena, L., \& Marks, A. (2019). Habitus and reflexivity in tandem? Insights from postcolonial Sri Lanka. The Sociological Review, 0038026119825552.

Wong, P. P. (1998). Coastal tourism development in Southeast Asia: Relevance and lessons for coastal zone management. Ocean \& Coastal Management, 38(2), 89-109.

World Travel and Tourism Council (WTTC) (2017). Thailand in World top 10 for long term tourism growth: The nation. Retrieved from http://www.nationmultimedia.com/news/business/EconomyAndTourism/30309754

World Travel and Tourism Council (WTTC) (2019). One in five Thai baht spent is in Travel \& Tourism, according to new WTTC research. Retrieved from https://www.wttc.org/about/media-centre/press-releases/ press-releases/2019/one-in-five-thai-baht-spent-is-in-travel-and-tourismaccording-to-new-wttc-research/

Yeo, S.J., \& Heng, C.K. (2014). An (extra)ordinary night out: Urban informality, social sustainability and the night-time economy. Urban Studies, 51(4), 712-726.

Yotsumoto, Y. (2013). Formalization of urban poor vendors and their contribution to tourism development in Manila, Philippines. International Journal of Japanese Sociology, 22(1), 128-142.

Young, M.N., Ahlstrom, D., Bruton, G.D., \& Rubanik, Y. (2011). What do firms from transition economies want from their strategic alliance partners? Business Horizons, 54(2), 163-174.

Zhang, X., Song, H., \& Huang, G. Q. (2009). Tourism supply chain management: A new research agenda. Tourism Management, 30(3), 345-358 
Zhao, W., \& Ritchie, J. B. (2007). Tourism and poverty alleviation: An integrative research framework. Current Issues in Tourism, 10(2-3), 119-143. 


\section{Summary}




\section{Summary}

Informal economies have been growing, in particular, in the developing world. Nearly two-thirds of the world's employed population earn their livelihoods in the informal economies. The informal economy entrepreneurs provide essential products and services, enhance supply chains, generate employment, and contribute substantially to the economic and social life of communities worldwide. However, the views of informal entrepreneurs have often been marginalized and the issues affecting them are frequently left unobserved in academic or professional debates. Little is known about the informal tourism economy's characteristics in the existing literatures and so far, no study has estimated the size of the informal tourism economy. Yet, the informal tourism entrepreneurs enter into tourism markets with important skills, qualities, and attributes - in the forms of economic, social, cultural, and dream capitals - which could be utilized more successfully to enable them to contribute to broader economic development initiatives.

This $\mathrm{PhD}$-thesis, based on in-depth empirical research, investigates how informal tourism entrepreneurs co-construct their informal tourism sector through their practices. Using an interdisciplinary approach (e.g. mainly sociological and anthropological perspective but also an economic one), this PhD-thesis sees the informal sector as a social system in which people continuously shape and reshape their livelihoods, individually and collectively. More specifically, this $\mathrm{PhD}$-thesis investigates how evolving conditions in the tourism field and beyond simultaneously affect the capital deployment and habitus adaptations of informal tourism entrepreneurs and uses the macroeconomic indicators to estimate the size of the informal tourism economy and its relations to the general economy. To this end, this $\mathrm{PhD}$-thesis offers a more complete understanding of the practice of the informal tourism entrepreneurs and the informal tourism economy and its entrepreneurs' contribution to national economies.

Chapter 2 investigates the field relations in the (in)formal tourism system and focuses on the positions of actors (with an emphasis on the informal tourism entrepreneurs) and their structural relations in the tourism system. It then sheds light on the determination of relevant actors and the nexus of their interconnected relations to the informal tourism entrepreneurs. The two questions guiding the research are (a) How do informal tourism entrepreneurs position themselves in the tourism system and (b) Which 
structural field relations exist in the (in)formal tourism system? In order to answer these questions, this study first demonstrates the basic capitals of informal tourism entrepreneurs, stresses the misfit between the field conditions and their capitals, and, based on this analysis, maps out their positions in relation to other dominating tourism stakeholders' positions in the social fields of power, value and culture.

Further, the study in Chapter 2 reveals the extent to which the informal entrepreneurs are excluded from policy actions which particularly aim at supporting entrepreneurialism in tourism, and highlights the missed opportunity in increasing entrepreneurial activities in combining resources and or improving processes. It is argued that examining the different types of fields and their relations with tourism offers great potential to explore social practices by means of responding to the challenge in tourism studies to engage more fully with practice-based approaches to tourism. To achieve this aim, this study has adopted a qualitative method including 32 narrative interviews, media analysis, policy documents analysis, and non-participant observation of the informal tourism entrepreneurs over three periods between 2015 and 2016 in Chiang Mai, Thailand. The analysis of data is performed through a narrative analysis that categorised stories as small, intermediate and big stories illustrating insights, understandings and interpretations of different layers of the stakeholders' fields. The informal entrepreneurs' narratives contributed to the small stories, reflections by NGO executives and private sector organisations, based on the semi-structured interviews and document analysis, resulted in the intermediate stories and perspectives of the macro-level government and policy makers - derived from interviews and policy document and media analyses - generated the big stories. Overall, it is found that the informal tourism entrepreneurs need to mobilise and utilise their connections with other stakeholders to improve their social position in these fields.

Chapter 3 investigates the species and volumes of capital held by the informal tourism entrepreneurs. Although identifying the role of different types of capital in creating competitive tactics has received substantial attention in tourism studies, a few studies have offered an integrated view across these capitals and compared them to each other to ascertain which types of capital are salient for informal entrepreneurs to survive. The study presented in this chapter sheds light on this issue by demonstrating the adoption of capital mix by informal tourism entrepreneurs at different stages of their 
enterprises and in this way influencing the structure of the field. The question that guided the research is "Which forms and sizes of capitals do the informal entrepreneurs use and convert at different stages of their enterprises' development processes?"

The study in Chapter 3 argues that the informal entrepreneurs enter into the tourism economy with specific types of capital and fill in the product and service gaps in the formal tourism economy. Contrary to the previous studies on capital that have tended to do so from a single, static viewpoint - typically economic, social or cultural - this study claims that capitals are dynamic and interconnected with each other. Each stakeholder in the field preserves their capital, and aims to acquire new capital or increase its value. Each field favours different combinations of capital and it is not only the volume of capital that is important but also its liquidity, convertibility and susceptibility to attrition. Therefore, it is argued that the informal tourism entrepreneurs strategize their capital portfolio in relation to their enterprises' development process and the field's requirements. Chapter 3 further discusses the informal entrepreneurs' complex capital conversion in tourism economies. The data was obtained by fieldwork on the top three tourist islands in Thailand, where a total of 78 filmed interviews and 426 photographs were collected. Visual documentation (e.g. taking photos, analysing maps, and filming interviews) and non-participant observation constituted the information gathering methods in this study. A qualitative thematic data analysis was applied to this visual dataset in order to generate a multifaceted analysis of informal entrepreneurs' capital mix and to observe the conversion of these different forms of capital within their complex networks. The results demonstrated the species and volume of capital held by informal tourism entrepreneurs at their development stages (i.e. freelancer, small size, mid-size and large size). In addition, Bourdieu's forms of capital (i.e. economic, cultural, social and symbolic) has been extended by adding a new form of capital, labelled as dream capital, which acts as a catalyst to convert other types of capital to economic capital at all entrepreneur development stages.

Chapter 4 investigates the habitus of informal tourism entrepreneurs and seeks answers to the question "How does habitus adapt under the influence of major and minor individual and social structural change?".

While recent research on habitus has advanced our understanding on the role of habitus in exploring social reproduction, much less research exists 
regarding how habitus actually adapts under the influence of individual and social structural change. Moreover, in tourism studies habitus has often been examined in relation to lifestyles, in particular taste formation, and only a few studies have used social agents' habitus to understand processes of change at tourism destinations. Chapter 4 seeks to obtain a more complete view of what influences habitus adaptation by informal tourism entrepreneurs by considering social changes as well as individual changes.

The study in Chapter 4 is based on an ethnographic study containing 53 semi structured in-depth interviews with informal tourism entrepreneurs, observing the informal tourism entrepreneurs in their work, participating in social activities with them and taking photographs. Frequent research visits to the same destinations (Koh Samui, Koh Phangan, and Koh Tao) in three consecutive years $(2013,2014$ and 2015) were undertaken. The results identified the existence of a classification of four modes of habitual behaviour: (1) Understanding and appreciating the field and its conditions, (2) Challenging core beliefs systems, (3) Applying a practical sense to 'objective possibilities', and, (4) Challenging non-reflective dispositions.

Chapter 5 takes an economic perspective and introduces the first study that estimates the size of the informal tourism economy and empirically studies the dynamic interplay between trends in the (in)formal tourism economy and the labour market.

It is argued that without knowing the size of the informal tourism economy it is not possible to calculate the total contribution of the tourism sector to a national economy. Moreover, only examining concepts in the formal economy provides just a very partial representation of the nature of economies and labour markets.

Further the study in Chapter 5 empirically studies the informal and formal tourism economies' influence on several features of the labour market rather than only focussing on impacts of the formal sectors. The analysis is based on a dynamic general equilibrium model that allows us to understand how the informal and formal tourism economies evolve over time and behave during the economic and political up- and down-turns, and how their developments relate to (un)employment, labour force participation, self-employment in the service sector and gender. This approach offers a highly flexible means for assessing the multiple-causes and multiple-indica- 
tors in estimating the size of the informal economy. The model is used by combining the detailed data set from the World Development Indicators (WDI) compiled by the World Bank over the period 1974 - 2014 and GDP data over the period 19502014 retrieved from the Penn World Table (PWT) version 9. The results suggest that while the relationship between formal and informal economies is negative in the aggregate, they do not move in the same direction in particular sectors - for example this relationship is positive in the tourism sector.

Chapter 6 brings the findings of the four studies in this PhD-thesis together and draws conclusions. First, the informal tourism economy encompasses a range of positions, activities and motivations, rendering it a complex and multi-dimensional field. Second, the informal tourism entrepreneurs are more flexible than the formal entrepreneurs in adapting quickly to the changing conditions in tourism markets and re-positioning in these fields. They are keen to collaborate with other stakeholders in the tourism sector to achieve success. Third, the informal tourism entrepreneurs determine the proportions of their capital portfolio based on their perceptions of the field conditions, which determine and structure their contribution to tourism destinations. Fourth, the binary distinctions between formal/informal entrepreneurship represent a false logic, as increasingly, entrepreneurs can be seen to engage in some less formal or informal activities alongside their role in the formal, structural economy, blurring the distinctions between formal and informal economic practice. Fifth, the informal tourism entrepreneurs adapt their habitus based on their perceptions of the individual and social changes in their social field. While major social and individual changes challenge informal entrepreneurs in their core belief systems and non-reflective dispositions, minor changes allow them to understand and appreciate the social conditions better, and to create a practical sense of objective possibilities. Sixth, although it is known there is a negative correlation between the general formal and informal economies, this is not true at the sectoral level, at least for the tourism sector. The formal and informal tourism economies move in rather a similar fashion. This means, when the formal tourism economy grows, the informal tourism economy grows as well; vice versa is also true. Seventh, while a significant and positive correlation exists between the informal tourism and general informal economy, the former one is more affected by global crises and regional environmental disasters than the latter one. However, both show similar reactions to recessions and political instability at a destination. Finally, the informal tourism 
entrepreneurs have significant capitals to create jobs, mitigate unemployment, support and teach skills to one another, and complement the supply gaps in the formal tourism economy.

Further this chapter discusses implications for academics and practitioners, and provides a description of several future research topics based on the themes which emerged during the entire research process. First, this PhD-thesis offers interventions and hands-on actions to policy makers and destination governors rather than thinking the whole phenomenon holistically and/or analysing it as a set of significations and discourses. Second, it demythologizes the common sense view that informal entrepreneurs are marginalized, traditional, underdeveloped and backward entities, and shows empirically that informal tourism entrepreneurs have important and relevant capitals (e.g. skills, qualities, attributes, and networks), and contribute substantially to the socio-economic world of destinations in achieving their broader sustainable development goals. Third, this $\mathrm{PhD}$-thesis addresses the evolution of informal tourism entrepreneurship from their role of poverty alleviation and survival strategy for unemployment in developing countries to their existence as trusted and socio-economically essential entities of the social system. It calls for inclusive frameworks and hybrid solutions in which informal entrepreneurs are recognised for their benefits to society in academic and professional debates. 
About the author 


\section{About the author}

Erdinç Çakmak (Ankara, 1973) studied at the Faculty of Political Science at Ankara University, Turkey and obtained his Bachelor degree in 1997. After graduation he started his career at a multinational company and secured different marketing positions in Turkey and Georgia. In 2000 he moved to the Netherlands, and he obtained an M.Phil. in Business from the University of Tilburg.

In 2007 he made a switch to a career as an academic at Breda University of Applied Sciences (formerly NHTV). Over the years he has developed, coordinated and taught a range of courses on destination management, marketing communication, context related and field research at introductory and advanced levels. He has (co-)authored more than 30 academic papers, book chapters, (co-)edited special volumes, books, and apart from that (co)-chaired international conferences and special sessions on the topics power relations in tourism, conflict-ridden destinations, and tourism paradoxes. He has been the vice president of the international tourism group RC50 at the International Sociology Association since 2014. 
Cover Design:

Tamer F. Çakmak

Cover Photo:

Murat Polat 


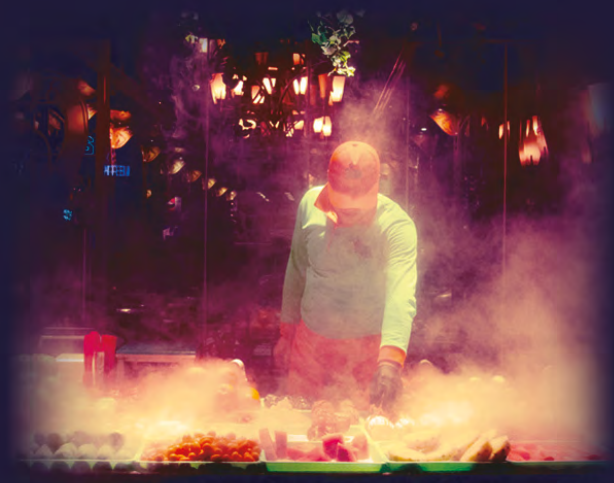

